\title{
A review of high impact weather for aviation meteorology
}

Article

Accepted Version

Gultepe, I., Sharman, R., Williams, P., Zhou, B., Ellrod, G., Minnis, P., Trier, S., Griffin, S., Yum, S. S., Gharabaghi, B., Feltz, W., Temimi, M., Pu, Z., Storer, L., Kneringer, P., Weston, M. J., Chuang, H.-y., Thobois, L., Dimri, A. P., Dietz, S. J., França, G. B., Almeida, M. V. and Neto, F. L. A. (2019) A review of high impact weather for aviation meteorology. Pure and Applied Geophysics, 176 (5). pp. 1869-1921. ISSN 00334553 doi: https://doi.org/10.1007/s00024-019-02168-6 Available at https://centaur.reading.ac.uk/83842/

It is advisable to refer to the publisher's version if you intend to cite from the work. See Guidance on citing.

To link to this article DOI: http://dx.doi.org/10.1007/s00024-019-02168-6

Publisher: Springer

All outputs in CentAUR are protected by Intellectual Property Rights law, including copyright law. Copyright and IPR is retained by the creators or other copyright holders. Terms and conditions for use of this material are defined in the End User Agreement. 


\section{CentAUR}

Central Archive at the University of Reading

Reading's research outputs online 


\title{
A Review Of High Impact Weather For Aviation Meteorology
}

\author{
I. Gultepe $e^{1,2,3}$ \\ ${ }^{1}$ Ismail Gultepe, MRD, ECCC, Toronto, Ontario, Canada. Ismail.gultepe@canada.ca
}

${ }^{2}$ Adj. Prof., Appl. Sci. and Engineering Faculty, University of Ontario Institute of Technology, Oshawa, ON, Canada

R.Sharman; sharman@ucar.edu;

National Center for Atmospheric Research, Research Applications Laboratory

P.O. Box 3000, Boulder, Colorado 80307

Paul D.Williams; p.d.williams@ reading.ac.uk

Department of Meteorology, University of Reading, Earley Gate, Reading RG6 6BB, UK

Binbin Zhou; Binbin.Zhou@noaa.gov

IMSG and EMC/NCEP/NOAA, College Park, MD, USA

G.Ellrod; gary.ellrod@gmail.com

EWxC, LLC, Granby, CT, USA

P.Minnis;p.minnis@nasa.gov

Science Systems and Applications, Inc.One Enterprise Parkway, Suite 200, Hampton, VA 23666

StanTrier, trier@ucar.edu

National Center for Atmospheric Research, Research Applications Laboratory

P.O. Box 3000, Boulder, Colorado 80307

S.Griffin, sarah.griffin@ssec.wisc.edu

Space Science and Engineering Center, Cooperative Institute for Meteorological Satellite Studies (CIMSS)

1225 W. Dayton, University of Wisconsin - Madison, Wisconsin 53706

Seong.S.Yum, seongsooyum@gmail.com

Dept. of Atmospheric Sciences, Yonsei Univeristy, Seoul 03722, Korea

B. Gharabaghi; bgharaba@uoguelph.ca

Water Resources Engineering, School of Engineering, University of Guelph, 50 Stone Road East, Guelph, Ontario, N1G 2W1, Canada

W. Feltz; wayne.feltz@ssec.wisc.edu

Space Science and Engineering Center,Cooperative Institute for Meteorological Satellite Studies (CIMSS)

1225 W. Dayton, University of Wisconsin-Madison, Wisconsin 53706

M.Temimi; marouane.temimi@ku.ac.ae

Water \& Environ. Eng. Program, Masdar Institute, Khalifa University of Science and Technology, Abu Dhabi, UAE

Z.Pu; zhaoxia.pu@utah.edu

Department of Atmospheric Sciences, University of Utah, Salt Lake City, Utah, USA

L.N.Storer; luke.storer@pgr.reading.ac.uk

Department of Meteorology, University of Reading, Earley Gate, Reading RG6 6BB, UK 
P.Kneringer, philipp.kneringer@uibk.ac.at

University Innsbruck, Innsbruck, Tirol Austria

M.J.Weston,mjweston@masdar.ac.ae

Masdar Institute of Science and Technology, Abu Dhabi, UAE

Hui-ya Chuang, hui-ya.chuang@noaa.gov

NCEP Environmental Modeling Center, 5830 University Research Court, College Park, MD 20740, USA

L.Thobois, lthobois@leosphere.com

Leosphere Inc., 3 Rue Jean Rostand 91400 Orsay, France

A.P. Dimri, apdimri@hotmail.com

School of Environmental Sciences, Jawaharlal Nehru University, New Delhi, India

S.J.Dietz, Sebastian.Dietz@uibk.ac.at

University of Innsbruck, Innsbruck, Austria

Gutemberg B. França, gutemberg@lma.ufrj.br

M.V.Almeida, valdonel@lma.ufrj.br

F.L.Albquerque Neto, albuquerque@lma.ufrj.br

Department of Meteorology Federal University of Rio de Janeiro As. Athos da Silveria Ramos, 274 Cidade

Universitária 22941-616, Rio de Janeiro, Brazil,

Submitted to Pure and Applied Geophysics

Special Issue on Aviation Meteorology

June 1-Aug 22-Dec11 2018

${ }^{3}$ Corresponding Author: Ismail Gultepe, MRD, ECCC, Toronto, Ontario, Canada. Ismail.gultepe@canada.ca 


\begin{abstract}
This review paper summarizes current knowledge available for aviation operations related to meteorology and provides suggestions for necessary improvements in the measurement and prediction of weather-related parameters, new physical methods for numerical weather predictions (NWP), and next-generation integrated systems. Severe weather can disrupt aviation operations on the ground or in-flight. The most important parameters related to aviation meteorology are wind and turbulence, fog visibility (Vis) and ceiling, rain and snow amount and rates, icing, ice microphysical parameters, convection and precipitation intensity, microbursts, hail, and lightning. Measurements of these parameters are also functions of sensor response times and measurement thresholds in extreme weather conditions. In addition to these, airport environments can play an important role leading to intensification of extreme weather conditions or high impact weather events, e.g., anthropogenic ice fog. To observe meteorological parameters, new remote sensing platforms, namely wind LIDAR, sodars, radars, and geostationary satellites, and in-situ observations at the surface and in the cloud, as well as aircraft and Unmanned Aerial Vehicles (UAV) mounted sensors, are becoming more common. Because of prediction issues at smaller time and space scales (e.g., $<1 \mathrm{~km})$, meteorological forecasts from NWP models need to be continuously improved. Aviation weather forecasts also need to be developed to provide information that represents both deterministic and statistical approaches. In this review, we present available resources and issues for aviation meteorology and evaluate them for required improvements related to measurements, nowcasting, forecasting, and climate change, and emphasize future challenges.
\end{abstract}

Keywords: Fog and precipitation visibility, Aviation Meteorology, Ice microphysics, Wind shear and Gust, Nowcasting and Forecasting 


\section{Introduction}

Numerous studies have shown that weather severely impacts both civilian and defense aviation operations (e.g., Cook et al. 2009, Rudra et al., 2015, Gultepe et al. 2014; 2017a). The impact of atmospheric processes on aviation has been recognized since the 1900s. For example, Dines (1917) stated that "thus it appears that the demand of the airman on the meteorologist is that he shall be able to forecast wind and fog, and to less extent clouds, on the route, the airman is proposing to follow." Presently, his comments on aviation-related parameters such as wind speed $\left(\mathrm{U}_{\mathrm{h}}\right)$ and visibility (Vis) are still valid. Weather conditions that cause or contribute to the aviation accidents include wind, visibility/ceiling, high density altitude, turbulence, carburetor icing, updrafts/downdrafts, precipitation, icing, thunderstorms, wind shear, thermal lift, temperature (T) extremes, and lightning (NTBS 2010). Figure 1a shows a bar plot of the statistics of weather-related conditions from 1994 to 2003 that affect near-surface aviation operations; they are mostly wind and visibility (NTSB 2010). In Figure 1a, Vis, ceiling height $\left(h_{c}\right)$, and precipitation related conditions occurred 485 times, wind and turbulence 1381 times, and icing and engine icing 150 times. This work suggested that from 2003 through 2007, there were 8,657 aviation related accidents and weather was a factor in 1,740 of these accidents. Figure 1b shows these parameters in percentiles also for 1994-2003 period; wind and visibility are still the most critical parameters. For small, non-commercial aircraft (Part 91 class) the primary cause of weather-related accidents from 2000-2011 was adverse winds, followed by low ceilings $\left(h_{c}\right)$ (Figure 1c). At cruising levels of commercial jet aircraft (Part 121 class), this picture 
is different, with over $70 \%$ of weather-related accidents from $2000-2011$ being related to turbulence (Figure 1d) (e.g., Sharman and Lane 2016).

\section{FIGURE 1}

Delays and damage to aircraft during landing, taking off and high-level cruise due to hazardous weather can often occur. Gultepe et al. (2007) stated that a three-days freezing fog event in the UK resulted in about 50M US\$ in financial losses for businesses. Kessinger et al. (2006) also stated that aviation hazards for oceanic flights could impact both safety, economic efficiency, and productivity that lead to a total cost of about 62.7M US\$ per year. Cook et al. (2009) quantified the impact of weather factors on flight delays and find the contributing factors are highly airport dependent. Because of its importance to aviation, the National Oceanic and Atmospheric Administration (NOAA) National Weather Service (NWS) operationally provides forecasts of volcanic ash, cloud-top height, turbulence, lightning detection, precipitation, icing, and low clouds and fog. These forecasts are available to the public through their website (https://www.aviationweather.gov/).

Strong wind regions within jet streams called jet streaks (JS) can also affect aircraft operations (Uccellini and Johnson 1979; Uccellini 1980). They studied transverse circulations in the left exit and right entrance regions of jet streaks (which are the divergence regions) using Numerical Weather Prediction (NWP) models. Rose et al. (2004) detailed the interactions between upper and lower level jets, and the development of severe convective system. They stated that "in the (jet) exit region, the geometry of this adjustment, combined with warm, moist, lower tropospheric air to the right and ahead of the jet streak and cool, dry air at the jet streak level, produced the differential advections that convectively destabilized the atmosphere." Results of their work 
suggest that development of severe convective storms can be influenced by mass and momentum fluxes along the propagation of an upper tropospheric jet streak. The development of a low-level jet (LLJ) usually was not considered for convection development in regard to synoptic-scale processes (Uccellini 1980). He stated that a systematic upper level flow pattern led to leeside cyclogenesis or a leeside trough, and that produced the strong pressure gradient forces needed for the development of LLJs. These studies suggested that improved knowledge of the relationships between JS and LLJ are important for understanding aviation weather hazards. Clear-air turbulence (CAT) and eddies related to jet streams can also be extremely important for mountainous and high-level flights near jet streams (e.g., Ellrod and Knapp 1992).

Reduced Vis, commonly caused by fog and precipitation (Gultepe et al. 2009), is also caused by dust and ash (Fig. 2). The transport of fine-grained dust by strong winds can occur over a broad range of time and spatial scales (Hadley et al. 2004) and impact not only Vis but have also been associated with engine failure.

\section{FIGURE 2}

Another critical hazard for aviation is aircraft icing (Isaac and Schemenauer, 1979; Guttman and Jeck 1987; Politovich 1989; Tafferner et al., 2003; Vivekanandan et al. 2001). Prediction of icing and deicing conditions (at the airports) is important for flight safety (Rasmussen et al. 2001; Black and Mote 2015). The accumulation of ice on aircraft before takeoff has long been recognized as one of the most significant safety hazards affecting the aviation industry. As little as $0.1 \mathrm{~mm}$ of clear ice over 2 minutes on a wing surface can increase drag and reduce airplane lift by $25-30 \%$ and reduce critical angle of attack by 8 degrees (https://aircrafticing.grc.nasa.gov/1_1_3_2.html; TC 2004) 
Recently it has been realized that prevention of aircraft engine power losses due to high ice water content (HIWC) at higher elevations is essential for safe aviation operations (Leroy et al. 2016; 2017). The HIWC conditions, typically associated with deep convection, can cause engine power loss and air data events (affecting altitude and airspeed measurements) on commercial aircraft and need to be better characterized (Mason et al., 2006).

Improvements in aviation nowcasts and forecasts require better measurements and predictions of atmospheric parameters such as $\mathrm{T}, \mathrm{RH}$, wind and turbulence, icing, and Vis. These parameters are also related to climatic change over various scales. Therefore, for future research, the impact of climate change on meteorological parameters needs to be evaluated. For example, state-of-theart research done by Goodman and Griswold (2017) suggest that temperature and pressure are important for aviation applications because they can impact aircraft drag and lift. Their work suggested suggests that aviation related impacts due to climate change need to be evaluated.

In another example, state-of-the-art global climate models were used in the Coupled Model Intercomparison Project Phase 5 (CMIP5) simulating climate extreme indices described by the Expert Team on Climate Change Detection and Indices (ETCCDI) (Sillmann et al. 2001; 2013). In their work, the climatic indices based on daily $\mathrm{T}$ and precipitation amounts and rates were calculated using multi-model simulations. They found that the duration of cold and warm spells changed significantly since the 1950s. These works also suggest that climate change issues related to aviation operations are needed be evaluated in depth. 
Global and regional weather prediction systems are needed to characterize the atmospheric state with the detail required to diagnose aviation related meteorological parameters.

Accurate predictions of the most dangerous processes related to Vis, turbulence, icing, convection and icing are essential to reduce in-flight injuries, structural damage, ground preparations for flights, and flight delays (e.g., Mecikalski et al. 2007, Sharman et al. 2012; Sharman and Lane 2016; Karstens et al 2018). Therefore, forecasting and nowcasting of aviation related meteorological parameters require a better understanding of the underlying meteorological processes. In this respect, knowledge of dynamics of upper-level and low-level jets, gusts, eddies, large-amplitude gravity waves, wind shear (including low level wind shear (LLWS)) and physics of cloud, fog, and precipitation can be very important for aviation mission planning and reducing financial losses (Uccelini and Johnson 1979; Zhou et al., 2004; NWSPD 2004; FAA 1988 Thobois et al 2018).

The goal of this review is to provide a summary of meteorological parameters, processes, and their prediction issues that are critical for aviation operations and that create challenges for forecasters. The critical parameters, processes, and analysis techniques of importance for aviation meteorology over various scales can be listed as

- Weather physics

1. Clouds and fog

2. Ice and droplet microphysics

3. Precipitation type and rate

4. Freezing precipitation

5. Icing, and ground deicing

6. Frost

7. Visibility and ceiling

8. Blowing snow

9. Convective activities and high ice water content

10. Lightning

11. Ash and dust 


\section{Physical parameterizations}

- Weather Dynamics

1. Turbulence

2. Wind gusts

3. Waves

4. Jet streak intensity

5. Low Level Wind Shear (LLWS)

6. Microburst and tornados

7. Temperature and $R H$ (relative humidity)

- Weather Forecasting (Multi-scale)

1. NWP time and space scale issues

2. Data integration

3. Artificial intelligence

4. Deterministic versus probabilistic methods for nowcasting

5. Integrated systems

6. Climate change modeling for aviation applications

7. Contrails and climate change

8. Reporting systems for aviation meteorological applications

Considering the above items, NWP and climate change models play an important role on their own or integrated with observations to improve nowcasting and long-term forecasting of high impact weather events. Weather-related events such as fog, precipitation, clear-air and in-cloud turbulence, wind shear, gust, or icing may be related to changing climate conditions; if this is the case, for the next 50 years and beyond, aircraft flying conditions need to be considered to improve future aviation operations in response to extreme weather conditions.

In this overview, observations will first be summarized in the next sections and followed by discussions of NWP issues. Then, integrated methods will be introduced for aviation operation applications. In the final section, future issues and possible challenges related to observations, NWP, and climate change will be provided. 


\section{Observations}

Observations are needed to discern and monitor meteorological parameters required for safe and efficient aviation operations. These are clearly needed in the terminal area of major airports and at cruise levels along flight routes, but also over wide areas to support a range of operational activities at smaller airfields and other remote locations. Helicopter air ambulance operation in remote areas, for example, represents a particular aviation weather need but one which creates significant forecasting challenges. Observations are important since some parameters are poorly diagnosed by NWP models at the scales needed by the aviation community. Clearly, observations are critical for providing monitoring and nowcasting related to aviation meteorological parameters for operations, and that cannot be predicted accurately with NWPs alone for lead times less than a few hours.

\section{a) Ground based in-situ observations}

The Aviation Automated Weather Observation System (AV-AWOS) originally suggested by Mandel (1975) provides meteorological parameters critical for aviation operations. Their proposed AWOS included additional parameters such as Vis and sky conditions. Later, Wade (2003) used the ASOS (Automated Surface Observing Systems) with a the light-emitting diode weather identifier (LEDWI) sensor to discriminate drizzle from other particles because precipitation rate from drizzle is usually less than $0.25 \mathrm{~mm} \mathrm{hr}^{-1}$. AWOS and ASOS were designed for unattended locations and use multi-sensor based algorithms (Ramsay et al 1999). Presently, these types of systems are continuously being improved by adding ultrasonic 3D wind systems, fog and precipitation sensors, as well as a portable ceilometer and a microwave radiometer (Ware et al., 2010; Gultepe et al., 2018). In addition to individual ground based in- 
situ sensors, compact meteorological platforms were also developed for visibility, icing, fog, and precipitation type studies and applications such as Landolt et al. (2010) and), Rasmussen and Landolt (2008)), and Gultepe et al. (2018). Sims et al. (2000) used an integrated icing diagnostic algorithm (IIDA) that extensively utilized ground based in-situ systems with other observational and prediction systems. Similarly, supersites having various high-resolution ground based in-situ sensors (see next subsection) were also designed and used for operations.

\section{b) Meteorological Supersites}

Meteorological supersites with various sensors can be designed for specific goals related to atmospheric-hydrologic-oceanographic applications. Presently, these supersites with extensive ground based in-situ and remote sensing platforms have been used by researchers (Rasmussen et al. 2012, Gultepe et al. 2018, 2015; Ralph et al. 2014; Song et al., 2018). They were designed for aviation and forecasting validations/operations and included mainly observations representing Vis, $\mathrm{U}_{\mathrm{h}}$, turbulence, fog $(\mathrm{FG})$, precipitation amount $(\mathrm{PA})$ and intensity $(\mathrm{PR}), \mathrm{h}_{\mathrm{c}}$, and cloud base height $\left(\mathrm{h}_{\mathrm{b}}\right)$, and atmospheric profiling of meteorological parameters. Although usually located at a single point representing a small area around it, Gultepe et al. (2018) used their supersites with satellite (smaller weather observing sites) meteorological sites located within a $1 \mathrm{~km}$ perimeter radius. These observations provided statistical advantages to evaluate the scale issues related to measurements (Gultepe et al. 2018). The fact that most accidents occur around airports emphasizes that high resolution observations and areal representation of observations as done in above work are needed to improve aviation operations/NWP simulations. 


\section{c) Aviation Weather reports}

Detailed airport observations can be used for making flight decisions by pilots and airport authorities, and for verifying forecasts. These observations usually are reported at 30-min or 60min intervals as METARs (Meteorological Aviation Routine Weather Reports). At some airports, observations are also performed by using weather sensors autonomously (Gultepe et al. 2017). Weather forecasts for aviation operations are provided 2 hrs in advance based on trendtype forecasts (TRENDs) and over $2 \mathrm{hrs}$ as terminal aerodrome forecasts (TAFs) (Jacobs and Maat 2004). Both TAFs and TRENDs contain information on Uh, Vis, cloud amount $\left(\mathrm{C}_{\mathrm{a}}\right), \mathrm{h}_{\mathrm{b}}$, and PR in the vicinity of the airport (Lynn 1997). The TAF can be issued as often as 12 times a day, including eight short TAFs with lead times from 1 to $10 \mathrm{~h}$, and four long TAFs with lead times from 8 to $26 \mathrm{~h}$ (Jacobs and Maat 2004). In fact, most aircraft landing and takeoff decisions are made based on Vis and $h_{b}$, as well as wind conditions at the airports (Thobias et al 2018).

PIREPS (voice-transmitted pilot reports) are commonly used for to report icing and turbulence validations conditions and they are easily available but the PIREP reporting system was not proposed to be used for research or forecasting applications (Schultz and Politovich 1992a, 1992b; Kelsch and Wharton 1996; Schwartz 1996). They stated that inspection of PIREPS on turbulence and icing conditions reveal serious shortcomings that limit their usefulness. Lately, Bernstein et al. (2004) also stated that icing algorithms developed by many others overestimated icing amounts compared to PIREPS. These works suggest that the PIREP reporting system need to be improved, and Shultz and Politovich (1992a; 1992b) suggested that the FAA should consider creating a standard PIREPS system similar to the standard airways report made by surface weather reporting stations. 
The TAFs and TRENDs are a good source of meteorological short time predictions and provide important support for forecasters. The TAF and TREND guidance and the AUTOTAF encoding software have been developed and implemented in close cooperation with the German company Meteo Service Weather Research (Knüppfer 1997; Jacobs and Maat 2004). Automated TAFs (Lynn 1997; Kilpinen 1994) use both direct NWP model outputs and model observation soundings (MOS; Glahn and Lowry 1972; Hart et al. 2004). The MOS-based methods usually use local data as in Jacobs and Matt (2004). In their work, an approach using observations from upstream locations and local data were used. Recently, blended algorithms for aviation operations have been suggested for improving short term forecasts (Bailey et al. 2016). A combined physical-statistical approach is often applied to low clouds and Vis predictions because of NWP short-term prediction issues. Herzegh et al. (2015) developed an expert system for Vis and cloud base $\left(\mathrm{h}_{\mathrm{b}}\right)$ forecasts based on blended numerical model and observational data. They used current and historical METARs, GOES observations, NWP output from the Rapid Update Cycle (RUC ), NCEP (National Center for Environment Prediction), and GFS (global forecasting system) runs, MOS forecasts and observational based rule methods for short term predictions.

\section{d) Aircraft in-situ observations for icing}

Research aircraft observations have been used for meteorological research extensively and here we only provided icing related research that generated significant improvements for icing measurements and predictions (Politovich 1989; Cooper et al. 1984; Sand et al. 1984; Isaac et al. and Schemenauer 1979; Isaac et al. 2005; Reehorst et al. 2005). For example, icing research 
using aircraft platforms has been done by NASA Glenn, Canadian NRC (National Research Council) and EC (Environment Canada), NCAR, and University of Wyoming (Politovich 1989, 1996; Isaac et al. 2005; Serke et al. 2008; Reehorst et al. 2005). Bernstein et al. (2005) developed a Current Icing Algorithm (CIP) that utilized satellite, radar, surface, lightning and PIREPS observations together with 3D model hourly diagnostics to retrieve icing and SLD potentials. Figure 3a shows the conceptual diagram of their CIP algorithm that was adapted by FAA to be used operationally. Figure $3 \mathrm{~b}$ shows an example of the splintering mechanismwhich generated many small droplets which then quickly froze during a wet snow case at $\mathrm{T}=-3^{\circ} \mathrm{C}$ on March 15 2013 during SAAWSO project took place over St. Johns' area, NL, Canada.

\section{FIGURE 3}

Based on aircraft in-situ observations of cloud microphysical parameters from aircraft, super cooled large droplets (SLD) impact on aviation certification was also emphasized by Politovich (1989), Isaac et al. (2005), and Bernstein et al. (2005). Politovich (1989) noted that substantial loss in rate of climb capability occurs in less than 10 mins when droplet number concentration, $\mathrm{N}_{\mathrm{d}}<0.1-1 \mathrm{~cm}^{-3}$ and mean volume diameter (MVD) at about 30-400 $\mu \mathrm{m}$. Various icing types occurring at the surface of aircraft (Politovich 1996; Levis 1947; 1978) can significantly impact aircraft lift and drag forces that can lead to aircraft accidents. Lately, high ice water content is also found to be an important factor for aircraft engine icing (Leroy et al. 2016; Haggerty et al. 2018) and that needs to be further researched for operational applications.

\section{e) Satellite Observations}

Observations from passive radiometric imagers on operational satellites, such as the Geostationary Operational Environmental Satellites (GOES), are used extensively for evaluation 
of meteorological events, nowcasting, and assimilation into NWP modeling systems. Both imager and sounder spectral radiances and relevant parameters derived from those radiances have been used extensively for these purposes. Examples of these products and potential applications are discussed below and in following sections.

In addition to passive radiometric imagers on satellites, active remote sensing platforms are also starting to be used on the satellites such as Cloudsat (Sun-Mack 2017; Deng et al. 2010 ) and CALIPSO (Smith 2014). The EarthCARE satellite mission is planned for 3D weather predictions by blending data from satellite based active sensors together with simulations from a 3D NWP model (Miller et al. 2014; Illingworth et al. 2015; Barker et al. 2011). The use of active sensors on these satellite platforms can provide insight information on cloud vertical structure, cloud top properties, and both microphysics and precipitation that can be blended with NWP simulations and ground based remote sensing platform data, and these can be used for aviation applications.

A variety of cloud properties are retrieved in near-real time using the Satellite Clouds and Radiation Property retrieval System (SatCORPS; https://satcorps.larc.nasa.gov) applied to global geostationary and polar orbiting satellite imager data (Minnis et al. 2008; Minnis et al. 2016) using adaptations of the algorithms of Minnis et al. (2011). The parameters retrieved include, among others, the scene identification of the pixel as either cloudy or clear, cloud top phase, cloud top and height temperatures and altitudes, cloud optical depth, and cloud particle effective radius. Recent additions include multi-layered cloud detection and properties, aerosol concentration over ocean, and convective cloud overshooting top identification (e.g., Bedka et al., 2017). These products are currently used for a number of aviation applications such as 
aircraft icing (Bernstein et al. 2006; Smith et al. 2012), engine icing (Yost et al. 2018), cloud ceiling, and aviation and severe weather NWP assimilation (Benjamin et al. 2016; Jones et al. 2016). They retain significant potential for additional use by aviation systems. Improvements and enhancements in the retrieved products will expand that potential. For example, determining the separation between multilayer clouds (Sun-Mack et al. 2018) will improve chances of flying in clear air in multilayered conditions, while knowing the thickness of an icing layer, even when a thick ice cloud lies above the supercooled clouds (e.g., Smith 2014), will provide more choices for pilots faced with a hazard and few options.

Another source of cloud information is the algorithm developed by Sieglaff et al. (2011), which classifies each GOES pixel into groups of clear, liquid water, supercooled liquid water, mixed phase, opaque ice, non-opaque ice, and multilayered ice cloud (ice cloud is the highest cloud layer). These groups are described in the work of Pavolonis and Heidinger (2004) and Pavolonis et al. (2005). Details of the algorithm can be found in Pavolonis (2010a,b) and Heidinger (2010). Similarly, Liu et al. (2009) also defined cloud types based on China's FY-2C multichannel images and a neural network method. The satellite cloud analyses utilize clear-sky background correction, satellite zenith angle, and sensor spectral response functions. These were then used for the cloud mask and type algorithms to be portable to many sensors. The cloud-type algorithm relies on an upfront cloud mask algorithm to determine which pixels contain cloud Heidinger (2010). The satellite observations can usually lead to detection of cloud phase, fog, icing, and turbulence from spectral radiance measurements (Minnis et al. 2011; Pavolonis et al. 2010a, 2010b, Pavolonis and Heidinger 2004; Smith et al. 2012, Gultepe et al. 2007; Ellrod and Pryor 2018). Integrated systems based on in-situ observations, NWP model output, as well as GOES 
satellite products can improve monitoring fog conditions that include fog area and its intensity (defined by optical depth).

A number of efforts have focused on detecting and analyzing overshooting tops using GOES products from VIS (Visible) and IR (Infrared) imagery (Nair et al. 1998; Mecikalski et al. 2007; Bedka et al. 2010). In addition to garnering information directly from the VIS reflectance and IR brightness temperatures, and their differences with other channels to detect overshooting tops, texture analyses have allowed the discrimination of convective cloud features within a shield of stratus-like clouds that often cover a convective complex. Figure 4a,b,c show the texture-based clustering analysis results based on Mecikalski et al. (2007). In this figure, large-scale convective structures are visible, along with smaller cumulus and stratiform clouds. Figure $4 \mathrm{~d}$ shows a cloud-top pressure product developed through the combination of height estimates from the $\mathrm{CO}_{2}$ ratio technique for the upper clouds and from the older "IR window" technique for lower clouds (Schreiner et al. 1993; Donovan et al. 2007). The IR window technique uses the $11 \mu \mathrm{m}$ thermal IR temperature to estimate $\mathrm{T}$ at cloud top, and combines it with an atmospheric sounding to get $\mathrm{T}$ to a corresponding pressure and height. The isolated overshooting cumulus tops were also detected as in red. Improvements on this technique have been reported by Bedka and Khlopenkov (2016).

\section{FIGURE 4}

The reasons for recent advances in aviation safety due to meteorological satellites are their ability to provide critical information of weather conditions, the enhanced speeds of data transmission and computer analysis, better calibrated high-resolution satellites, algorithm maturity, and more reliable validation data. Therefore, hazards, such as turbulence, in-flight 
icing, convective storms, and volcanic ash, can be diagnosed from satellite-based observations, and are used extensively in national aviation forecasting systems (Mecikalski et al. 2007). The algorithms are always subject to improvement based on validation studies using in-situ observations, passive (e.g., microwave) and active (radar and lidar) remote sensing, and integrated observations.

The aviation products in NOAA NWS operations include volcanic ash, cloud-top height, turbulence, lightning detection, precipitation, icing, and low clouds and fog (Schmit et al. 2017; Goodman et al. 2012). Recently, with the introduction of GOES-16 (16th Geostationary Operational and Environmental Satellite) products, lightning detection for aviation applications will also be possible. New sensors available on GOES-16 include total lightning detection and mapping of in-cloud and cloud-to-ground flashes (from the Geostationary Lightning Mapper (GLM; Goodman et al. 2012; Goodman et al. 2011). It is expected that the use of GLM data for severe weather research can improve aviation weather forecasts.

Airborne ash from volcanic eruptions can also be a major threat to aviation safety (Casadevall 1994; Miller and Casadevall 2000; Hufford et al. 2000; Simpson et al. 2000). VIS satellite imagery can be used to detect ash clouds, but not to discriminate ash particles from natural water and ice clouds. Ash detection and discrimination is accomplished via multispectral infrared image analysis. The multispectral technique uses a strong $12-\mu \mathrm{m}$ absorption signature (e.g., Prata 1989; Hufford et al. 2000; Mecikalski et al. 2007), leading to a negative value of the 11-12 $\mu \mathrm{m}$ brightness temperature difference. As discussed by Ellrod et al. (2003), this technique is often termed as the reverse-absorption method. Volcanic eruptions usually release high concentrations 
of $\mathrm{SO}_{2}$ having strong absorption bands at 7.3 and $8.6 \mu \mathrm{m}$ that can aid the ash detection algorithms. $\mathrm{SO}_{2}$ absorption channels are presently available on the high-resolution Moderate Resolution Imaging Spectroradiometer (MODIS) imager and the Atmospheric Infrared Sounder (AIRS) sounding instrument in polar orbit on NASA's Earth Observing System (EOS) satellites, and with the next-generation operational geostationary satellites (e.g., Himawari-8, GOES-16) (Goodman et al. 2010; Hutchison et al. 2008; Mecikalski et al. 2007; Schmit et al. 2005).

The National Aeronautics and Space Administration (NASA) developed an Advanced Satellite Aviation-Weather Products (ASAP) system that transfers new satellite-observing products into operational use based on a collaborative effort with the FAA's existing Aviation Weather Research Program (AWRP) (Mecikalski et al. 2002; 2007). The ASAP ash detection algorithms are currently being developed at UW-CIMSS. The standard reverse absorption technique (Prata 1989) that uses channel differencing between 11-12 $\mu \mathrm{m}$ BBT (Black Body Temperature), is supplemented with VIS at $0.65 \mu \mathrm{m}$ and near-IR at $3.75 \mu \mathrm{m}$ channels for volcanic ash detection (Pavolonis et al. 2006). This new algorithm does not depend on a negative value of 11-12 $\mu \mathrm{m}$ brightness temperature difference because this difference is often absent in tropical eruptions and it is used globally

Hadley et al. (2004) studied the rare resuspension of volcanic ash and dust from the Katmai area volcanic eruption by strong winds on 20-21 September 2003 and found that the ash/dust cloud created severe disruptions to aviation operations while aircraft were attempting to avoid dust/ash clouds. Another volcanic ash event occurred from Mount Cleveland, Alaska when it erupted on 19 February 2009 and led to several severe disruptions of commercial aircraft traffic. The use of 
satellites for ash detection has recently become very common but issues with data analysis are still important, and more work needs to be done. Simpson et al. (2000) also suggested that detailed volcanic ash PIREPs are needed to improve real-time awareness for aviation routing.

Two major regions of dust originate from Asia (Gobi and Mongolian deserts) and Africa (Sahara Desert). Dust events usually occur when surface winds exceeding $5 \mathrm{~m} \mathrm{~s}^{-1}$ (Hadley et al. 2004) loft the dust particles into the atmosphere where they can travel across either the North Pacific or the tropical Atlantic Oceans, respectively (Gillette 1978). Dust can also affect radiative forcing and world climate (Myhre and Stordal 2001), as well as aviation safety (Simpson et al. 2003).

Satellite-based wind vectors can be used to infer wind shear, turbulence, and convective activity (Mecikalski et al. 2007;). In the northern latitudes, polar winds are needed for better aviation flight planning because of lack of other observations and issues with NWPs through assimilation of observations (Key et al. 2003). Polar winds from satellite based retrievals (Turner and Warren 1989; Herman 1993) can be highly effective for aviation management because of the lack of airport availability after long flight times over Arctic regions. Santek et al. (2010), using the National Centers for Environmental Prediction (NCEP) Global Forecast System (GFS), ran an experiment during August and September 2004, with and without the Terra satellite based MODIS (Moderate Resolution Imaging Spectroradiometer) Polar winds. From the five cases examined, it was determined that the addition of the polar winds modifies the mass balance in synoptic-scale waves near the polar jet streams that can affect flight planning. 


\section{f) LIDAR observations}

LIDAR-based observations are related to wind components based on motion of air particles, thin fog and clouds, backscattering ratio, and depolarization. Excluding deep and heavy in-cloud water content conditions, they can provide 3D wind components for terminal weather forecasts when they are used in specific scanning modes such as low elevation angles. They can also provide wind profiles to analyze turbulence, gust, and aerosol loading at higher levels.

LIDAR-based wind retrievals using the Doppler concept became important in the 1980s. Bilbro and Vaughan (1978) and Bilbro et al. (1984) used a coherent Doppler system to obtain 2-D wind components from an installation onboard the NASA Convair 990. For a recent overview of the use of LIDARs in atmospheric research see Reitebuch (2012). Recently, LIDARs have been used for aviation research and operations (Gultepe et al 2017; Fuertes et al 2014; Tucker et al 2009, and Sathe et al. 2011). Tucker et al. (2009) used a High Resolution Dial LIDAR (HRDL) at $2.022 \mu \mathrm{m}$ to study mixing height, turbulence, shear, and aerosol profiles. The HRDL velocity and backscattered signal measurements collected during a ship-based field campaign were used in wind analysis. In their work, wind air velocity variance profiles were used for mixing height estimation. This was a significant development of LIDAR use in the aviation research. Their

results are shown in Figure 5 which shows time-height cross sections of $\sigma_{w}^{2}$ (vertical air velocity variance) and $h_{o}(a)$, horizontal wind shear height $\left(h_{s p d}\right)(b)$, and multiple products related to shear and mixing height (c). Their work also suggested that a motion-stabilized scanning coherent Doppler LIDAR can perform azimuth scans, elevation scans, and zenith stares to obtain 
the velocity field in three dimensions from a moving platform and that can improve aviation forecasts over the coastal regions.

\section{FIGURE 5}

Lately, Doppler Lidar wind measurements have been used for aircraft operations at airports (Thobois et al. 2018; Chan and Shao 2007; Chan et al. 2006) to diagnose wind shear, gust, microburst, and aerosol loading, which can be serious issues for aviation operations (Sharman et al., 2012, Kessinger et al. 2006, Wong et al. 2013, Kim et al. 2015, 2016, and Gultepe et al. 2018). But, presently Doppler lidars are used mostly in an experimental mode at the airports. Among Doppler LIDARs commercially available are 1) Halo LIDAR (Gultepe et al 2016), 2) Leosphere Cube LIDAR (Thobois et al 2018), and 3) Lockheed Martin Coherent Technologies (LMCT) LIDAR (http://www.lockheedmartin.com). These LIDARS provide Doppler wind measurements in various scanning modes. The Halo LIDAR observations were used to obtain backscatter ratio and VAD winds, and compared to CL51 ceilometer backscatter ratio observations during an ice fog event occurred nearby Heber City, UT, are shown in Figs. 6a and 6b, respectively. The Cube Doppler LIDAR from Leosphere Inc is designed specifically for aviation applications and provides related aviation wind and turbulence parameters continuously (Tobia et al., 2018). Examples of turbulence estimation from LIDARs can be found in e.g., Frehlich and Cornman (2002), Hill et al. (2010), Chan (2016), and Vrancken (2016).

\section{FIGURE 6}

LMCT LIDAR at $2 \mu \mathrm{m}$ (latest one at $1.6 \mu \mathrm{m}$ ) uses pulsed laser light to detect particles and varying weather conditions in the atmosphere (Bluestein et al 2010; De Wekker et al. 2012; Bluestein et al 2014). The company has developed a pulsed coherent 2 limiting diode-pumped solid-state LIDAR receiver on an injection-seeded, Q-switched, 2 micron laser that meets Navy 
requirements for remote sensing, moderate range, high spatial resolution wind field measurements around air stations and aircraft carriers.

\section{g) Sodar observations}

The SOnic Detection And Ranging (SODAR) is often used for atmospheric profiling. SODAR uses the Doppler concept to estimate 3D wind profiles from the propagation characteristics of high frequency sound waves to investigate the atmospheric boundary layer and has been used since 1980s. For example, SODAR data were used to investigate the boundary layer dynamics in detail by Motta, et al. (2005), Sumner and Masson (2006), Gottschall and Peinke (2008), and Van den Berg (2008). In these works, atmospheric stability, wind shear, and turbulence intensity were analyzed for wind energy production. Gerz et al. (2009) and Chan (2014) used SODAR observations specifically for nowcasting applications to investigate aviation related meteorological events, such as fog, gust, and wind shear, at the Frankfurt International Airport and at the Hong Kong International Airport, respectively. Silva et al. (2016) developed a conceptual model to investigate wind profile changes using 234 runway cases that utilized a SODAR and surface meteorological station data from the Guarulhos International Airport (GIA) São Paulo, Brazil. França et al. (2018) also used SODAR data for training a neural network model for nowcasting the low level wind profiles at the lead times of 45 mins for the GIA Airport.

\section{h) Radar observations}

Doppler and dual-polarized radars (and connectional ones) such as $\mathrm{X}(8-12 \mathrm{GHz}), \mathrm{C}(4-8 \mathrm{GHz})$, and $\mathrm{S}(2-4 \mathrm{GHz})$ band radars have been used to detect convective activity and intensity, as well as 
icing conditions within clouds to identify particle microphysical characteristics (Merritt, 1969; Rasmussen et al 1992; Ryzhkov et al. 2002; Schuur et al. 2012; Smith et al 2016; Hubbert et al 2018). Storm precipitation type and intensity are related to Vis, icing levels, and convective intensity, and these are all important for aviation operations. Smith et al. (2016) developed the Multi-Radar Multi-Sensor (MRMS) system that is operational at the National Centers for Environmental Prediction (NCEP). The MRMS system consists of the Warning Decision Support System-Integrated Information (WDSS-II; Lakshmana et al. 2007) suite. The severe weather and aviation products, as well as the quantitative precipitation estimation (QPE) products, are created by the National Mosaic and Multi-Sensor QPE (NMQ; Zhang et al. 2011) system.

Dual polarized Doppler radars such as the Weather Surveillance Radar-1988 (WSR-88D) radar and radars with dual polarization capabilities such as S-band radars (S-Pol) can improve rainfall estimates, discriminate ice and rain, identify hail cores and updraft regions, and as a result in general increase data quality (Hubbert et al. 2017, 2018; Chandrasekar et al. 2013; Kumjian 2012 and 2013a,b). Hubbert et al stated that the Weather Surveillance Radar-1988 Doppler polarimetric (WSR-88DP) is not able to scan along vertical planes (RHIs), and although this may be acceptable for operational purposes, it does limit research objectives. The S-Pol has increased range resolution using $1-\mu$ s transmit pulse length that corresponds to $150-\mathrm{m}$ compared to WSR88DP's $250-\mathrm{m}$ resolution. The result is that S-Pol is able to obtain high-resolution, high-dataquality measurements related to storm structure and microphysics. In the end improved storm physics and dynamical information can further be used for aviation operations that concern with 
wind and turbulence, gust, icing, high IWC, and low visibilities, as well as lightning and particle type and phase.

Dual polarized radars can effectively be used for melting layer and particle phase and type detection (Schuur et al. 2012; Ryzhkov et al. 2002, 2013; Van Den Broeke 2016; Hubbert et al 2018). The sensitivity of this radar decreases with reducing particle size. Particle phase and 3D wind structure can improve forecasting and nowcasting algorithms related to gust and low Vis. Van Den Broeke et al. (2016) stated that quasi-vertical profiles of the polarimetric radar variables could improve short term forecasts in winter. Hubbert et al. (1018) summarized polarimetric variables used in S-Pol data interpretation. Figure 7 shows range-height plots of related polarization, reflectivity, and Doppler velocities from a convective storm. Using Z (indicates core of storms), $\mathrm{Z}_{\mathrm{DR}}$ defined as differential reflectivity (reflectivity weighted particle mean axis ratio of particle distribution), $V_{D}$ (particle motion), and $\varphi_{D P}$ defined as differential phase (particle microphysics), LDR defined as linear depolarization ratio (particle shape), $\mathrm{K}_{\mathrm{DP}}$ defined as specific differential phase (particle type and shape), $\rho_{\mathrm{hv}}$ defined as co-polar correlation coefficient (particle type and phase) pco-x (cloud electrification). A combination of these variables can be used for storm physics and dynamics as suggested by Hubbert et al. (2018) that can further be used for operation applications.

\section{FIGURE 7}

Doppler radar applications for fog and Vis work can be used to provide accurate nowcasting products for aviation weather. Hamazu et al. (2003) used a 35-GHz scanning Doppler radar (Ka band, $27-40 \mathrm{GHz}$ ) for fog observations and prediction. They used the three-dimensional structure of reflectivity and velocity field in a fog event for short term predictions. The characteristics and 
performance of an 8.6-mm-wavelength Doppler radar were described in observing sea fog. The Doppler radar measurements were also used for eddy dissipation rate predictions. Aircraft based turbulence measurements with well-coordinated Doppler radar spectral width measurements were used to estimate energy dissipation rates within thunderstorms anvils (Meischner et al. 2001; Cohn 1995). The lower limit detectable dissipation rate with the C-band Doppler radar is found to be about $10^{-3} \mathrm{~m}^{2} \mathrm{~s}^{-3}$. Techniques for deriving Doppler radar estimates of energy dissipation rate has also been described by Williams and Meymaris (2016), and comparisons to in situ aircraft measurements are provided in Dehghan et al. (2014). Doppler spectrum width as measured by operational weather radars was used for both turbulence and wind shear estimation and could possibly be used for severe weather warnings (e.g., Hocking and Hocking 2018).

The K-band radars (Ku (12-18GHz), K(18-27 GHz), Ka (27-40 GHz) (Matrosov 1995; LofflerMang et al. 1999), and W-band radars (40-300 GHz, Gossard et al. 1997; Mead et al., 1989) have been used for cloud microphysical structure but usually they are not used operationally for Aviation operations. When large water mass content exists within clouds, these radar beams can be attenuated significantly. Presently, Ku and Ka band radars are part of active sensors used on GPM satellite that focuses on precipitation from the space (Skofronic-Jackson et al. 2017). These cloud radars can provide specific information for cloud and fog properties, as well as precipitation information but they are operationally expensive and mostly they are used for experimental research.

\section{i) Atmospheric thermodynamic profiling}

\section{1) Water vapor and temperature profiling}

Water vapor profiling is critical for weather forecasting because of the detail it can provide about cloud formation, nucleation processes, and storm development. Ferrare et al. (1995) provided a 
summary of water vapor measurements that included satellite-based retrievals (Soden et al. 1994), microwave (Han et al. 1994), differential absorption LIDAR (DIAL) (Ismail and Browell 1994), and Raman LIDAR (Ansman et al. 1997; Whiteman et al. 1992). The difference between the Raman LIDAR and DIAL LIDAR is that the former measures only vapor mixing ratio (qv) and the latter measures both qv and T. Recent overviews of the DIAL can be found in Wirth (2012), and Fix (2012). The work of Wulfmeyer (1998) used a DIAL system developed at the MaxPlanck Institute (MPI) in Hamburg for the measurement of absolute humidity profiles and this has been improved through the work of many others (Wulfmeyer et al. 1995, Wulfmeyer and Bosenberg 1996; Wulfmeyer 1998', and Wulfmeyer and Bosenberg 1998).

The radar-RASS system (Radio Acoustic Sounding System) was developed at the University of Hamburg for measuring wind profiles in the lower troposphere and virtual temperature profiles in the boundary layer (Peters et al. 1988; Peters 1990). The turbulent variables measured with the DIAL system and the radar-RASS include vertical profiles of water vapor and vertical wind variance and latent heat flux that uses the eddy correlation technique. Neely and Thayer (2011) also used a similar method to study high level moisture profiles over Greenland, which can be used to detect thermal and dynamical instabilities leading to particle formation and eventually cloud formation.

The main competitor to the use of Raman systems for water vapor profiling is the differential absorption LIDAR method (DIAL). In this method, two wavelengths of laser light are used. One wavelength is absorbed by the molecule of interest; one is not. Because the two wavelengths are nearly the same, their atmospheric transmission is similar, except for absorption by water vapor 
molecules (e.g., Fix 2012). Eichinger et al. (1999) used a Raman LIDAR to study ABL vapor profiles. The DIAL systems have some inherent advantages over Raman LIDARs profiles. The DIAL systems are generally smaller, lighter, and use considerably less energy than Raman LIDAR systems. They can be used for aircraft based research because atmospheric backscatter increases with a range in a downward-looking system, and thus partially compensates the decrease in signal strength with range. Because of the strong atmospheric attenuation of both UV and near-UV light channels, DIAL systems in the near-IR are better suited for deep atmospheric water vapor sounding profiles.

The Profiling microwave radiometers (PMWRs) have been also used for measuring $\mathrm{q}_{\mathrm{v}}$ and $\mathrm{T}$, as well as Liquid Water Content (LWC) which can be important for supercooled droplet detection and icing conditions (Solheim et al. 1998; Gultepe et al. 2014). The Radiometrics Inc. MP$3000 \mathrm{~A}$ profiling radiometer is used to retrieve the profiles of T, $\mathrm{RH}$ with respect to water $\left(\mathrm{RH}_{\mathrm{w}}\right)$, and LWC over Whistler Mountain (Ware et al., 2013; Gultepe et al 2014). The MP-3000A observes $21 \mathrm{~K}$-band $(22-30 \mathrm{GHz})$ and $14 \mathrm{~V}$-band $(51-59 \mathrm{GHz})$ microwave channels at multiple elevation angles, one zenith infrared (9.6-11.5 $\mu \mathrm{m})$ channel, and surface temperature, humidity and pressure sensors. The atmosphere is semi-transparent in the K-band and lower V-band channels during non-precipitating conditions, receiving emission from the atmosphere in addition to cosmic background radiation. The PMWR provides $\mathrm{T}, \mathrm{qv}, \mathrm{RH}_{\mathrm{w}}$, and $\mathrm{LWC}$ in the vertical (Bianco et al., 2005) but it needs to be validated using in-situ observations; this may be a challenge for stratiform clouds because of a weak signal from cloud water content compared to convective clouds' water content. Integrated liquid water retrieval from microwave radiometer observations near the $22.2 \mathrm{GHz}$ water vapor molecular resonance is well established (Westwater, 
1978; Turner et al., 2007). Integration of above remote sensing platforms can cover atmospheric thermodynamic conditions over the airports, and when they are combined with LIDAR and Radar observations, as well as with surface in-situ observations, both clear air and cloud regions nearby airports can be analyzed for aviation hazards.

Atmospheric thermodynamic profiling for operational icing research is important to prevent aviation accidents. Serke et al $(2008 ; 2014)$ developed a compact small platform attachable to a radiosonde balloon that is similar to the radiosonde unit. With this system they were able to measure liquid water content profile within the clouds. This state-of-the-art icing platform promises to develop future balloon based systems to be used for icing and thermodynamic profiling.

In Arctic regions, profiles of water vapor can be important for aviation nowcasting applications, such as fog and low clouds, and storm development. The Arctic LIDAR Technology (ARCLITE) facility, having a Rayleigh/Mie/Raman LIDAR system, has been in operational use since 1993 at the Sondrestrom Upper Atmospheric Research Facility, Kangerlussuaq, Greenland (Neely and Thayer 2011). In their research, molecular and aerosol backscatter is measured at $532 \mathrm{~nm}$ to retrieve $\mathrm{T}$ profiles, and a Raman channel for molecular nitrogen (608 $\mathrm{nm}$ ) to determine aerosol extinction values. A Raman water vapor channel at $661 \mathrm{~nm}$ was used to measure water vapor mixing ratio profiles into the upper troposphere. They suggested that use of Raman LIDAR technology for ABL water vapor soundings is available and is comparable with balloon based profiles. Because measurements of water vapor profiles in Arctic environments are rare, DIAL 
and Raman LIDAR based methods for water vapor profiling can improve fog, cloud, and Vis for short term predictions.

\section{2) UAVs thermodynamic profiling}

Unmanned aerial vehicles (UAVs) are becoming very popular for meteorological and environmental applications (e.g., Bottyan et al. 2013; 2016; Gultepe et al. 2018). UAVs can be accurately controlled by ground based pilots to move the UAVs in certain flight paths that represent constant altitude flights and profiling models. Measurements from the UAVs include various meteorological parameters similar to a radiosonde sounding. In addition to $\mathrm{T}, \mathrm{RH}_{\mathrm{w}}$, pressure (P), altitude (z), Vis, $\mathrm{U}_{\mathrm{h}}$ and direction (Gultepe et al 2018; Bates et al 2013). They may also be used for air quality monitioring of trace gases such as $\mathrm{O}_{3}, \mathrm{CO}_{2}, \mathrm{CO}$, and PM2.5, and earth surface morphology, including snow coverage, water accumulation, and surface temperature. Measurements from UAVs have also been used to estimate temperature and velocity turbulence levels (e.g., Lawrence and Balsley 2013). For aviation operations, UAVs can be used near airports to gather weather information that can help to improve the NWP's initial conditions and monitor weather conditions in real time. Although they have limitations on flying time (e.g., quadcopter UAVs), 3D wind measurement issues, and flying into the clouds and fog, they are being developed for extreme weather conditions (with fixed wing UAVs), and in the future they can fly into the cloud systems (Wick et al. 2018; Wurman et al. 2012), and may have potential for continuous and accurate weather measurements. Uncertainty in UAV measurements can be significant for wind related parameters because of the impact of the rotors or body of the UAV on airflow (Gultepe et al. 2018). Therefore, additional work is needed to improve wind measurements from UAVs (Reineman et al. 2013; Gultepe et al. 2018). Various meteorological 
parameters from the UAVs are also being used by others (Jonassen et al. 2012) for boundary layer (BL) research. These parameters include aerosol number concentrations $\left(\mathrm{N}_{\mathrm{a}}\right)$, fog droplet number concentration $\left(\mathrm{N}_{\mathrm{d}}\right)$, Vis, particle spectra, and air quality parameters (Boer et al. 2017; Gultepe et al. 2017).

The UAVs can be used to improve NWP predictions for meteorological applications that include wind speed, Vis, RH and T. A work by Jonassen et al. (2012) stated the importance of the use of UAV systems to improve NWP simulations, and this area of research is needed for further development of aviation products.

\section{3) Aircraft based in-situ systems}

Commercial aircraft flights can provide additional observations of meteorological parameters related to aviation operations. Automated meteorological reports from on board sensors mounted on major commercial air carriers are generally referred to internationally as Aircraft Meteorological Data Relay (AMDAR) reports. In the U. S. they are also called Aircraft Communication Addressing and Reporting System (ACARS) reports, and the meteorological data is referred to as Meteorological Data Collection and Reporting System (MDCRS) (Moninger et al. 2003). The MDCRS reports are essential for NWP model initializations, especially for rapidly updated models such as the NOAA's WRF-RAP model (Benjamin et al. 2016). Also, the commercially available Tropospheric Airborne Meteorological Data Reporting system (TAMDAR), utilizing commercial flight data collection systems, provides a data base for aviation parameters such as wind, turbulence, temperature, etc. (Moosakhanian et al. 2006). The TAMDAR data (Moninger et al. 2010; Benjamin et al. 2006a,b; Fournier 2006) used with the RUC model over three year period revealed that TAMDAR data significantly improved RUC 
forecasts. The meteorological parameters obtained from AMDAR and TAMDAR are similar to radiosonde measurements. TAMDAR also provides EDR (defined as energy dissipation rate to the $1 / 3$ power) estimates and icing detection amount. Moninger et al. (2010) over two 10-day periods provided results on meteorological parameters such as $\mathrm{T}, \mathrm{RH}_{\mathrm{w}}$, and wind representing winter and summer conditions. The assessment showed that TAMDAR's impacts on 3-h RUC forecasts of temperature, relative humidity, and wind are found to be positive and, for temperature and relative humidity, the improvements were substantial.

Estimates of turbulence are also available from selected AMDAR flights as either derived equivalent gust velocity (DEVG), or EDR. Both of these turbulence estimation algorithms are summarized in Sharman (2016); for more detailed discussions see Sharman et al. (2014), Cornman (2016), and Kim et al. (2017). Stickland (1998) compared DEVG and EDR estimations for aviation applications, and even though both are supposedly aircraft-independent, he recommended the use of EDR for aviation operations. This recommendation has been followed up by requiring EDR to be the international standard for aircraft turbulence intensity reporting (ICAO 2001). EDR can also be estimated from second-order structure functions of the AMDAR winds (Frehlich and Sharman 2010), and possibly through Mode-S and ADS-B (Automatic Dependent Surveillance-Broadcast) messages (Kopec et al. 2016). So far though, these techniques have not been implemented operationally.

Another experimental commercial aircraft on-board system is the Backscatter Cloud Probe (BCP) that provides information about the concentration and size of ice crystals in clouds. The probe has been tested as part of the European Research Infrastructure program, IAGOS (In- 
service Aircraft for a Global Observing System). Bestwick et al. (2015) demonstrated that the BCP measurements could be used to diagnose HIWC conditions, providing pilots with an onboard warning of an HIWC hazard. The sensor output could also be broadcast as part of other systems such as TAMDAR. Additional research is needed for use of the BCP operationally.

A number of experiments including the EU High Altitude Ice Crystals (http://www.haic.eu ) and North American HIWC Projects (Strapp et al. 2016), were developed and executed using remote sensing and airborne in situ assets. Leroy et al. $(2016 ; 2017)$ characterized the ice particle size distributions in HIWC using in situ measurements while Protat et al. (2014) used airborne Cband polarimetric radar data to profile the cloud ice water content within HIWC clouds. Yost et al. (2017) developed a prototype method for detecting HIWC conditions using geostationary satellite data coupled with in-situ total water content (TWC) observations obtained during aircraft-related icing projects. They developed three satellite-derived parameters that were used for determining high HIWC probability conditions. These include 1) the overshooting convective updraft or textured anvil cloud, 2) tropopause-relative infrared brightness T, and 3) daytime-only cloud optical depth. Their results are consistent with aircraft flight reports obtained near deep convective storms and cirrus anvils (Lawson et al. 1998; Mason et al. 2006; Bravin et al., 2015). Prediction of HIWC conditions needs to be improved by combining NWP model simulations and remote sensing results. Both require more in-situ observations to establish reliable statistics (Gultepe and Heymsfield 2016; Haggerty et al., 2018).

Overall, observations from various observational platforms summarized above can contribute to improvements of aviation nowcasts, weather reports, and NWP predictions extensively, and they 
may eventually lead to improvements in aviation operations, but their limitations should also be considered.

\section{NWP models}

NWP models are important for improving aviation related nowcasts (defined here as lead times $\leq$ $3 \mathrm{hrs}$ ) and forecasts over medium and large lead times (>3 hrs). Their short-term success in nowcasting is strongly related to the incorporation of observations. An NWP model's ability to accurately simulate atmospheric dynamical and physical processes depends critically on several initialization parameters and PBL characteristics (Jonassen et al. 2012). The spatial grid resolution and the parameterization schemes used to represent processes related to clouds, radiation, precipitation, and turbulence are most crucial ones (Pleim and Xiu 1995; Alapaty et al. 2001; Teixeira et al. 2008; Lin et al 1983; Tomita 2008; Khairoutdinov and Kogan, 2000; Ferrier et al. 1994; Herrington et al. 2013; Pu et al. 2018).

The quality of the data used to initialize and force the model for predictions is also essential for the success of numerical model simulations. Many models are initialized from global atmospheric analyses or forecasts (e.g., from the Global Forecast System (GFS) or the European Centre for Medium-Range Weather Forecasts (ECMWF)) with low resolutions typically being $15-50 \mathrm{~km}$ in the horizontal and 3-6 $\mathrm{h}$ in time. Therefore, scale issues play an important role for predictions over short times scales. These atmospheric data may not be accurate enough for highresolution simulations of local features such as fog or turbulence, and these can be sensitive to small errors in the large-scale flow (Nance and Durran 1997; Belair et al. 1998; Khairoutdinov and Randall 2006; Kucken et al. 2012; Selz and Craig, 2014). Because of these errors, data 
assimilation techniques using detailed and accurate observations are necessary for generating more accurate initial conditions for NWP models for all scales. The quality of the analysis data for model initialization depends mainly on the data assimilation techniques, which compile the short-range forecasts (from the NWP model to generate the first guess), observations, and their error statistics (Kalnay 2003; 1996). Also, the quality and coverage of the observations used to create the analysis have influences on the accuracy of the analysis (e.g., Langlandet al. 1999). Observations can be particularly sparse over areas such as the world's oceans and the Arctic and Antarctic, and that likely leads to large uncertainties in predictions.

\section{a) downscaling}

Because of scale issues model output can include large uncertainties in the predicted parameters. The winds can be to some extent reproduced by numerical downscaling of a state-of-the-art ECMWF operational analysis using the WRF model (Jonassen et al. 2012). However, by assimilating profile data obtained from the UAS (Unmanned Airplane Systems) at Eyrarbakki in southwest Iceland in their analysis, substantial improvements of wind, T, and RH in the region were achieved. Vislocky and Fritsch (1995) developed a statistical model to predict parameters that are important for aviation and used automatic nonlinear/linear methods that use NWP MOS (Model Output Statistics) data. Their method was time consuming, but with increasing computer resources their method can improve integrated predictive systems over various scales.

\section{b) Initial conditions}

Initialization of NWP forecasts requires assimilation of various observations for regional models as well as short-range NWP model outputs (Kalnay 2003; 1996, Warner 2011). For instance, 
inputs into the operational MRMS-Severe/Aviation system (Smith et al. 2016; Wen et al. 2017; Benjamin et al. 2009) include radar data from the U.S. WSR-88D network, GOES radiances and cloud properties (Minnis et al. 2008), surface terrain elevation information, the National Lightning Detection Network (Orville 2008; Smith et al. 2016), and hourly surface and upper-air analyses from the Rapid Refresh model (Benjamin et al. 2009). Several individual and automated algorithms have been developed using the MRMS system to obtain an integrated forecasting and analysis system that provides real-time products applicable to severe weather and aviation nowcasting. In this system, automated algorithms based on data from multiple radars provided better information with greater temporal resolution and spatial coverage than a single-radar.

\section{c) Turbulence}

Since operational NWP models are too coarse to even begin to resolve turbulence scales relevant for aircraft, post-processing algorithms applied to NWP model output is commonly used to infer regions of likely turbulence. These inferences are based on "diagnostics" of turbulence derived typically from spatial gradients of various NWP model output variables. In the past, various post-processing turbulence diagnostics have been proposed, and some are used operationally. For example, the TI (Turbulence Index) diagnostic developed by Ellrod and Knapp (1992) uses NWP model output velocity fields to derive a diagnostic based on the product of horizontal wind deformation and vertical wind shear. The TI has been used by the Aviation Weather Center (NOAA/AWC) (Behne 2008), the Air Force Weather Agency (Brooks and Oder 2004), the Met Office in the United Kingdom (Turp and Gill 2008), and the Canadian Meteorological Centre (Turcotte and Verret 1999). The physical basis of TI was considered initially due to frontogenesis through the process of dynamical deformation (Mancuso and Endlich 1966; Ellrod 
and Knapp 1992). The hypothesis suggested that stronger horizontal thermal gradients caused by frontogenesis can lead to an increase in the vertical shear of the horizontal wind through the thermal wind relation, and indicates that a higher potential for CAT occurs via the local reduction in Richardson number ( $\mathrm{Ri}$ ) and consequent production of Kelvin-Helmholtz instability). Commercial aircraft encounter severe, or greater, turbulence about 5000 times each year. These incidents resulted in tens of millions of dollars in injury claims per year (Sharman et al. 2006). In fact, these statistics were obtained only for the US airspace and are not a global representation. A significant limitation for the forecasting of all aviation turbulence types is to identify the source of gravity waves (McCann 2001; McCann et al 2012; Knox et al 2008). Observations from early field projects (Sorenson 1964) indicated that two flow regimes associated with CAT are possible: strongly cyclonic and strongly anticyclonic flows. Because the TI neglects anticyclonic shear or curvature in its derivation, Ellrod and Knox (2010) suggested that a new way should be taken to account for the anticyclonic shear.

The Graphical Turbulence Guidance (GTG) product uses an ensemble mean of many different diagnostics, which seems to improve the statistical performance of the turbulence forecasts (Sharman et al. 2006, Kim et al. 2011, Sharman and Pearson 2016, Kim et al. 2018). Example turbulence diagnostics typically used for clear-air and mountain wave sources include vertical and horizontal wind shears, static stability, wind speed, horizontal deformation, frontogenesis, ageostrophic indicators, turbulent kinetic energy (TKE), and Richardson number (Ri) (e.g., Knox et al. 2016). These diagnostics are designed to capture grid-scale processes (10-100 km) that may lead to sub-grid scale turbulence. 
The GTG product does provide short-term forecasts, but its usage is limited by a 1-h update cycle, because of the latency in receiving the underlying NWP-model data and the time required to compute the turbulence diagnostics. Therefore, forecasts are usually not available until at least $2 \mathrm{~h}$ beyond the valid time. Also, Pinto et al. (2015) and Sharman and Pearson (2016) stated that because of the highly transient and small spatial scales of turbulence associated with convective storms, neither the NWP model nor the turbulence-forecasting post-processing algorithms are particularly skillful at forecasting turbulence associated with convection. To address these issues, Pearson and Sharman et al. (2016) developed a turbulence nowcast system (GTGN) which merges turbulence observations with short-term GTG forecasts to produce more timely and accurate information for tactical turbulence avoidance. Their results suggested that turbulence nowcasts integrated with observations considerably outperforms the corresponding turbulence forecasts.

\section{d) Low level wind shear (LLWS)}

Low level wind shear (LLWS) at airports can occur due to fronts, thunderstorms, inversions, and surface obstructions (FAA-P-8740-40, 2008). Traditionally, surface in-situ wind sensors are used to identify LLWS cases, but recently, remote sensing platforms and aircraft based measurements are also used for detection. The surface sensors are located at the certain distances along the flight paths (Thobois et al. 2018; Oude et al. 2018), but do not cover higher levels; therefore, Doppler lidar (for cloud free conditions) and radars (cloudy air conditions) can be used for LLWS detection (Chan et al. 2007). Low level wind shear prediction using NWP models depends on model time and space resolutions (especially within the PBL), model physics, and large scale forcing conditions, and initial conditions. Using an NWP model, and the QuikSCAT 
space borne scatterometer (QSCAT) and Buoy observations (Kara et al. 2007, 2008) stated that wind speed errors near ocean boundaries can be up to $5 \mathrm{~m} \mathrm{~s}^{-1}$ and for high resolution NWP forecasts, RMSE in wind speed can also be as high as $4 \mathrm{~m} \mathrm{~s}^{-1}$. Banta et al. (2017) also suggested that wind speed error in NWPs were larger than the required accuracy at high resolution areas and suggested the use of LIDAR observations to improve forecasts (McCarty et al 2017). Gao et al. (2012) and Moninger et al. (2010) stated that errors in AMDAR measurements can be as high as 4-6 $\mathrm{m} \mathrm{s}^{-1}$ and suggest some corrections. Wind directional errors can be up to 35 degrees for AMDAR measurements and usually increases toward to the surface (Gao et al. 2012). Therefore, measurements of the wind speed from various measurement systems and wind speed and direction from NWP models need to be improved since they are directly used in the LLWS calculations (Chun et al. 2017).

\section{e) Physical processes for aviation nowcasts}

The production of aviation meteorological forecasts is based mainly on forecasters using numerical weather prediction (NWP) model data in combination with available observations (e.g., Jacobs and Matt 2004, Fahey et al. 2016, Bright et al. 2016). Their work suggests that NWP modeling has not yet reached a state where physical processes such as clouds and precipitation can be resolved at the spatial and temporal resolutions necessary for reliable aviation weather forecasts. Jacobs and Maat (2004) also emphasized that various physical processes associated with fog and low stratus clouds are not adequately described in NWP models due to the complexity of the underlying physical processes and the lack of sufficient vertical resolution in the atmospheric BL. Because of this, sudden weather changes on small time and spatial scales can only be evaluated and predicted if the forecaster has access to detailed observations 
concerning current weather changes. The results of their work strongly emphasized that quality of short-term forecasts, up to $6 \mathrm{~h}$, depends mainly on the availability of local and upstream observations.

\section{f) Icing}

Most if not all, current icing algorithms include empirical relations (e.g., temperature dependency) as described in Thompson et al. (1997), for tractability. In their work, inflight icing potential was predicted using algorithms developed by the National Center for Atmospheric Research (NCAR), the National Weather Service's National Aviation Weather Advisory Unit, and the Air Force Global Weather Center. The numerical model data from the Eta, MAPS, and MM5 models were used in their research. As part of the WISP94 field program (Thompson et al. 1997), detailed evaluations of icing algorithms were conducted. Most of the icing algorithms used in NWPs are only functions of T (Noh et al. 2013; Tan and Storelvmo 2016; Odegaard 1997). Thompson et al. (1997) stated that they all predict a flat or increasing frequency of icing at decreasing temperatures. On the other hand, statistical studies of pilot-reported icing (Rasmussen et al. 1992) suggested that the number of icing reports decreases with decreasing $\mathrm{T}$. Note that saturation vapor pressure also diminishes with decreasing $\mathrm{T}$. The decreases usually occurs at lower temperatures $\left(<-15^{\circ} \mathrm{C}\right)$ because of increasing ice nucleation processes at cold $\mathrm{T}$ and less available vapor content. In the Thompson et al. work (1997), all algorithms predicted increasing or stable icing at lower temperatures as expected because of nature of the parameterizations used in the models. These models simply diagnose icing conditions empirically where clouds can occur as a function of $\mathrm{RH}$ and $\mathrm{T}$ interval between $0^{\circ} \mathrm{C}$ and $-20^{\circ} \mathrm{C}$. In fact, the large uncertainty in RH, as high as $10-15 \%$ (Gultepe et al. 2016), may lead to 
substantial differences in icing rates. Similar issues also exist for airport ground operations where de-icing calculations are strongly related to T and Vis (Thompson et al. 1997, Brown et al. 1997). Traditionally, the need for ground de-icing was assessed based on horizontal Vis, but research by Rasmussen et al. $(2001,2003)$ showed that the icing hazard was more dependent on the liquid equivalent of snowfall rate. This discovery led to the development of NCAR's Weather Support to De-Icing Decision Making System (WSDDM, Rasmussen, et al. 2001). These works signify that icing research is presently immature and need to be improved for NWP model simulations for aviation operations.

\section{g) Visibility Reduction due to Fog and Precipitation}

Visibility reduction due to fog and precipitation is critical for aircraft operations. In fact, fog represents one of the most hazardous weather events affecting aviation activities. Over last decade, progress has been made in the study of fog processes (e.g., MATERHORN-fog, Gultepe et al. 2016) and climatology (Hodgess and Pu 2016; Albers 1977; Tardif and Rasmussen, 2007; Dorman et al. 2017). NWP models were also used for simulating various types of fog events (e.g., Bergot et al. 2007; Guedalia and Bergot 1994; Bott et al. 1990; Pu et al. 2016; Lin et al. 2017; Chachare and $\mathrm{Pu}$ 2018) and indicated that numerical simulation of fog is sensitive to various physical parameterization schemes (Gultepe et al 2006; Stolinga and Warner 1999), initial model conditions (Jones 1965; Anderson 1996), and land surface processes (Guedalia and Bergot 1994). Specifically, numerical prediction of the fog presents one of the challenges in NWP due to uncertainties in model physics and Vis algorithms (Gultepe et al. 2009, Guedalia and Bergot 1994, Lin et al. 2017). Also, significant errors in near-surface atmospheric variables

prevent accurate prediction of fog and precipitation (especially snow) in NWPs (e.g., Pu et al. 
2016; Pu 2017). These errors, therefore, need to be reduced when using NWP models for Vis predictions.

\section{h) Satellite data assimilations}

Satellite-based wind vectors can be used to infer wind shear, turbulence, and convective activity. Convective clouds identified by the CCM (convective cloud mask, Mecikalski et al. 2007) were supported by the work of Velden et al. $(1997,1998,2005)$ that developed the atmospheric motion vector (AMV) algorithm. In this way, GOES-based wind products can be utilized for wind-related event analysis and in data assimilation that can be used for NWP initial conditions and nowcasting applications. Short-term ( 0 to $1 \mathrm{hr})$ convective storm nowcasting remains a problem for operational weather forecasting and poses a significant financial risk for the aviation industry (Sieglaff et al. 2011). The NWP models, meteorological observations, and radar are used for short-term convective forecasting, but all have shortcomings. Geostationary imagers data can help reduce some uncertainty, and that can be valuable for convective initiation

predictions. The University of Wisconsin Convective Initiation (UWCI) nowcasting algorithm provides an objective, satellite-based decision support tool (Mecikalski et al. 2007).

\section{i) Cloud base height}

Cloud base height is an important parameter for aviation operations (Table 1), but without proper prediction of cloud microphysical parameters, $\mathrm{h}_{\mathrm{c}}$ cannot be estimated accurately. Its estimation is related to cloud total water content (CTWC) and relative humidity (as well as dew point temperature depression (Guttman and Jeck 1987). The formation of cloud at low levels is also related to PBL physical and dynamical conditions. Unfortunately, cloud total water content (TWC) can be subject to large uncertainties in the PBL forecasted properties, because of issues 
related to model resolution at low levels and turbulence/physical processes interactions. For example, a warm bias of about $3.3^{\circ} \mathrm{C}$ in SST can lead to a $\mathrm{q}_{\mathrm{v}}$ bias of $1.2 \mathrm{~g} \mathrm{~kg}^{-1}$ that was simulated by ECMWF (Sun et al., 2003). Improved NWP prediction of RH and T in the PBL can lead to more accurate TWC forecasting and that can be used for improving prediction of $\mathrm{C}_{\mathrm{h}}$ levels.

\section{j) Microphysical schemes for fog, cloud, and precipitation predictions}

NWPs need better physically-based algorithms to improve fog, cloud and precipitation processes. Detailed, but accurate, microphysical algorithms are required at various scales to obtain reliable precipitation amount and types, Vis, wind, and turbulence, and cloud radiative properties. Recently it is stated that there are some new microphysical algorithms based on improving the single particle growth history (Harrington 2013a; 2013b) rather than assumed size distributions for each particle phase (Gultepe et al. 2018; Ferrier 1994, Lin et al. 1983) improved predictions. Pu et al. (2018) found that the simulation of clouds within mesoscale convective systems is sensitive to the various microphysical schemes. They commented that ice hydrometeors play an important role in the accurate numerical prediction of clouds and precipitation. Lately, there has been a shift in the way ice-phase hydrometeors are represented in microphysics schemes, moving from predefined hydrometeor categories with prescribed physical characteristics (e.g., bulk density) and focusing on the prediction of the particle physical evolution instead (e.g., Harrington et al. 2013a,b; Morrison and Milbrandt 2015). This has led to the smoother evolution of ice crystals during growth and avoids the artificial process of “conversion', between ice categories and auto-conversion processes. Further improvements of the microphysical algorithms can lead to the development of better weather warning and decision making systems. 
The NCEP and UKMet Office are working together to create World Area Forecast (WAF) guidance for the aviation weather community worldwide. NCEP has a plan to upgrade its GFS to a Finite Volume - Version 3 model in 2019 (FV3: see https://www.gfdl.noaa.gov/fv3/fv3documentation-and-references), which will employ an advanced cloud-allowed microphysical scheme, so that better cloud-related predictions such as Vis, ceiling, and reflectivity, can be provided to the global aviation weather community.

Based on the various challenging topics described above, NWP predictions for nowcasting applications related to aviation operations may include large uncertainties; therefore, integrated methods should be considered for short term forecasts (e.g., lead time $<6$ hours), and these are described in next section.

\section{Integrated systems}

\section{a) Numerical guidance systems for aviation}

A numerical guidance system (NGS) for aviation applications that includes post-processing NWP model output and local and upstream observations over high-resolution topographical data can be used to provide information on changing weather conditions at airports (Hansen et al. 2008). The NGS, supported by detailed predictions of Vis, ceiling, wind, and precipitation observations as well as TAF and TREND type weather forecasts, can be used more efficiently for aviation weather nowcasts. 
The NGS can be supplied with high-resolution remote sensing observations such as radar, LIDAR, and wind profilers. For example, Nakamura et al. (2009) and Luce et al. (2010) used both LIDAR and radar to study CAT conditions below a cirrus cloud system. A statistical approach, known as the Graphical Turbulence Guidance (Sharman et al. 2006, Sharman and Pearson 2017), was developed to predict turbulence using a weighted regression of multiple turbulence diagnostics. This product and others such as convection, icing, ceiling and visibility, and surface wind gusts are available operationally on NOAA's Aviation Digital Data Service website (https://www.aviationweather.gov/).

\section{b) Integrated systems for nowcasting and test bed sites (supersites)}

Integrated weather nowcast systems rely on both in-situ and remote sensing observations as well as NWP model forecasts. Test bed sites (also called supersites) are an integral part of meteorological research and operations. Ralph et al. (2013) emphasized that they can foster new forecast innovations and their transition into operations. Ralph et al. (2013) determined that these developments related to supersites present new opportunities for businesses and agencies to improve their products and services. Their work extensively studied the importance of test beds for research and operations. They stated that: "Test beds tend to be "outsiders" relative to either the core mission of forecasting or the core mission of research. In spite of this, they enable more rapid improvements in forecast services and demonstrate tangible relevance of research centers to forecast services in the future." A supersite, planned by NWS as the "Operations Proving Ground (OPG)" in Kansas City, MO, will provide full integration testing of new tools and methods in an operational environment. These OPGs require a well-established research community focused on performing exploratory research and development. They also suggested 
that transformational research can provide breakthrough advances for forecast/operation services in the future. Ralph et al. (2013) clearly stated the objectives of test beds are to accelerate the translation of research and development into operations, services, and decision making for short lead time periods. Overall, a test bed site can be used for operational systems, and provide better use of data in forecasts and applications to improve economic/public safety benefits.

A new integrated system for aviation operations called The Short-Term Prediction Research and Transition (SPoRT) program using NASA, NOAA, and DoD satellite data and research capabilities is available to the operational weather community to improve short term weather forecasts on regional and local scales (Ralph et al. 2013; Stano et al. 2010; Ellrod and Gultepe 2007). The SPoRT focuses on weather and aviation related problems that include the timing and location of severe weather, changing weather conditions influenced by topography, visibility, land-ocean boundaries, and the monitoring weather in remote areas. The SPoRT involves forecasters in the entire process who help develop product training materials and help assess the utility of the products.

The NOAA NWS Advanced Weather Interactive Processing System (AWIPS, Argyle et al. 2017; Raytheon, 2016) program is a complex network of systems that ingest and integrate meteorological, hydrological, satellite, and radar data for display at Weather Forecast and River Forecast Centers. Weather forecasters then use the data to provide accurate weather, water, and climate predictions and highly reliable warnings and advisories (Kelly and Ghirardelli 1998). As stated in their work, the AWIPS results are extensively used in aviation operations and nowcasting, including time-sensitive, high-impact warnings to protect life and property 
(Ghirardelli and Glahn 2010). They stated that the Localized Aviation MOS (Model Observed Sounding) Program (LAMP) consisting of analyzing observations, advective models, and statistical methods can improve the longer-range MOS forecasts based on the GFS model.

One of the earlier integrated systems developed was the CAN-Now project, and its primary objective was to provide a four-season Forecasting/nowcasting system at the major Canadian airports with detailed nowcasts and forecasts (Isaac et al. 2014). The CAN-Now output allows airport related decision makers, including pilots, dispatchers, de-icing crews, ground operators, and air traffic controllers to make accurate decisions to improve safety and efficiency. The prototype nowcasts rely on existing routinely available weather information including NWP model output, site climatologies, remote sensing and lightning network observations, and in-situ measurements of wind, precipitation, visibility, ceiling, and temperature. The integrated nowcast system called The Adaptive Blending of Observations and Models (ABOM) system was developed by Bailey et al. (2009) to be included in the CAN-Now system. The prototype system was used in a nowcasting mode for detecting weather hazards and providing forecasts out to about 3-6 h for most phenomena, and out to $36 \mathrm{~h}$ for some subsets of phenomena.

There are several other types of integrated systems that are being used in Europe. The integrated nowcasting through comprehensive analysis (INCA) (Haiden et al. 2011) and AROME-NWC (Auger et al. 2015; Seity et al. 2011) are common ones. It includes downscale processes and updates NWP predictions using the latest observations from surface in-situ observations and high-resolution $(1 \mathrm{~km})$ orography data. A verification of INCA simulations of T, RH, and wind analyses was performed against high-resolution network observations in Austria by Kann et al. 
(2011) and Haiden et al. (2011). The AROME was developed in France that uses a nonhydrostatic mesoscale model version simulated for the forecast time range of $0-30 \mathrm{~h}$ (Auger et al. 2011; Seity et al., 2011). This model is initialized by using a 3-D variational data assimilation scheme (3DVar), and that provides the initial fields relevant for an accurate nowcast; This system was related to the ALADIN-France model (Fischer et al., 2005). Integrated turbulence nowcasts have been developed that use short-term NWP forecasts nudged by in situ and radar observations of turbulence (Pearson and Sharman 2016).

Another example of the use of integrated systems to detect and nowcast hazardous weather is provided by the low-level wind shear (LLWS) alert systems. It is well-known that thunderstorms can be accompanied by intense updrafts and downdrafts. The strong downdrafts or downbursts below cloud base on or near the ground can force low flying aircraft downward, and can also cause strong divergent flow, producing low-level (horizontal) wind shear which can lead to unexpected rapid changes in aircraft airspeed. The outflow winds associated with downbursts have horizontal extents $>4 \mathrm{~km}$ and can persist from 5-30 min. During the Joint Airport Weather Studies project (McCarthy et al. 1982), Doppler radar examination of numerous thunderstorm downdrafts and outflows indicated that wind shear particularly hazardous to aircraft occurred on much smaller temporal and spatial scales, and Fujita (1981, see also McCarthy and Serafin 1984, Wilson and Wakimoto, 2001) termed this smaller scale, but more hazardous downdrafts/outflows as "microbursts". The damaging outflow winds associated with microbursts have horizontal extents of $\leq 4 \mathrm{~km}$ and can persist from 2-10 min, typically (Wilson et al. 1984). 
The scale and suddenness of microbursts make them particularly hazardous to aircraft departing or approaching an airport. Thunderstorm outflow or microburst wind shear is known to have caused 21 aircraft accidents with 438 fatalities in the United States between 1975 and 1994.(Wolfson et al. 1994). In response to these accidents, the Federal Aviation Agency (FAA) developed and deployed three ground-based low altitude wind-shear detection systems: the Low Altitude Wind Shear Alert System (LLWAS) (e.g., Linden and Simpson 1985, Wilson and Gramzow 1991), the Terminal Doppler Weather Radar (TDWR) (e.g., Wilson et al. 1984, Michelson et al. 1990), and the Airport Surveillance Radar Weather Systems Processor (ASR-9 WSP) (Weber and Stone 1995, Cho 2015). The FAA-sponsored Integrated Terminal Weather System (ITWS) uses TDWR reflectivity data with short-term NWP model nowcasts to predict microburst intensity and location (Wolfson et al. 1994). Since the deployment of these systems, along with enhanced pilot training, commercial aircraft LLWS accidents have dropped to nearly zero in the U.S. The dramatic decrease in these accidents testifies to the safety benefits provided by these detection systems.

Enhanced physical understanding of the microburst phenomenon has been provided by highresolution simulations (e.g., Proctor 1988, 1989, Orf et al. 1996, Orf and Anderson 1999, Nicholls et al. 1993), and laboratory studies (e.g., Ferrero et al. 2014). Because of its importance to aviation, LLWS is routinely forecasted using the vector wind difference of wind between 2000 ft AGL (619.5 m) and the surface (e.g., NOAA NWS Instruction 10-813, 2016), although these forecasts are mainly driven by resolvable non-convective sources, e.g., frontal passages, lowlevel jets, lee side mountain effects, sea breeze fronts, etc. As NWP model resolution increases 
to become convection-resolving, routine microburst nowcasts using both observations and NWP forecasts will become routine.

\section{c) Artificial Intelligence for high-impact weather}

As done for other scientific research involving large data sets, increasing data volume and resolution of observations, as well as model simulation output for weather forecasting, led to the application of artificial intelligence for aviation (AIA) research and guidance. Because current NWP models runs have increased time and space resolutions (McGovern et al. 2017; Weygandt et al. 2009), as well as new observing systems, including in-situ observations, weather radars, LIDARs, and GOES-16 also generate data at high time and space scale resolutions (Stano et al. 2010; Goodman et al. 2012), forecasters and users do not have time to make rapid decisions if data are not somehow prepared for easy evaluation in advance (Karstens et al. 2015). These data sets are called "big data." Artificial intelligence (AI) methods (Pasini and Marzban 2008) use various techniques to process big data sets and then apply the results to weather forecasting issues, which are crucial for creating timely weather reports (McGovern et al. 2017). They stated that AI techniques based on physical understanding of the environment could improve prediction skill of high-impact weather situations. The AI approach expands information available over MOS techniques (Glahn and Lowry 1972) for deriving probabilistic, categorical, and deterministic forecasts available from NWP models.

McGovern et al. (2017) provided an extensive summary of AI techniques used in the meteorological applications. Haupt et al. (2008) also provided an overview of AI techniques applicable to artificial neural networks (ANNs), including decision tree algorithms, genetic 
algorithms (Allen et al. 2007), fuzzy logic, and principal component analysis (Elmore and Richman 2001). In this area, using a decision tree technique, Burrow et al. (2005) developed lightning detection algorithms for mid-latitudes. Williams (2014) used a random forest approach to diagnose convectively-induced turbulence. These works suggest that AI methods are starting to be used extensively in post-processing of NWP output and in-situ observations.

The AI systems and statistical based neural network systems can help transfer knowledge related to aviation forecasts into the aviation operations when fast computer systems become easily available in the future.

\section{Future Challenges and Issues}

There are various challenging topics related to aviation meteorology that can significantly impact aviation operations, and these are summarized below.

\section{a) Visibility and Ceiling Issues}

Jacobs and Maat (2005) show that for lead times greater than $4 \mathrm{~h}$, the TAF guidance provides more accurate cloud $h_{c}$ and Vis forecasts than those derived manually by forecasters. For shorter lead times $(<3 \mathrm{hr})$, their work suggested that the differences in the comparisons of aviation related parameters are found to be small. For aviation applications, the economic value of reliable weather forecasts is very high (Hansen et al 2009; Gultepe et al 2016). For this reason, large occurrence of high impact weather related to $h_{c}$ and Vis at an airport can reduce airport capacity that can leadi to enormous economic costs. The cloud ceiling (defined in meters for cloud cover $>=6 / 10$ of the sky) predictions can be performed based on NWP predictions using the lowest level of cloud total condensed water content (TCWC). The fuzzy logic-based analog 
forecasting systems (Hansen 2007; Bankert et al. 2004) can also be used for this purpose. A terminal aerodrome forecast (TAF) provides weather conditions and their most probable time of occurrence. The $C_{h}$ and Vis (defined by Glickman 2000) are the two variables that together determine flight category [e.g., instrumented flight rules (IFR where $\mathrm{Ch}<1000 \mathrm{ft}$ or Vis $<3$ miles) or visual flight rules (VFR) (see Table 1 for flight condition definitions, Verlinden and Bright 2017).

Table 1: FAA based flight classification that is based on cloud ceiling height and horizontal visibility.

\begin{tabular}{|l|c|c|}
\hline Flight classification & Cloud ceiling (ft) & Horizontal Visibility (miles) \\
\hline IFR & $<1000$ & $<3$ \\
\hline MVFR & $>=1000$ and $<=3000$ & $>=3$ and $<=5$ \\
\hline VFR & $>3000$ & $>5$ \\
\hline
\end{tabular}

In addition to this, the meteorological and aviation scientific communities recently studied meteorological parameters important for aviation operations that are related to ceiling height and Vis forecasts (Rudack and Ghirardelli 2010). These forecasts are valuable for making economical decisions and societal context (e.g. the loss of life). Gultepe et al. (2007) suggested that reductions in Vis can be caused by several hydrometeors including fog, haze, mist, rain, snow, and blowing snow. Figure 2 shows the meteorological events that contribute to the integrated Vis estimations. Because of Vis complexity and difficulty in measurements especially in cold climates, its use in NWPs can be difficult and includes large uncertainties (Gultepe et al. 2006, 2018). 


\section{b) Contrails and Frost}

Contrail formation, development, and dissipation are important for aviation and climate sciences but studies on these are limited. Contrails form when water vapor condenses on IN (ice nuclei) and then freeze on aerosols from the exhaust of aircraft engines at $\mathrm{T}$ less than typically $-40^{\circ} \mathrm{C}$ (see e.g., Schumann et al. 2012 for an overview). Although contrails at $-40^{\circ} \mathrm{C}$ occur at high levels in midlatitudes and tropical weather, they can also occur near the surface during Arctic winter (Gultepe et al. 2015). Heymsfield et al. $(2010 ; 2011 ; 2005)$ also stated the importance of contrail microphysical conditions for better understanding of ice cloud nucleation processes. Contrails can indicate higher values of moisture at the cold temperatures that may cause frost and light snow precipitation at high northern latitudes (Gultepe et al. 2016; 2017). Figure 8 shows heavy frost conditions occurred on an ice particle counter sensor during an Arctic project (Gultepe et al., 2015; 2018). Frost formation on aircraft surfaces is also a condition for deicing at the airports which is a required by the FAA (2004).

\section{FIGURE 8}

Over the northern latitudes, contrails, including aircraft-produced ice particles (APIPs), can be visible within the ABL over the airports (Gultepe and Heymsfield 2016; Heymsfield et al. 2011; Schumann and Heymsfield 2017; Gultepe et al. 2014; 2015, Woodley et al. 1991; Langmuir et al. 1948; Ludlam 1956). Contrails may modify the atmospheric environment in several ways. For example, Heymsfield et al. (2011) stated that holes in clouds are also due to inadvertent seeding of clouds with IN particles generated by aircraft and these are produced through spontaneous freezing of cloud droplets in air (Heymsfield and Sabin 1993; Heymsfield and Sabin 1989) and that is cooled as it flows around aircraft propeller tips or jet aircraft wings. Their work also suggested that polar clouds are particularly susceptible to the APIPs effects through 
modifications in radiative processes. This may also suggest that ice crystals sampled by aircraft probes over the Arctic environment may include APIPs and these need to be researched. Also, contrails are considered as prototype cirrus which impacts the energy budget of the atmosphere by reflecting incoming SW radiation and trapping outgoing IR radiation (Markowicz and Witek 2011, Schumann et al. 2012; Spangenberg et al. 2013; Minnis et al. 2013). How contrails from an aircraft can contribute to global climate change was studied in detail by Minnis et al. (1998, 1999), Schumann et al. (2012), Schumann and Heymsfield (2017). Whether or not contrails would contribute to global warming or cooling is still not clear, and probably cannot be ascertained without resort to high-resolution climate models (Schumann and Mayer 2017).

\section{c) Climate change impact on aviation}

Future research on the combined impacts of climate change and climate variability on aviation operations can help airlines and other aircraft operators for long term planning. For example, Goodman and Griswold (2017) investigated future density-altitude (DA) trend evaluations. Their work stressed the importance of future investigations on the impacts of ENSO and Atlantic Oscillations (AO) on DA to be used in seasonal-scale planning of aviation operations. The weight restriction is an important factor in planning future flight operations, therefore, needs to be evaluated. For this reason, airlines may need to be rescheduled out of the hottest parts of the day. Other potential impacts include anticipated jet stream changes with consequent impacts to CAT (e.g., Williams and Joshi 2013; Williams 2017; Storer et al. 2017), and changes to convection (e.g., Del Genio et al. 2007) and other extreme events (Puempel and Williams 2016).

Both Irvine et al. (2016) and Williams (2016) suggested that the effect of wind changes as a potential impact of climate change on aviation can be important for future aviation operations. This is of particular interest for trans-Atlantic flights, where the pattern of upper-level winds 
over the north Atlantic, in particular the location and strength of the jet stream, strongly influences both the optimal flight route and the resulting flight time. Some of these effects may be mitigated by "climate optimized routing" procedures (e.g., Matthes et al. 2012).

\section{FIGURE 9}

Figure 9 shows the time series of cold spell $\mathrm{T}$ and warm spell $\mathrm{T}$ indexes obtained from CMIPS models (Sillmann et al. 2013a,b) where increasing warm days and slightly decreasing cold days are seen from 1948 to 2005 . Therefore, increasing convective activities are likely expected and that can be related to shear, turbulence, and heating processes and these can play an important role for planning procedures of the aviation applications.

\section{d) Operational satellites}

Lately, geostationary satellites with more than the traditional five imaging channels are being used for weather analysis and operations, and these satellites carry additional channels in the IR windows. A review paper on geostationary satellites is given this special issue by Ellrod and Pryor (2018); therefore, limited information is provided in this sub-section. The Advanced Baseline Imager (ABI) is used on the Geostationary Operational Environmental Satellite-R Series (GOES-16). ABI views Earth with 16 spectral bands (compared to five on previous GOES), including two visible channels, four near-infrared channels, and ten infrared channels. Himawari 8 is a Japanese weather satellite and carries an Advanced Himawari Imager (AHI) with also a 16 channel multispectral imager to capture visible and infrared images of the AsiaPacific region (Berndt et al 2018). The instrument was designed and built by Exelis Geospatial Systems (now Harris Space \& Intelligence Systems). The FY-4 (FengYun-4) is the China Meteorological Administration (CMA) second-generation three-axis stabilized, geostationary 
meteorological satellite developed by CAST (China Academy of Space Technology) (Yang et al 2017). Two variants of spacecraft of the FY-4, with one carrying optical sensors and the other carrying microwave sensors were developed. It carries an AGRI (Advanced Geosynchronous Radiation Imager) with 14 channels, VISSR (Visible and Infrared Spin-Scan Radiometer) 5 channels, GIIRS (Geostationary Interferometric Infrared Sounder), LMI (Lightning Mapping Imager, Goodman et al. 2011), and a SEP (Space Environment Package).

New generation imagers are also being deployed on polar-orbiting satellites, which provide aviation information over high-latitude regions, which are only partially observed by geostationary orbiters. These new imagers, such as the Visible Infrared Imaging Radiometer Suite (VIIRS) on the Suomi National Polar-orbiting Partnership (NPP) satellite and NOAA-20+ series, provide a large number of channels that are similar to or more expansive than their geostationary satellite counterparts (Menzel et al. 2018). They will greatly enhance the satellite information useful for aviation over Polar Regions. Inclusion of spectral IR capability for geostationary satellites such as Chinese GIIRS (Menzel et al. 2018) can improve knowledge obtained for atmospheric stability, providing information on convective weather warnings and forecasts (Chiodi and Harrison 2010). Spectral IR capability has been used in polar orbiting satellites (e.g., AIRS (the Atmospheric Infrared Sounder), CrIS (Cross-Track Infrared Sounder; Zhang et al. 2016, Wang et al., 2012) and IASI (the Infrared Atmosphere Sounding Instrument) on Aqua, Suomi-NPP, NOAA-20, and METOP (Meteorological Operation) satellites; Mittaz and Harris 2011; Blumstein et al. 2007; Wang and Cao 2008) to obtain T, RH, and wind vertical structure in the region with no clouds and above the cloud tops. More extensive development of spectral IR techniques could revolutionize technology related to aviation weather forecasts. 
To improve nowcasting techniques for detecting, tracking, and monitoring the early development of small convective clouds, convective initiation forecasts over the CONUS and possibly over marine environments were studied in detail using satellite observations (Mecikalski et al. 2007). Historically, most of the convective weather predictions used weather radars (e.g., Mueller et al. 2003). However, radars usually do not see the early stages of convective cloud development prior to precipitation development. Since the 1990s, NCAR began to incorporate satellite information into convective storm nowcasting system (the Auto-Nowcaster). Satellite feature

detection algorithms (e.g., Bankert 1994; Roberts et al. 1999; Tag et al. 2000, and Roberts and Rutledge 2003) were usually used to classify cloud types, identify surface convergence boundaries, and monitor the cloud growth based on the changes in their IR cloud-top T. These developments were positive for nowcasting systems but additional data sets from GOES-16 channels can further provide information related to cloud types and related physics and dynamical processes, and need to be researched.

\section{e) Measurement uncertainties}

1) T and RH: A better understanding of the uncertainties in observations can be important for decision making systems, and that can be used for obtaining better physical parameterizations for NWP simulations and improvements in data assimilation techniques (e.g. 4-D Var) for model initial conditions. T and RH uncertainties in NWP predictions can be very large and that affects the prediction of cloud formation, visibility, and convective intensity, and surface-air interactions through turbulent fluxes using NWPs (Feingold 1999). Figure 10 shows $\mathrm{RH}_{\mathrm{w}}$ measurements obtained during the FRAM project (Gultepe et al. 2014; Gultepe 2015). This plot shows that Vis 
is strongly related to $\mathrm{RH}_{\mathrm{w}}$; increasing $\mathrm{RH}_{\mathrm{w}}$ results in decreasing Vis. A small change in $\mathrm{RH}_{\mathrm{w}}$ at about $4-5 \%$ can lead to Vis changes from $50 \mathrm{~km}$ down to few meters. This means the possible errors in $\mathrm{RH}_{\mathrm{w}}$ from NWP predictions can lead to significant issues for aviation forecasts, e.g. Vis and cloud types and that can affect operations significantly.

\section{FIGURE 10}

2) Visibility and Ceiling height: The present challenges of Vis and $h_{c}$ measurements are related to precipitation/fog hydrometeors types and scale issues (Gultepe and Isaac 2004; 2006). They suggested that discrimination of droplets from precipitation and its usage in Vis parameterizations are critical for NWP Vis predictions. Figure 11a shows a scatter plot of Vis measurements from the most commonly used sensors (Vaisala FD12p and Sentry sensors), and ice fog crystals (Fig. 11b) occurring over Yellowknife International Airport (CYK) during the FRAM ice fog project (2010-2011 winter, Gultepe et al. (2016); ice fog crystal sizes were

usually $<300 \mu \mathrm{m}$ ). The concentration of the Vis observations (along green line) in Fig. 11a is seen above the 1:1 line (red line), indicating that FD12p Vis values were usually larger than Sentry Vis by about $50 \%$. For this reason, in automated observing systems, a double Vis sensor approach should be used for model validations and comparisons with METAR observations. Especially, this needs to be improved for cold climate applications where warming trend can cause severe cold fog events (Figure 12).

\section{FIGURE 11}

\section{FIGURE 12}

Based on its occurrence, forecasting Vis over short time intervals (0-6 hrs) is challenging and most NWP models do not explicitly predict Vis (Chmielecki and Raftery 2011); therefore, Vis forecasts must first be derived from other meteorological parameters such as cloud water content 
(CWC), $\mathrm{RH}_{\mathrm{w}}$, and precipitation. Roquelaure and Bergot $(2008,2009)$ were the first to use Bayesian model averaging (BMA) in Vis forecasting. Zhou et al. (2009) also described the use of a short-range ensemble forecast system to generate probabilistic visibility forecasts. The UK Met Office Global and Regional Ensemble Prediction System (MOGREPS) and NOAA NCEP Ensemble Prediction Model (Zhou et al. 2009; Zhou and Du 2010) have already been used for probabilistic aviation weather predictions (Gill and Buchanan 2014; Chun et al. 2017; Kim et al., 2015).

Operationally, aviation-related interests in the US typically use two types of ceiling and Vis forecasts provided by the NWS Global Forecast System (GFS) model: 1) GFS MOS forecasts and 2) GFS Localized Aviation Model Output Statistics Program (LAMP) forecasts. Both the GFS MOS and GFSLAMP produce probabilistic forecasts for seven ranges of Vis and return to the user a categorical forecast corresponding to the most likely range of values. These existing methods do not provide a general framework for generating a full predictive probability density function (PDF) for Vis (Chmielecki and Raftery 2011). They stated that predictive PDFs are attractive for Vis forecasts because both thresholds of ceiling height and Vis correspond directly to the conditions governing flight rules. A predictive PDF allows the user to determine the probability of Vis falling below any threshold of interest rather than a single pre-specified threshold. Therefore, PDF based approaches for ensemble prediction of Vis and ceiling height need more research.

Cloud ceiling measurements are usually performed by ceilometers or are based on manual observations of sky conditions at airports. It is defined as the height of the lowest layer of clouds above the surface that is either broken or overcast, but not thin. The broken and overcast 
conditions are measured by the "octals", which are 8 equal segments of the sky. The ceilometers measurements usually provide cloud conditions at 3 levels e.g. low clouds, middle clouds, and high level clouds, but they may not have the same meaning as man-made observations. Therefore, these measurements should be properly compared and integrated for aviation applications

\section{3) Turbulence and EDR}

Measurements of 3D wind components and prediction of EDR and gust conditions are also critical to aviation operations (Sharman et al. 2018, Gultepe et al. 2018, current issue). Although gust values usually are presented based on the horizontal wind components, the vertical component also plays a significant role in gust and EDR estimation. These can be obtained using in-situ ultrasonic sensors (Gultepe et al. 2018) or from AMDAR or TAMDAR EDR reports from commercial flights, and also likely from remote sensing platforms such as LIDAR and radar, and inferences for satellite features (Benjamin et al. 2007). In all events, EDR is an estimated quantity that is not actually "measured", so it is particularly difficult to determine the uncertainty in the estimate. Pearson and Sharman (2017) studied EDR from onboard aircraft estimates versus nearby METARs wind speed and wind gust measurements (Figures 13a and 13b, respectively). The fits for each represent large variability in data. The scatter around the mean curves was very large. This is not surprising since turbulence is a microscale phenomenon with large spatial and temporal variability. But this implies that uncertainties in the use of dynamical parameterizations for EDR versus gust can be large and NWPs need probabilistic approaches or better diagnostic approaches.

\section{FIGURE 13}




\section{4) Low Level Wind Shear (LLWS) measurements}

As provided previously low level wind shear measurements can have large uncertainties based on measurement field designs and instrument type. For example, ultrasonic wind sensors (2D or 3D) can have issues when icing or precipitation occur (Gultepe et al. 2018). If they are heated for icing conditions, additional issues may arise due to heating the tips of sensing units. On the other hand, icing may also affect conventional wind measurements using regular anemometers. Use of Doppler LIDAR based techniques may work nicely to obtain good results for clear air and light cloud conditions but under the heavy precipitation and large optical thickness conditions they cannot penetrate in-cloud conditions and will fail for wind measurement retrievals (Thobois et al. 2018). Table 2 (ICAO 2005) provides criteria for low LLWS definitions that indicates the accuracy wind speed and direction measurements should have.

Table 2: Synthesis of the ICAO guidelines for observing low level wind shears (ICAO, 2005).

\begin{tabular}{|c|c|c|}
\hline Features & Alerts & Warnings \\
\hline Coverage & $\begin{array}{l}3 \mathrm{NM} \text { extension to runways is commonly used } \\
\text { whatever the wind shear equipment (LLWAS, Lidars, } \\
\text { TDWR/Radars) }\end{array}$ & $\begin{array}{l}\text { Up to } 9.55 \mathrm{~km} \text { for a glide } \\
\text { slope of } 3 \mathrm{Deg} \text { in order to } \\
\text { monitor up to the altitude of } \\
500 \mathrm{~m} .\end{array}$ \\
\hline Update Frequency & $\begin{array}{ll}\text { - } & \text { LLWAS: update every } 30 \mathrm{sec} \\
\text { - } & \text { Radar/lidar: update between } 1 \text { to } 6 \mathrm{mins}\end{array}$ & $\begin{array}{l}\text { Typically } 5 \text { minutes are used } \\
\text { for radars and lidars }\end{array}$ \\
\hline Resolution & $\begin{array}{l}\text { - LLWAS: } 1 \mathrm{NM} \text { between } 2 \text { anemometers } \\
\text { - RADAR: } 100-250 \mathrm{~m} \\
\text { - Lidar: } 100-200 \mathrm{~m}\end{array}$ & Same as alerts \\
\hline Scanning patterns & $\begin{array}{l}\text { One horizontal scan (PPI) at } 3 \text { deg scans per approach } \\
\text { are used }\end{array}$ & $\begin{array}{l}\text { Several products can be used } \\
\text { from } 2 \text { to } 5 \text { PPI scans }\end{array}$ \\
\hline $\begin{array}{l}\text { Methods for } \\
\text { computing alerts }\end{array}$ & $\begin{array}{l}\text { Wind shear alerts: Headwind/tailwind changes } \\
\text { over } 1 \text { NM or along the runway superior to } 15 \\
\text { Knots. } \\
\text { - Microburst alerts: Headwind/tailwind changes } \\
\text { over } 1 \text { NM or along the runway superior to } 40 \\
\text { Knots. } \\
\text { - LLWAS: NCAR Algorithm } \\
\text { RADAR: Runway-oriented wind shears } \\
\text { algorithms like the ones developed by MIT- } \\
\text { Lincoln Lab for TDWR, HKO algorithm, } \\
\text { products of commercial software like } \\
\text { RAINBOW5 developed by Selex and IRIS } \\
\text { developed by Vaisala. }\end{array}$ & $\begin{array}{l}\text { Additional products can be } \\
\text { computed from radial radar } \\
\text { or lidar data according to } \\
\text { local needs like shear } \\
\text { products, gust front } \\
\text { detection, wind } \\
\text { reconstruction }\end{array}$ \\
\hline
\end{tabular}




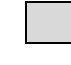

\section{1}

\section{f) Convection parameterization and prediction}

Convection parameterization based on NWP models, observations, and integrated methods can play an important role for aviation operations. Use of forecaster contributions for providing convective outlooks, mesoscale concepts, and severe weather warnings such as heavy precipitation, hail, and tornado watches can improve short term predictions for aviation operations that usually need a forecast warning time of less than a $1 \mathrm{hr}$ time-period. The Storm Prediction Center (SPC) (Karstens et al. 2018; Cohen et al. 2017) also has a human component for severe weather prediction. This needs to be considered because accumulated errors of NWP model physical components for predictions can be significant during simulation times less than 1 hr. In fact, synoptic scale environments associated with severe weather can complicate short term predictions and human based knowledge can help to improve short term predictions.

Convection-allowing numerical model (CAM) ensembles can provide extensive information related to storm intensity, location, and evolution but do not forecast accurately maximum hail size at the surface (McGovern et al. 2017). Based on the large variability related to meteorological observations and NWP scale issues, and deterministic parameterizations, probabilistic analysis of the aviation meteorological parameters predictions are needed. For example, Figure 14 shows the observed frequency of hail amount for sizes $>25 \mathrm{~mm}$ versus forecast probability using the CAM Analysis and Prediction of Storms (CAPS) ensemble predictions using methods provided in McGovern et al. (2017). In the inset, it shows the same for the actual numbers of cases. In this inset, observed frequency increases while forecast probability decreases significantly. Based on various simulations using conditions given in the legend 
(McGovern et al. 2017), it is seen that increasing counts result in lower predictability of the meteorological parameters (Fig. 14). Verification results and a single forecast case in this figure are given for the machine-learning hail forecasts and other storm surrogate probability forecasts, including HAILCAST, column total graupel, and updraft helicity (McGovern et al. 2017). The Random Forest (RF) analysis (Ahijevych et al. 2016) used for this experiment was trained using CAPS ensemble forecasts during May-June 2014, and evaluated based on CAPS ensemble forecasts. The performance diagram in Fig. 14a shows that for a given probability threshold, the machine-learning models tend to have fewer false alarms, a lower frequency bias, and higher overall accuracy than other methods. The attributes diagram in Fig. 14b indicates that the probabilities from the machine-learning models and updraft helicity are generally reliable, while other methods tend to produce probabilities that are overconfident. These results suggest that probabilistic approaches for convection prediction need to be developed in the future that are based on RF or other AI methods.

The demand for accurate nowcasts of convective precipitation that includes heavy precipitation and hail has led to development of the high-resolution data assimilation and rapid cycling numerical weather prediction system (e.g., Sun et al. 2013). In their work, they reviewed the recent progress on the use of NWP for nowcasting convective precipitation and provided future expected challenges and opportunities. They emphasized that NWP models generally produce larger quantitative precipitation forecasts (QPFs) than nowcasting systems beyond a few forecast hours. Therefore, they suggest blending radar echo extrapolation with a numerical model run to generate a seamless 0-6-h forecast. Nowcasting and Initialization for Modeling Using Regional Observation Data System (NIMROD; Golding 1998) was the first system that used blended radar 
echo extrapolation with a NWP output. For the first hour nowcast, the extrapolation of the observed precipitation field was given full weight, and it was gradually relaxed with increasing lead time to where the model eventually received full weight. This method was better than earlier radar echo tracking systems. The blending of the corrected model forecasts with extrapolation forecasts allows for a smooth transition from the extrapolation to model forecasts (Sun et al. 2013). Similar results have been shown over the years starting with Browning (1980), Doswell (1986), and Austin et al. (1987). A recent paper by Sokol and Zacharov (2012) described a new blending method that assimilates the extrapolated radar reflectivity with a nudging technique. The decrease in skill by extrapolation related to the size and organization of the precipitation were also emphasized by Wilson (1966) and Wilson et al. (1998). Based on a large set of predictor fields, and inserting the location of boundary layer convergence lines in NCAR's AutoNowcaster (ANC) (Mueller et al. 1993), Wilson et al. (2004) predicted storm initiation up to one hour in advance that shows the importance of BL processes. The ANC system uses fuzzy logic to combine predictor fields that reflect the atmospheric environmental conditions and boundary layer forcing based on observations and numerical model runs.

To meet the needs of nowcasting, numerical models have to be run at resolutions of at least a few kilometers. Wilson and Roberts (2006) stated that the 10-km Rapid Update Cycle (RUC10) 3-h forecasts issued every $3 \mathrm{hr}$ were correct at predicting areas of convective initiation only 13\% of the time. Sun et al. (2013) stated that possible factors limiting the model's ability to predict precipitation initiation, likely was insufficient model resolution in addition to many other factors. Models with high resolutions can enable the explicit representation of convective processes without cumulus parameterization schemes. These models are called as "convection-permitting" 
or "convection-allowing" NWP (e.g., Sun et al. 2013). Many other studies show that forecasts from the convection-permitting models produced more skillful guidance than those from a coarser-resolution model employing convective parameterization (e.g., Done et al. 2004; Kain et al. 2006; Weisman et al. 2008; Clark et al. 2009). Verification of convection forecasts is challenging, and innovative methods are needed to account for small errors in model derived location and timing (e.g., Pinto et al. 2015).

\section{FIGURE 14}

\section{g) Observational methods}

The accurate testing of nowcasting products is strongly related to observations and their analysis. Golding (1998) suggested that the products should be assessed against both point observations and analyses.

Nowcasting systems usually integrate observations with Numerical Weather Prediction (NWP) model products for short term predictions up to six hours ahead. In Golding et al. (1998), precipitation, cloud, and visibility were the main conditions. The precipitation rate in the analysis used a combination of the processed radar and satellite data, surface reports, and NWP simulation output. The precipitation type was also diagnosed in their work using NWP fields. Improving nowcasts is a strong function of the integrated systems that are used in the observations and model outputs (Bailey et al. 2009). Developments of these nowcasting systems in the near future likely will be improved by artificial intelligence (AI) methods.

Generally, NWP prediction assessments against point observations are only reported for analyses because the representativeness errors of meteorological parameters are of similar magnitude to 
the forecast errors. He stated assessments against analyses performed over restricted geographical areas are considered good because of observational coverage. If not considered, then the verification statistics can be very uncertain. Because of possible natural variability in observations, use of supersites with satellite stations (Gultepe et al. 2018; Ralph et al. 2013) should to be further researched for data assimilation and model output validations. Verifications performed by (Vislocky and Fritsch 1997) showed that the observations-based methods were not only far superior to persistence climatology at all lead times (5\%-20\% improvement) but also outperformed the MOS-based technique at the 1- and 3-h lead time projections with skill increases averaging four percentage points. This suggests that for nowcasting applications, observations should be weighted more than MOS techniques.

\section{h) Overall summary}

In the future, although expanded computational techniques can be expected to reduce the uncertainty in the predicted parameters related to aviation meteorology, improvements in individual models and physical parameterizations and their careful verification is paramount (e.g., Yano et al. 2018 and references therein). Viz., physical parameterizations related to aviation meteorology forecasting are not well-represented at NWP scales presently in use; therefore, new scale-dependent physical parameterizations will be needed to improve the NWPs predictions in deterministic or probabilistic approaches.

Forecasting accuracy of high impact weather parameters are strongly dependent on availability of integrated data sets (both observations and predictions) and should take advantage of probabilistic forecast methods (Benjamin et al. 2010; Zhou et al. 2009). Unfortunately, errors 
related to components of the NWP ensemble simulations do not usually cancel out each other but tend to accumulate. As shown in this review, both measurements and statistical approaches, as well as newly developed scale-dependent physical (e.g. Vis) and dynamical parameterizations (e.g. EDR, CAT) are needed to improve the accuracy of the NWP model predictions that are related to core physical and dynamic processes.

Overall, the issues with predictions of gusts and EDR, Vis, precipitation amount and rate, fog, icing/deicing, and lightning as well as convective intensity require more advanced designs for the meteorological supersites and physically-based approaches for parameterizations of severe weather parameters under various climatic environments. In this respect, in-situ observations at the surface and within the atmospheric layer in both cloud and cloud-free regions are required to improve the aviation nowcasting and also for improving the accuracy of the long-range forecasts.

In response for the needs of global aviation community, NCEP and UK Met Office are currently assigned by ICAO (International Civil Aviation Organization) to create World Area Forecast (WAF) guidance for the aviation weather community worldwide. Both centers are now providing operational global icing and turbulence forecasts based on their global forecast systems. NCAR's fuzzy logic icing and GTG turbulence algorithms have already been implemented into NCEP's Unified Post Processor (UPP) to generate both icing and turbulence forecasts (Chuang et al. 2018). Results of this collaboration indicate that aviation meteorology issues are not only locally recognized but also globally, and need to be evaluated and integrated. 
Acknowledgment: This review paper is funded by the various institutions representing coauthors given in the title, and received technical and funding support from ECCC and SAR offices in Canada that were related to fog and visibility issues. S. S. Yum is supported by the Research and Development Program for KMA Weather, Climate and Earth System Services (\#2016-3100) of National Institute of Meteorological Sciences (NIMS). We also would like to thank for the reviewers for their comments to improve the manuscript, and specifically to one of the reviewers who made specific comments on satellite and radar based platforms to be used for aviation meteorology.

\section{Figure Captions}

Figure 1a-b: Statistics for aircraft related accidents related to meteorological parameters from 1994 to 2000: (a) actual numbers of accidents and (b) probabilistic distributions in pie chart (Data from NTSB 2010).

Figure 1c-d: Part 91-Weather as cause/factor during all accidents for the period of 2000-2011. The NTSB (National Transportation Safety Board) based statistics which resulted in 19441 accidents and $29 \%$ of these accidents were related to weather conditions (c) (Eick, 2014) and Part 121-air carrier weather related cause/factors for 2000-2011 (d).

Figure 2: Various weather conditions representing visibilities related to warm fog, moisture, rain, freezing fog, ice fog, snow, blowing snow, and ashes (from top left to the right boxes).

Figure 3: CIP (Cloud Icing Project) conceptual diagram (a). Precipitation types: snow (asterisks), rain (large open circles), and freezing drizzle (small gray circles). (Adapted from Bernstein et al 2005) (C) American Meteorological Society. Used with permission. (b) shows a picture of 
splintering mechanism, which generated many small droplets and then quickly froze occurred during a wet snow case at $\mathrm{T}=-3^{\circ} \mathrm{C}$ on March 152013 during SAAWSO project (Gultepe et al. 2017) took place over St. Johns' area, NL, Canada .

Figure 4: Example of texture-based clustering of GOES imagery on Dec. 5 2003: Three-band red, green, blue (RGB) image (a) and color-coded clustering classifier (b). Color bar shows cloud types (c). An example of the GOES-12 imager-derived cloud top pressure product at $1800 \mathrm{U} \mathrm{T}$ C 15 Nov 2005 is shown in (d). (Adapted from Mecikalski et al. 2007). () American Meteorological Society. Used with permission.

Figure 5: The $\sigma_{\mathrm{w}}{ }^{2}$ profiles (a), horizontal mean wind speed profiles (b), and $\sigma_{\mathrm{w}}{ }^{2}$ profiles (c) for a 24-h period on 11 Aug 2006 during TexAQS 2006 project (Adapted from Tucker et al. 2009).

Figure 6: Example observations of the 16 January 2015, mountain ice fog event that occurred during the MATERNHORN project over the Utah Mountains; Halo backscatter ratio and 3D winds based on Doppler velocities and VAD technique (a), and CL-31 Backscatter ratio ( $\beta$ ) (b).

Figure 7: A reflectivity RHI of a large convective cell gathered at 0005:23 UTC 26 Jun 2015. Reflectivity field (Z) is shown in (a) where the dashed line marks the $55-\mathrm{dBZ}$ contour; $60 \mathrm{dBZ}$ is seen up to $13 \mathrm{~km} \mathrm{MSL}$, indicating the likely presence of large hail, Doppler velocities in (b), the various regions based on $\mathrm{S}-\mathrm{Pol}$ radar $\mathrm{Z}_{\mathrm{DR}}$ marked with white contour lines and are labeled (c), and differential phase $\phi_{\mathrm{DP}}$ is shown in (d); starting offset is set at about $0^{\circ} \mathrm{C}$ and over marked regions of vertical ice crystals, $\phi_{\mathrm{DP}}$ is decreasing in range (d). Adapted from Hubbert et al. (2018), (C) American Meteorological Society (AMS). Used with permission.

Figure 8: Frost formation on ice particle counter sensor which occurred during the FRAM ice fog project in Barrow, AL, on April 162008. 
Figure 9: Time series of percentile indices from 1948 to 2005 of the ensemble mean (solid) and median (dashed) of 31 CMIP5 models (black) and 18 CMIP3 models (green). The shading indicates the interquartile ensemble spread (range between the 25th and 75th quantiles). Note that the percentile indices from the reanalysis ERA40 (blue) from 1958 to 2001 and NCEP1 (red) from 1948 to 2005 are calculated with a different base period (1961 to 1990) than those from ERA-Interim (cyan) and NCEP2 (orange) with a base period from 1979 to 2008. Displayed are global averages over all land for CSDI (a) and for WSDI (b). Grey shading along the horizontal $\mathrm{x}$-axis indicates the evolution of globally averaged volcanic forcing according to Sato et al. (1993) (Adapted from Sillmann et al. 2013). (C) American Meteorological Society. Used with permission.

Figure 10: Vis versus $\mathrm{RH}_{\mathrm{w}}$ from a severe fog case event at the FRAM site during in Snow-V10 project.

Figure 11: Vis from FD12P sensor against Sentry Vis (a) for all precipitation types and ice fog, and ice fog crystals (b) collected during FRAM-IF project took place over Yellowknife International Airport (2010-2011 Winter).

Figure 12: Ice fog occurrence over the Arctic Ocean on Aug 242010 (Permission by G. Toth).

Figure 13: Plots of 117069 wind speed (a) and 15382 wind gust observations in Knots (b) matched with in situ EDR (Eddy Dissipation Rates) reports within $5 \mathrm{~km}, 5$ min, and $1000 \mathrm{ft}$ of each other. Median speed and gust values within each 1-kt bin are shown as black dots. Fit lines to the median values are shown in black (linear) and purple (square root) (Adapted from Pearson and Sharman 2017). (C) American Meteorological Society. Used with permission. 
Figure 14: Performance diagram comparing different hail forecasting methods (a). Attributes diagram indicating the reliability of different forecasting methods (b) (Adapted from McGovern et al. 2017). (C) American Meteorological Society. Used with permission. 


\section{REFERENCES}

Ahijevych, D., J. O. Pinto, J. K. Williams, and M. Steiner, 2016: Probabilistic forecasts of mesoscale convective system initiation using the random forest data mining technique. Wea. Forecasting, 31, 581-599, doi:10.1175/WAF-D-15-0113.1.

Alapaty, K., N.L. Seaman, D.S. Niyogi, and A.F. Hanna, 2001: Assimilating Surface Data to Improve the Accuracy of Atmospheric Boundary Layer Simulations. J. Appl. Meteor., 40, 2068-2082.

Albers, H.W., 1977: ICAS items. Bull. Amer. Meteor. Soc., 58, 342-343,

Allen, C. T., S. E. Haupt, and G. S. Young, 2007: Source characterization with a genetic algorithm-coupled dispersion-backward model incorporating SCIPUFF. J. Appl. Meteor. Climatol., 46, 273-287.

Anderson, J.L., 1996: Selection of Initial Conditions for Ensemble Forecasts in a Simple Perfect Model Framework. J. Atmos. Sci., 53, 22-36,

Ansmann, A., I. Mattis, U. Wandinger, F. Wagner, J. Reichardt, and T. Deshler, 1997: Evolution of the Pinatubo Aerosol: Raman Lidar Observations of Particle Optical Depth, Effective Radius, Mass, and Surface Area over Central Europe at 53.4 N. J. Atmos. Sci., 54, 2630-2641.Appleman, H., 1953: The formation of exhaust condensation trails by jet aircraft. Bull. Amer. Meteor. Soc., 34, 14-20.

Auger, L., O. Dupont, S. Hagelin, P. Brousseau and P. Brovelli, 2015: AROME-NWC: a new nowcasting tool based on an operational mesoscale forecasting system. Q. J. R. Meteorol. Soc. 141: 1603-1611. 
Austin, G. L., P. Dionne, and M. Roch, 1987: On the interaction between radar and satellite image nowcasting systems and mesoscale numerical models. Proc. Mesoscale Analysis and Forecasting, Vancouver, BC, Canada, European Space Agency, 225228.

Bailey M. E., Isaac G. A., Driedger N., Reid J. 2009: Comparison of nowcasting methods in the context of high-impact weather events for the Canadian Airport Nowcasting Project. International Symposium on Nowcasting and Very Short Range Forecasting,30 August - 4 September 2009, Whistler, British Columbia.

Bailey, M.E., G.A. Isaac, I. Gultepe, I. Heckman and J. Reid, 2014: Adaptive Blending of Model and Observations for Automated Short-Range Forecasting: Examples from the Vancouver 2010 Olympic and Paralympic Winter Games. J. of Pure and Applied Geophysics. DOI 10.1007/s00024-012-0553-x. 171, 257-276.

Bankert, R.L., 1994: Cloud Classification of AVHRR Imagery in Maritime Regions Using a Probabilistic Neural Network. J. Appl. Meteor., 33, 909-918.

Bankert, R.L., M. Hadjimichael, A.P. Kuciauskas, W.T. Thompson, and K. Richardson, 2004: Remote Cloud Ceiling Assessment Us,ing Data-Mining Methods. J. Appl. Meteor., 43, $1929-1946$.

Bankert, R.L., C. Mitrescu, S.D. Miller, and R.H. Wade, 2009: Comparison of GOES cloud classification algorithms employing explicit and implicit physics. J. Appl. Meteor. Climatol., 48, 1411-1421, 
Banta, R., Y. Pichugina, A. Brewer, E. James, J. Olson, S. Benjamin, J. Carley, L. Bianco, I. Djalalova, J. Wilczak, M. Hardesty, J. Cline, and M. Marquis, 2017: Evaluating and Improving NWP Forecast Models for the Future: How the Needs Of Offshore Wind Energy Can Point the Way. Bull. Amer. Meteor. Soc. doi:10.1175/BAMS-D-16-0310.

Barker, H. W., Jerg, M. P., Wehr, T. , Kato, S. , Donovan, D. P. and Hogan, R. J. (2011), A 3D cloud construction algorithm for the EarthCARE satellite mission. Q.J.R. Meteorol. Soc., 137: 1042-1058. doi:10.1002/qj.824

Bates, T.S., P. K. Quinn, J. E. Johnson, A. Corless, F. J. Brechtel, S. E. Stalin, C. Meinig, and J. F. Burkhart, 2013: Measurements of atmospheric aerosol vertical distributions above Svalbard, Norway, using unmanned aerial systems (UAS). Atmos. Meas. Tech., 6, 2115-2120.

Bedka, K., J. Brunner, R. Dworak, W. Feltz, J. Otkin, and T. Greenwald, 2010: Objective Satellite-Based Detection of Overshooting Tops Using Infrared Window Channel Brightness Temperature Gradients. J. Appl. Meteor. Climatol., 49, 181-202.

Bedka, K. M. and Khlopenkov, K., 2016: A probabilistic multispectral pattern recognition method for detection of overshooting cloud tops using passive satellite imager observations, J. Appl. Meteorol. Clim., 55, 1983-2005, https://doi.org/10.1175/JAMCD-15-0249.1,

Behne, D., 2008: NAM-WRF verification of subtropical jet turbulence. Electron. J. Operational Meteor., Paper 2008-EJ3. [Available online at http://www.nwas.org/ej/pdf/2008EJ3.pdf.]. 
Bélair, S., P. Lacarrère, J. Noilhan, V. Masson, and J. Stein, 1998: High-Resolution Simulation of Surface and Turbulent Fluxes during HAPEX-MOBILHY. Mon. Wea. Rev., 126, 2234-2253.

Bernstein, B.C., F. McDonough, M.K. Politovich, B.G. Brown, T.P. Ratvasky, D.R. Miller, C.A. Wolff, and G. Cunning, 2005: Current Icing Potential: Algorithm Description and Comparison with Aircraft Observations. J. Appl. Meteor., 44, 969-986.

Benjamin, S., S. Weygandt, J. Brown, M. Hu, C. Alexander, T. Smirnova, J. Olson, E. James, D. Dowell, G. Grell, H. Lin, S. Peckham, T. Smith, W. Moninger, J. Kenyon, and G. Manikin, 2016: A North American Hourly Assimilation and Model Forecast Cycle: The Rapid Refresh. Mon. Wea. Rev., 144(4), 1669-1694. doi:10.1175/MWRD-150242.1 .

Benjamin, S. G., W. R. Moninger, T. L. Smith, B. D. Jamison, and B. E. Schwartz, 2006b: Impact of TAMDAR humidity, temperature, and wind observations in RUC parallel experiments. Preprints, 12th Conf. on Aviation, Range, and Aerospace Meteorology, Atlanta, GA, Amer. Meteor. Soc., 4.5.

Benjamin, S. G., W. R. Moninger, T. L. Smith, B. D. Jamison, and B. E. Schwartz, 2006a: TAMDAR aircraft impact experiments with the Rapid Update Cycle. Preprints, 10th Symp. on Integrated Observing and Assimilation Systems for tmosphere, Oceans, and Land Surface, Atlanta, GA, Amer. Meteor. Soc., 9.8. Available online at http://ams.confex.com/ams/pdfpapers/.

Benjamin, S. G., W. R. Moninger, T. L. Smith, B. D. Jamison, E. J. Szoke, and T. W. Schlatter, 2007: 2006 TAMDAR impact experiment results for RUC humidity, temperature, and 
wind forecasts. Preprints, 11th Symp. on Integrated Observing and Assimilation Systems for the Atmosphere, Oceans, and Land Surface, San Antonio, TX, Amer. Meteor. Soc., 9.2.Available at http://ams.confex.com/ams/pdfpapers/119903.pdf.

Benjamin, S. G., B. D. Jamison, W. R. Moninger, S. R. Sahm, B. E. Schwartz, and T. W. Schlatter, 2010: Relative short-range forecast impact from aircraft, profiler, radiosonde, VAD, GPS-PW, METAR, and mesonet observations via the RUC hourly assimilation cycle. Mon. Wea. Rev., 138, 1319-1343.

Benjamin, S. G., and Coauthors, 2009: Rapid Refresh/RUC project technical review. NOAA/ESRL/GSD Internal Review. [Available online at http://ruc.noaa.gov/pdf/RRRUC-TR_11_3_2009.pdf.].

Benjamin, S. G., and Coauthors, 2004: An hourly assimilation-forecast cycle: The RUC. Mon. Wea. Rev., 132, 495-518

Berndt, E., N. Elmer, L. Schultz, and A. Molthan, 2018: A Methodology to Determine Recipe Adjustments for Multispectral Composites Derived from Next-Generation Advanced Satellite Imagers. J. Atmos. Oceanic Technol., 0, https://doi.org/10.1175/JTECH-D17-0047.1.

Bergot, T., E. Terradellas, J. Cuxart, A. Mira, O. Liechti, M. Mueller, and N.W. Nielsen, 2007: Intercomparison of Single-Column Numerical Models for the Prediction of Radiation Fog. J. Appl. Meteor. Climatol., 46, 504-521. 
Bernstein, B. C., C. A. Wolff, and P. Minnis, 2006: Practical application of NASA-Langley advanced satellite products to in-flight icing nowcasts. Proc. 44th AIAA Aerospace Sci. Mtg. \& Exhibit, Reno, NV, January 9-12, AIAA-2006-1220, 18 pp.

Bianco, L., Cimini, D., Marzano, F.S., \& Ware, R. (2005). Combining microwave Radiometer and Wind Profiler Radar measurements for High-Resolution Atmospheric Humidity Profiling. Journal of Atmospheric and Oceanic Technology. 22, 7, 949-965.

Bilbro, J.W. and W.W. Vaughan, 1978: Wind Field Measurement in the Nonprecipitous Regions Surrounding Severe Storms by an Airborne Pulsed Doppler Lidar System. Bull. Amer. Meteor. Soc., 59, 1095-1100.

Bilbro, J., G. Fichtl, D. Fitzjarrald, M. Krause, and R. Lee, 1984: Airborne Doppler Lidar Wind Field Measurements. Bull. Amer. Meteor. Soc., 65, 348-359.

Black, A.W. and T.L. Mote, 2015: Characteristics of Winter-Precipitation-Related Transportation Fatalities in the United States. Wea. Climate Soc., 7, 133-145.

Blumstein, D., B. Tournier, F. R. Cayla, R. F. T. Phupin, C. Bull, and G. Ponce, 2007: In-flight performance of the infrared atmospheric sounding interferometer (IASI) on MetOp-A. Atmospheric and Environmental Remote Sensing Data Processing and Utilization III: Readiness for GEOSS, M. D. Goldberg et al., Eds., International Society for Optical Engineering (SPIE Proceedings, Vol. 6684), 66840, doi:10.117/ 12.560907.

Bluestein, H.B., M. M. French, I. PopStefanija, R. T. Bluth, and J. B. Knorr, 2010: A mobile, phased-array Doppler radar for the study of severe convective storms: The MWR05XP. Bull. Amer. Meteor. Soc., 91, 579-600. 
Bluestein, H.B., J.B. Houser, M.M. French, J.C. Snyder, G.D. Emmitt, I. PopStefanija, C. Baldi, and R.T. Bluth, 2014: Observations of the Boundary Layer near Tornadoes and in Supercells Using a Mobile, Collocated, Pulsed Doppler Lidar and Radar. J. Atmos. Oceanic Technol., 31, 302-325.

Boer G. D., S. Palo, B. Argrow, G. LoDolce, J. Mack, R.-S. Gao, H. Telg, C. Trussel, J. Fromm, C. N. Long, G. Bland, J. Maslanik, B. Schmid, and T. Hock, 2017:The pilatus unmanned aircraft system for lower atmospheric research. Atmos. Meas. Tech. Discuss., 8, 11987-12023, 2015. Bottyán, Z., Zoltán Tuba and A. Z. Gyöngyösi, 2016: Weather Forecasting System for the Unmanned Aircraft Systems (UAS) Missions with the Special Regard to Visibility Prediction, in Hungary. L. Nádai and J. Padányi (eds.), Critical Infrastructure Protection Research, Topics in Intelligent Engineering and Informatics, DOI 10.1007/978-3-319-28091-2_2.

Bottyán, Z., F. Wantuch, A. Z. Gyöngyösi, Z. Tuba, K. Hadobács, P. Kardos, and R. Kurunczi, 2013: Development of a Complex Meteorological Support System for UAVs. World Academy of Science, Engineering and Technology International Journal of Geological and Environmental Engineering Vol:7, No:4.Bott, A., U. Sievers, and W. Zdunkowski, 1990: A Radiation Fog Model with a Detailed Treatment of the Interaction between Radiative Transfer and Fog Microphysics. J. Atmos. Sci., 47, 2153-2166.

Bravin, M., Strapp, J. W., and Mason, J., 2015: An investigation into location and convective lifecycle trends in an ice crystal icing engine database, Tech. rep., SAE Technical 
Paper 2015- 01-2130, SAE International, Warrendale, Pennsylvania, USA, doi:10.4271/2015-01-2130.

Bright, D. R., S. A. Lack, and J. A. Sparks, 2016: A Summary of Turbulence Forecasting Techniques Used by the National Weather Service. In: Aviation Turbulence: Processes, Detection, Prediction, R. Sharman and T. Lane, Eds., Springer, 213-226.

Brooks, G. R., and A. Oder, 2004: Low level turbulence algorithm testing at-or-below 10,000 ft. Preprints, 11th Conf. on Aviation, Range, and Aerospace Meteorology, Hyannis, MA, Amer. Meteor.Soc., P4.16. [Available online at http://ams.confex.com/ams/pdfpapers/82122.pdf.].

Brown, R., 1973: New indices to locate clear-air turbulence. Meteor. Mag., 102, 347-361.

Brown, B.G., G. Thompson, R.T. Bruintjes, R. Bullock, and T. Kane, 1997: Intercomparison of In-Flight Icing Algorithms. Part II: Statistical Verification Results. Wea. Forecasting, $12,890-914$.

Browning, K. A., 1980: Local weather forecasting. Proc. Roy. Soc. London, A371, 179-211.

Burrows, W.R., C. Price, and L.J. Wilson, 2005: Warm Season Lightning Probability Prediction for Canada and the Northern United States. Wea. Forecasting, 20, 971-988.

Casadevall, T. J., 1994: The 1989-90 eruption of Redoubt volcano. Alaska: Impacts on aircraft operations. J. Volcanol. Geotherm. Res., 62, 301-316.

Chachere, C. and Z. Pu, 2018: Numerical Simulations of an Inversion Fog Event in the Salt Lake Valley During the MATERHORN-Fog Field Campaign. Pure and Applied Geophysics, DOI: 0.1007/s00024-018-1770-8 
Chachere, C., and Z. Pu , 2016: Connection between cold air pools and mountain valley fog events in Salt Lake City, Pure and App. Geo. , doi:10.1007/s00024-016-1316-x.

Chan, P. W., 2016: LIDAR-based turbulence intensity for aviation applications. In: Aviation Turbulence: Processes, Detection, and Prediction. R. D. Sharman and T. P. Lane, Eds., Springer Publications. Chapter 9, 193-209.

Chan, P. W. 2014. "Performance and Aviation Applications of Minisodars at Hong Kong International Airport.” Meteorological Applications 21: 62-73. doi:10.1002/met.1388.

Chan P. W, and Shao A.M., 2007: Depiction of complex airflow near Hong Kong International Airport using a Doppler LIDAR with a two-dimensional wind retrieval technique, Meteorologische Zeitschrift. 16, 491-504.

Chan, P.W., Shun, C. M., and Wu, K. C., 2006: Operational LIDARLIDAR-based System for Automatic Wind shear Alerting at the Hong Kong International Airport, 12th Conference on Aviation, Range, \& Aerospace Meteorology, American Meteorological Society, Atlanta, GA, USA, 29 January - 2 February 2006.

Chiodi, A.M. and D.E. Harrison, 2010: Characterizing Warm-ENSO Variability in the Equatorial Pacific: An OLR Perspective. J. Climate, 23, 2428-2439, https://doi.org/10.1175/2009JCLI3030.1

Doswell, C.A. III*, 1980: Synoptic-scale Environments Associated with High Plains Severe Thunderstorms. Published in Bulletin of the AMS. 61, 1388-1400.

Chandrasekar, V., R. Keránen, S. Lim, and D. Moisseev, 2013: Recent advances in classification of observations from dual polarization weather radars. Atmos. Res., 119, 97-111. 
Chmielecki, R.M. and A.E. Raftery, 2011: Probabilistic Visibility Forecasting Using Bayesian Model Averaging. Mon. Wea. Rev., 139, 1626-1636.

Cho, J. Y. N., 2015: "Enhanced Signal Processing Algorithms for the ASR-9 Weather Systems Processor", Journal of Atmospheric and Oceanic Technology, 32, 1847-1859.

Chun, H., J. Kim, D. Lee, S. Kim, M. Strahan, B. Pettegrew, P. Gill, P.D. Williams, U. Schumann, J. Tenenbaum, Y. Lee, H. Choi, I. Song, Y. Park, and R.D. Sharman, 2017: Research Collaborations for Better Predictions of Aviation Weather Hazards. Bull. Amer. Meteor. Soc., 98, ES103-ES107, https://doi.org/10.1175/BAMS-D-17-0010.1

Clark, A. J., W. A. Gallus Jr., M. Xue, and F. Kong, 2009: A comparison of precipitation forecast skill between small convection-permitting and large convectionparameterizing ensembles. Wea. \& Forecasting, 24, 1121-1140.

Cohen, A.E., S.M. Cavallo, M.C. Coniglio, and H.E. Brooks, 2017: Evaluation of Multiple Planetary Boundary Layer Parameterization Schemes in Southeastern U.S. Cold Season Severe Weather Environments. Published in Wea. \& Forecasting, 32, 18571884.

Cohn, S. A., 1995: Radar measurements of turbulent eddy dissipation rate in the troposphere: A comparison of techniques. J. Atmos. Oceanic Technol., 12, 85-95.

Colson, D., and H. A. Panofsky, 1965: An index of clear-air turbulence. Quart. J. Roy. Meteor. Soc., 91, 507-513.

Cook, L., B. Wood, A. Klein, R. Lee, and B. Memarzadeh, 2009: "Analyzing the Share of Individual Weather Factors Affecting NAS Performance Using the Weather Impacted 
Traffic Index, AIAA 2009-7017. 9th AIAA Aviation Technology, Integration, and Operations Conference (ATIO), Hilton Head, SC, September 2009. Doi: 10.2514/6.2009-7017.

Cornman, L. B., 2016: Airborne in situ measurements of turbulence. In: Aviation Turbulence: Processes, Detection, Prediction, R. Sharman and T. Lane, Eds., Springer, 97-120.

Cornman, L. B., C. S. Morse, and J. Cunning, 1995: Real time estimation of atmospheric turbulence severity from in-situ aircraft measurements. J. Aircraft, 32,171-177.

Dehghan, A., W. K. Hocking, and R. Srinivasan, 2014: Comparisons between multiple in-situ aircraft measurements and radar in the troposphere. J. Atmos. Sol.-Terr. Phys., 118, 64-77.

Del Genio, A. D., M.-S. Yao, and J. Jonas, 2007: Will moist convection be stronger in a warmer environment? Geophys. Res. Lett., 34, L16703, doi:10.1029/2007GL030525.

Deng, M., G. G. Mace, Z. Wang, and H. Okamoto, 2010: Tropical composition, cloud and climate coupling experiment validation for cirrus cloud profiling retrieval using CloudSat radar and CALIPSO lidar. J. Geophys. Res., 115, D00J15,doi:10.1029/2009JD013104.

DeWekker, S. F. J., K. S.Godwin,G.D.Emmitt, and S.Greco, 2012: Airborne Doppler lidar measurements of valley flows in complex coastal terrain. J. Appl. Meteor. Climatol., $51,1558-1574$.

Dines W.H., 1917: Meteorology and aviation. Mon. Wea. Rev., 45, 401-401, https://doi.org/10.1175/1520-0493(1917)45<401b:MAA>2.0.CO;2 
Donovan, M. F., E. R. Williams, C. Kessinger, G.Blackburn, P. H. Herzegh, R. L. Bankert, S. Miller, and F. R. Mosher, 2008: The identification and verification of hazardous convective cells over oceans using visible and infrared satellite observations. J. Appl. Meteor. Climatol.,47, 164-184.

Done, J., C. A. Davis, and M. L. Weisman, 2004: The next generation of NWP: Explicit forecasts of convection using the Weather Research and Forecasting (WRF) model. Atmos. Sci. Lett., 5, 110-117.

Dorman, C. E., J.F. Mejia, D. Korocin, and D..J..McEvoy, 2017: Worldwide Marine Fog Occurrence and Climatology. A chapter in the book of Marine Fog: Challenges and Advancements in Observations, Modeling, and Forecasting. DOI:10.1007/978-3-31945229-6_2.

Doswell, C. A., III, 1986: Short-range forecasting. Mesoscale Meteorology and Forecasting, P. Ray, Ed., Amer. Meteor. Soc., 689-719.

Dutton, J. A., and H. A. Panofsky, 1970: Clear air turbulence: A mystery may be unfolding. Science, 167, 937-944.

Eichinger, W.E., D.I. Cooper, P.R. Forman, J. Griegos, M.A. Osborn, D. Richter, L.L. Tellier, and R. Thornton, 1999: The Development of a Scanning Raman Water Vapor Lidar for Boundary Layer and Tropospheric Observations. J. Atmos. Oceanic Technol., 16, $1753-1766$.

Eick D., 2014: Turbulence related accidents and incidents. Presentation atNCAR Turbulence Impact Mitigation Workshop 2, 3-4 Sep 2014. Available online at: 
https://ral.ucar.edu/sites/default/files/public/events/2014/turbulence-impact-mitigationworkshop-2/docs/eick-turbulencerelatedaccidents.pdf

Ellrod, G.P. and J.A. Knox, 2010: Improvements to an Operational Clear-Air Turbulence Diagnostic Index by Addition of a Divergence Trend Term. Wea. Forecasting, 25, 789-798.

Ellrod, G. P., and I. Gultepe, 2007: Inferring low cloud base heights at night for aviation using satellite infrared and surface temperature data. J. of Pure and Appl. Geophy. Vol. 164, 1193-1205.

Ellrod, G.P., P. F. Lester, and J. Ehernberger, 2002: Clear air turbulence. Encyclopedia of the Atmospheric Sciences, J. R. Holton et al., Eds., Academic Press, 393-403.

Ellrod, G. P, B. H. Connell, and D. W. Hillger, 2003: Improved detection of airborne volcanic ash using multispectral infrared satellite data. /. Geophys. Res., 108, 4356, doi:10.1029/2002JD002802.

Ellrod, G.P., and D. I. Knapp, 1992: An objective clear-air turbulence forecasting technique: Verification and operational use. Wea. Forecasting, 7, 150-165.

Ellrod, G. P., 1985: Detection of high level turbulence using satellite imagery and upper air data. NOAA Tech. Memo. NESDIS 10, 30 pp.

Elmore, K. L., and M. B. Richman, 2001: Euclidean distance as a similarity metric for principal component analysis. Mon. Wea. Rev., 129, 540-549.Endlich, R. M., 1964: The mesoscale structure of some regions of clear-air turbulence. J. Appl. Meteor., 3, 261276. 
FAA, 1988: Advisory Circular on Pilot wind shear guide. AFS-200. AC No: 00-54, 56 pp.

FAA-P-8740-40, 2008: Wind Shear. HQ 101130. 8 pp.

Fahey, T., E. Wilson, R. O’Loughlin, M. Thomas, S. Klipfel, 2016: A History of Weather Reporting from Aircraft and Turbulence Forecasting for Commercial Aviation. In: Aviation Turbulence: Processes, Detection, Prediction, R. Sharman and T. Lane, Eds., Springer, 31-58.

Feingold, G., W.R. Cotton, S.M. Kreidenweis, and J.T. Davis, 1999: The Impact of Giant Cloud Condensation Nuclei on Drizzle Formation in Stratocumulus: Implications for Cloud Radiative Properties. J. Atmos. Sci., 56, 4100-4117,

Ferrare, R.A., S.H. Melfi, D.N. Whiteman, K.D. Evans, F.J. Schmidlin, and D.O. Starr, 1995: A Comparison of Water Vapor Measurements Made by Raman Lidar and Radiosondes. J. Atmos. Oceanic Technol., 12, 1177-1195.

Ferrero, E., L. Mortarini, M. Manfrin, M. Solari, and R. Forza (2014), Physical simulation of atmospheric microbursts, J. Geophys. Res. Atmos., 119, 6292-6305, doi:10.1002/2013JD021243.

Ferrier, B. S., W.K. Tao, and J. Simpson, 1995: A Double-Moment Multiple-Phase Four-Class Bulk Ice Scheme. Part II: Simulations of Convective Storms in Different Large-Scale Environments and Comparisons with other Bulk Parameterizations. J. of Atmos. Sci., 52, 1001-1033.

Ferrier, B. S., 1994: A double-moment multiple-phase four-class bulk ice scheme. Part I: Description. J. Atmos. Sci., 51, 249-280. 
Fischer, A.S., P. Terray, E. Guilyardi, S. Gualdi, and P. Delecluse, 2005: Two Independent Triggers for the Indian Ocean Dipole/Zonal Mode in a Coupled GCM. J. Climate, 18, $3428-3449$.

Fischer C, Montmerle T, Berre L, Auger L, Stefanescu S. 2005. Anover view of the variational assimilation in the ALADIN/France numerical weather-prediction system wave-driven circulation of the mesosphere.Q. J. R. Meteorol. Soc. 131: 3477-3492.

Fix, A., 2012: Tunable light sources for lidar applications. Atmospheric Physics - Background, Methods, Trends, Prediction, U. Schumann, Ed., Springer, 509-527.

Fournier, G., 2006: Development of the Canadian aircraft meteorological data relay (AMDAR) program and plans for the future.10th Symposium on Integrated Observing and Assimilation Systems for the Atmosphere, Oceans, and Land Surface, Atlanta, GA, Amer. Meteor. Soc. Annual Meeting. Available at https://ams.confex.com/ams/pdfpapers.

França, G.B., Almeida, M. V, Bonnet, S. M.and Albuquerque Neto, F. L. 2018. Nowcasting model of low wind profile based on neural network using SODAR data at Guarulhos Airport, Brazil. International Journal of Remote Sensing, 39:8, 2506-

2517, DOI: 10.1080/01431161.2018.1425562

Frehlich, R. G., and R. Sharman, 2010: Climatology of velocity and temperature turbulence statistics determined from rawinsonde and ACARS/AMDAR data. J. Appl. Meteor. Climatol., 49, 1149-1169, doi:10.1175/2010JAMC2196.1. 
Fuertes, F.C., G.V. Iungo, and F. Porté-Agel, 2014: 3D Turbulence Measurements Using Three Synchronous Wind Lidars: Validation against Sonic Anemometry. J. Atmos. Oceanic Technol., 31, 1549-1556.

Gerz, T., F. Holzäpfel, W. Gerling, A. Scharnweber, M. Frech, A. Wiegele, K.Kober, K. Dengler , and S. Rahm. 2009. "The Wake Vortex Prediction and Monitoring System WSVBS Part II: Performance and ATC Integration at Frankfurt Airport.” Air Traffic Control Quarterly 17 (4): 323-346. doi:10.2514/atcq.17.4.323.

Ghirardelli, J.E. and B. Glahn, 2010: The Meteorological Development Laboratory's Aviation Weather Prediction System. Wea. Forecasting, 25, 1027-1051.

Gill, P. G., 2012: Objective verification of World Area Forecast Centre clear air turbulence forecasts. Meteor. Appl., 21, 3-11, doi:10.1002/met.1288.

Gill, and P. Buchanan, 2014: An ensemble based turbulence forecasting system. Meteor. Appl., 21, 12-19, doi:10.1002/met.1373.

Gillette, D., 1978: A wind tunnel simulation of the erosion of soil: Effects of soil texture, sandblasting, wind speed, and soil consolidation on the dust production. Atmos. Environ., 12, 1735-1743.

Glahn, H. R., and D. A. Lowry, 1972: The use of model output statistics (MOS) in objective weather forecasting. J. Appl. Meteor., 11, 1203-1211.

Glahn, B., A.D. Schnapp, J.E. Ghirardelli, and J. Im, 2017: A LAMP-HRRR MELD for Improved Aviation Guidance. Wea. Forecasting, 32, 391-405.

Glickman, T. S., Ed., 2000: Glossary of Meteorology. 2d ed. Amer. Meteor. Soc., 855 pp. 
Golding B.W., 1998. Nimrod: a system for generating automated very short range forecasts. Meteorol. Appl. 5: 1-16.

Goodman, S. J.,, R. J. Blakeslee, W. J. Koshak, and D. Mach,2011: The GOES-R Series Geostationary Lightning Mapper (GLM). [Available online at ams.confex.com/ams/.

Goodman, S.J., J. Gurka, M. DeMaria, T.J. Schmit, A. Mostek, G. Jedlovec, C. Siewert, W. Feltz, J. Gerth, R. Brummer, S. Miller, B. Reed, and R.R. Reynolds, 2012: The GOESR Proving Ground: Accelerating User Readiness for the Next-Generation Geostationary Environmental Satellite System. Bull. Amer. Meteor. Soc., 93, 10291040 ,

Goodman, S.J., J. Gurka, M. DeMaria, T.J. Schmit, A. Mostek, G. Jedlovec, C. Siewert, W. Feltz, J. Gerth, R. Brummer, S. Miller, B. Reed, and R.R. Reynolds, 2012: The GOESR Proving Ground: Accelerating User Readiness for the Next-Generation Geostationary Environmental Satellite System. Bull. Amer. Meteor. Soc., 93, 10291040.

Goodman, C., and J. Griswold, 2017: Climate Impacts on Density Altitude and Aviation Operations. J. Appl. Meteor. Clim. doi:10.1175/JAMC-D-17-0126.1, in press.

Gossard, E.E., J.B. Snider, E.E. Clothiaux, B. Martner, J.S. Gibson, R.A. Kropfli, and A.S. Frisch, 1997: The Potential of 8-mm Radars for Remotely Sensing Cloud Drop Size Distributions. J. Atmos. Oceanic Technol., 14, 76-87, 
Guedalia, D. and T. Bergot, 1994: Numerical Forecasting of Radiation Fog. Part II: A Comparison of Model Simulation with Several Observed Fog Events. Mon. Wea. Rev., 122, 1231-1246

Guttman, N.B. and R.K. Jeck, 1987: Aircraft Icing Environment in Low Ceiling Conditions near Washington, D.C.. Wea. Forecasting, 2, 114-126,

Gultepe, I., Agelin-Chaab, M., Komar, J., G. Elfstrom, F. Boudala, B. Zhou, 2018: A Meteorological Supersite for Aviation and Cold Weather Applications. Pure Appl. Geophys. https://doi.org/10.1007/s00024-018-1880-3

Gultepe, I., A.J. Heymsfield, M. Gallagher, L. Ickes, and D. Baumgardner, 2017a: Ice Fog: The Current State of Knowledge and Future Challenges. Meteorological Monographs, 58, 4.1-4.24. https://doi.org/10.1175/AMSMONOGRAPHS-D-17-0002.1

Gultepe, I., A.J. Heymsfield, P.R. Field, and D. Axisa, 2017b: Ice-Phase Precipitation. Meteorological Monographs, 58, 6.1-6.36, https://doi.org/10.1175/AMSMONOGRAPHS-D-16-0013.1

Gultepe, I., and A. J. Heymsfield, 2016: Ice Fog, Ice Clouds, and Remote Sensing; Introduction. Pure and Appl. Geophy., 173, N.9. DOI: 10.1007/s00024-016-1380-2. 2977-2982.

Gultepe, I., T. Kuhn, M. Pavolonis, C. Calvert, J. Gurka, G.A. Isaac, A. J. Heymsfield, P.S.K. Liu, B. Zhou, R. Ware, B. Ferrier, J. Milbrandt, B. Hansen, and B. Bernstein, 2014: Ice fog in Arctic during FRAM-IF project: Aviation and nowcasting applications. Bulletin of Amer. Met. Soc., 95, 211-226. 
Gultepe, I., B. Zhou, J. Milbrandt, A. Bott, Y. Li, A. J. Heymsfield, B. Ferrier, R. Ware, M. Pavolonis, T. Kuhn, J. Gurka, P. Liu, and J. Cermak, 2015: A review on Ice Fog Measurements and Modeling. Atmospheric Research. 151, 2-19.

Gultepe, I., G. A. Isaac, P. Joe, P. Kucera, J. Thériault, and T. Fisico, 2014: Roundhouse (RND) Mountain Top Research Site: Measurements and Uncertainties for Winter Alpine Weather Conditions. J. of Pure and Applied Geophysics. DOI: 10.1007/s00024-0120582-5, 171, 59-85.

Gultepe, I., M. Pawgoski, and J. Reid. 2007: Using surface data to validate a satellite based fog detection scheme. J. of Weather and Forecasting, 22, 444-456.

Gultepe, I., R. Tardif, S.C. Michaelides, J. Cermak, A. Bott, J. Bendix, M. Müller, M. Pagowski, B. Hansen, G. Ellrod, W. Jacobs, G. Toth, S.G. Cober, 2007a: Fog research: a review of past achievements and future perspectives. J. of Pure and Applied Geophy., Special issue on fog, edited by I. Gultepe. Vol. 164, 1121-1159.

Gultepe, I., M. D. Müller, and Z. Boybeyi, 2006: A new warm fog parameterization scheme for numerical weather prediction models. J. Appl. Meteor., 45, 1469-1480.

Gultepe, I., H.J.S. Fernando, E.R. Pardyjak, S.W. Hoch, Z. Silver, E. Creegan, L. S. Leo, Z. Pu, S.F.J. De Wekker, and C. Hang, 2016: An Overview of the MATERHORN Fog Project: Observations and Predictability. Pure and Applied Geophysics. 173, N.9. DOI: 10.1007/s00024-016-1374-0. 2983-3010.

Gultepe, I., 2015: Mountain Weather: Observations and Modeling. Advances in Geophysics. June Issue. Vol. 56. 229-312 pp. 
Gultepe, I., and G. A. Isaac, 2004: An analysis of cloud droplet number concentration (Nd) for climate studies: Emphasis on constant Nd. Q. J. Royal Met. Soc., 130, Part A, No. 602, 2377-2390.

Gultepe, I., Starr, D. O'C., Heymsfield, A. J., Uttal, T., Ackerman, T. P., and Westphal, D. L., 1995: Dynamical characteristics of cirrus clouds from aircraft and radar observations in micro and meso-gamma scales. J. Atmos. Sci., 52, 4060-4078.

Gultepe, I., and Starr, D. O'C., 1995: Dynamical structure and turbulence in cirrus clouds: Aircraft observations during FIRE. J. Atmos. Sci., 52, 4659-4182.

Gultepe, I., G. Pearson J. A. Milbrandt, B. Hansen, S. Platnick, P. Taylor, M. Gordon, J. P. Oakley, and S.G. Cober, 2009: The fog remote sensing and modeling (FRAM) field project. Bull. Of Amer. Meteor. Soc., v.90, 341-359.

Hadley, D., G.L. Hufford, and J.J. Simpson, 2004: Resuspension of Relic Volcanic Ash and Dust from Katmai: Still an Aviation Hazard. Wea. Forecasting, 19, 829-840,

Haggerty, J., E. Defer, A. de Laat, K. Bedka, J.-M. Moisselin, R. Potts, J. Delanoë, F. Parol, A. Grandin, and S. DiVit. 2018: Detecting Clouds Associated with Jet Engine Ice Crystal Icing. Bull. Amer. Meteor. Soc., Accepted.

Haiden, T., A. Kann, C. Wittmann, G. Pistotnik, B. Bica, and C. Gruber, 2011: The Integrated Nowcasting through Comprehensive Analysis (INCA) System and Its Validation over the Eastern Alpine Region. Wea. Forecasting, 26, 166-183.

Haiden, T., A. Kann, and G. Pistotnik, 2014: Nowcasting with INCA During SNOW-V10. Pure and Appl. Geophy. 171-1, 171-2, DOI. 10.1007/s00024-012-0547-8 
Hamazu, K., H. Hashiguchi, T. Wakayama, T. Matsuda, R.J. Doviak, and S. Fukao, 2003: A 35GHz Scanning Doppler Radar for Fog Observations. J. Atmos. Oceanic Technol., 20, 972-986.

Han, Y., J. B. Snider, E. R. Westwater, S. H. Melfi, and R. A. Ferrare, 1994: Observations of water vapor by ground-based microwave radiometers and Raman lidar. J. Geoph. Res., 99, D9, 18695-18702.

Hansen, B., Ismail Gultepe and Alister Ling, 2009: Update on WIND-3: An analog forecasting system for ceiling and visibility. Joint session of the Sixth Conference on Artificial Intelligence Applications to Environmental Science and the 13th Conference on Aviation, Range and Aerospace Meteorology; 88th Annual Meeting of the American Meteorological Society, New Orleans, LA, 20-24 January 2008. Oral presentation.

Hansen, B., 2007: A Fuzzy Logic-Based Analog Forecasting System for Ceiling and Visibility. Wea. Forecasting, 22, 1319-1330.Harrington, J. Y., K. Sulia, and H. Morrison, 2013a: A method for adaptive habit prediction in bulk microphysical models. Part I: Theoretical development. J. Atmos. Sci., 70, 349-364.

Harrington, J. Y., K. Sulia, and H. Morrison, 2013b: A method for adaptive habit prediction in bulk microphysical models. Part II: Parcel model corroboration. J. Atmos. Sci., 70, 365-376, doi:10.1175/JAS-D-12-0152.1.

Hart, K.A., W.J. Steenburgh, D.J. Onton, and A.J. Siffert, 2004: An Evaluation of MesoscaleModel-Based Model Output Statistics (MOS) during the 2002 Olympic and Paralympic Winter Games. Wea. Forecasting, 19, 200-218. 
Haupt, S. E., and L. Delle Monache, 2014: Understanding ensemble prediction: How probabilistic wind power prediction can help in optimizing operations. WindTech International. Available at www.windtech-international.com/editorialfeatures/understanding-ensemble-prediction.

Heidinger, A. K., 2010: ABI cloud mask algorithm theoretical basis document. NOAA/NESDIS Center for Satellite Applications and Research, 67 pp.

Harrington, J.Y., K. Sulia, and H. Morrison, 2013: A Method for Adaptive Habit Prediction in Bulk Microphysical Models. Part I: Theoretical Development. J. of Atmos. Sci., 70, 349-364.

Herman, L., 1993: High frequency satellite cloud motion at high latitudes. Preprints, Eighth Symp. on Meteorological Observations and Instrumentation, Anaheim, CA, Amer. Meteor. Soc., 465-468.

Herzegh, P.H., E.R. Williams, T.A. Lindholm, F.R. Mosher, C. Kessinger, R. Sharman, J.D. Hawkins, and D.B. Johnson, 2002: Development of automated aviation weather products for oceanic/remote regions: Scientific and practical challenges, research strategies and first steps, Preprints, 10th Aviation, Range and Aerospace Meteorology Conference, AMS, Portland, OR, 13-16 May 2002.

Herzegh, P., G. Wiener, R. Bateman, J. Cowie, and J. Black, 2015: Data Fusion Enables Better Recognition of Ceiling and Visibility Hazards in Aviation. Bull. Amer. Meteor. Soc., $96,526-532$. 
Heymsfield, A.J., G. Thompson, H. Morrison, A. Bansemer, RM Rasmussen, P. Minnis, Z. Wang, and D. Zhang, 2011: Formation and spread of aircraft-induced holes in clouds. Science, AAAS, 333, 77-81.

Heymsfield, A.J., and R. M. Sabin, 1989: Cirrus crystal nucleation by homogeneous freezing of solution drops. J. Atmos. Sci., 46, 2252-2264.

Heymsfield, A.J., and R. M. Sabin, 1993: Homogeneous ice nucleation and supercooled liquid water in orographic wave clouds. J. Atmos. Sci., 50, 2335-2353.

Heymsfield, A., D. Baumgardner, P. DeMott, P. Forster, K. Gierens, and B. Kärcher, 2010: Contrail Microphysics. Bull. Amer. Meteor. Soc., 91, 465-472

Heymsfield, A., J., C. Schmitt, A. Bansemer, C. Twohy, M. Poellot, A. Fridland, and H. Gerber, 2005: Homogeneous ice nucleation in subtropical and tropical convection and its influence on cirrus anvil microphysics. J. Atmos. Sci., 62, 41-64.

Hill M., Calhoun R, Fernando H, Wieser A, Dörnbrack A, Weissmann M, Mayr G., and Newsom, R. 2010. Coplanar Doppler lidar retrieval of rotors from T-REX. Journal of Atmospheric Science, 67(3): 713-729.

Hocking, A., and Hocking, W. K., 2018: Tornado identification and forewarning with very high frequency windprofiler radars. Atmos. Sci. Lett., 19:e795. Doi: 10.1002/asl.795

Hodges, D., and Z. Pu, 2015: The climatology, frequency, and distribution of cold season fog events in northern Utah. Pure and Applied Geophysics, doi:10.1007/s00024-0151187-6. 
Hubbert, J. C., 2017: Differential reflectivity calibration and antenna temperature. J. Atmos. Oceanic Technol., 34, 1885-1906.

Hubbert, J.C., J.W. Wilson, T.M. Weckwerth, S.M. Ellis, M. Dixon, and E. Loew, 2018: S-Pol's Polarimetric Data Reveal Detailed Storm Features (and Insect Behavior). Bull. Amer. Meteor. Soc., 99, 2045-2060.

Hutchison, K.D., B.D. Iisager, T.J. Kopp, and J.M. Jackson, 2008: Distinguishing Aerosols from Clouds in Global, Multispectral Satellite Data with Automated Cloud Classification Algorithms. J. Atmos. Oceanic Technol., 25, 501-518,

Hufford, G. L., L. S. Salinas, J. J. Simpson, E. G. Barske, and D.Pieri, 2000: Operational implications of airborne volcanic ash. Bull. Amer. Meteor. Soc., 81, 745-755.

ICAO, 2005: Manual On Low-Level Wind Shear And Turbulence First Edition - 2005. Doc 9817, AN/449. . Publisher: International Civil Aviation Organization (ICAO). DOC09817-001-01-E-P. 213 pp.

Illingworth, A.J., H.W. Barker, A. Beljaars, M. Ceccaldi, H. Chepfer, N. Clerbaux, J. Cole, J. Delanoë, C. Domenech, D.P. Donovan, S. Fukuda, M. Hirakata, R.J. Hogan, A. Huenerbein, P. Kollias, T. Kubota, T. Nakajima, T.Y. Nakajima, T. Nishizawa, Y. Ohno, H. Okamoto, R. Oki, K. Sato, M. Satoh, M.W. Shephard, A. VelázquezBlázquez, U. Wandinger, T. Wehr, and G. van Zadelhoff, 2015: The EarthCARE Satellite: The Next Step Forward in Global Measurements of Clouds, Aerosols, Precipitation, and Radiation. Bull. Amer. Meteor. Soc., 96, 1311-1332. 
Irvine, E. A., Keith P. Shine, and Marc A. Stringer, 2016: What are the implications of climate change for trans-Atlantic aircraft routing and flight time? Transportation Research, Part D 47, 44-53.

Isaac, G.A., J.K. Ayers, M. Bailey, L. Bissonnette, B.C. Bernstein, S.G. Cober, N. Driedger, W.F.J. Evans, F. Fabry, A. Glazer, I. Gultepe, J. Hallett, D. Hudak, A.V. Korolev, D. Marcotte, P. Minnis, J. Murray, L. Nguyen, T.P. Ratvasky, A. Reehorst, J. Reid, P. Rodriguez, T. Schneider, B.E. Sheppard, J.W. Strapp, and M. Wolde, 2005: 43rd AIAA Aerospace Sciences Meeting and Exhibit 10 - 13 January 2005, Reno, Nevada, AIAA 2005-252 $18 \mathrm{pp}$.

Isaac, G.A., Monika Bailey, Faisal Boudala, William Burrows, Stewart G. Cober, Robert Crawford, Norman Donaldson, Ismail Gultepe, Bjarne Hansen, Ivan Heckman, Laura Huang, Alister Ling, Janti Reid, and Marc Fournier, 2014: The Canadian Airport Nowcasting System (CAN-Now), QJRM Meteorological Applications, 21, 30-49.

Isaac, G.A. and R.S. Schemenauer, 1979: Large Particles in Supercooled Regions of Northern Canadian Cumulus Clouds. J. Appl. Meteor., 18, 1056-1065.

Ismail, S. and E.V. Browell, 1994: Recent Lidar Technology Developments and Their Influence on Measurements of Tropospheric Water Vapor. J. Atmos. Oceanic Technol., 11, 7684

Jacobs, A.J. and N. Maat, 2005: Numerical Guidance Methods for Decision Support in Aviation Meteorological Forecasting. Wea. Forecasting, 20, 82-100. 
Jonassen, M.O., H. Ólafsson, H. Ágústsson, Ó. Rögnvaldsson, and J. Reuder, 2012: Improving High-Resolution Numerical Weather Simulations by Assimilating Data from an Unmanned Aerial System. Mon. Wea. Rev., 140, 3734-3756.

Jones, R.H., 1965: Optimal Estimation of Initial Conditions for Numerical Prediction. J. Atmos. Sci., 22, 658-663,

Jones, T. A., K. Knopfmeier, D. Wheatley, G. Creager, P. Minnis, and R. Palikonda, 2016: Storm-scale data assimilation and ensemble forecasting with the NSSL Experimental Warn-on Forecast. Part 2: Combined radar and satellite data experiments. Wea. Forecasting, 31, 297-327, doi:10.1175/WAF-D-15-0107.1.

Kain, J. S., and Coauthors, 2010: Assessing advances in the assimilation of radar data within a collaborative forecasting-research environment. Wea. Forecasting, 25, 1510-1521.

Kalnay, E., et al. (1996), The NCEP/NCAR 40-year reanalysis project, Bull. Am. Meteorol. Soc., $77,437-471$.

Kalnay, E., 2003: Atmospheric Modeling, Data Assimilation and Predictability. Cambridge University Press, 341 pp.

Kann, A., T. Schellander-Gorgas, and C. Wittmann, 2015: Enhanced short-range forecasting of sub-inversion cloudiness in complex terrain. Atmos. Sci. Let., 16, 1-9.

Kaplan,M. L., A.W.Huffman, K.M. Lux, J.D.Cetola, J. J.Charney,A. J. Riordan, Y.-L. Lin, and K. T. Waight III, 2005a: Characterizing the severe turbulence environments associated with commercial aviation accidents. Part 1: A 44-case study synoptic observational analyses. Meteor. Atmos. Phys., 88, 129-152. 
Kaplan,M. L., A.W. Huffman, K.M. Lux, J.D. Cetola, J. J. Charney,A. J. Riordan, Y.-L. Lin, and K. T. Waight III, 2005b: Characterizing the severe turbulence environments associated with commercial aviation accidents. Part 2: Hydrostatic mesoscale numerical simulations of super gradient wind flow and streamwise ageostrophic frontogenesis. Meteor. Atmos. Phys., 88, 153-173.

Kara, A. B., A. J.Wallcraft, and H. E. Hurlburt (2007a), A correction for land contamination of atmospheric variables near land-sea boundaries, J. Phys. Oceanogr., 37, 803- 818.

Kara, A. B., A. J.Wallcraft, C. N. Barron, H. E. Hurlburt, M.A. Bourassa, 2008: Accuracy of 10 m winds from satellites and NWP products near land-sea boundaries. J. Geoph. Res., 113, C10020, doi:10.1029/2007JC004516.

Karstens, C. D., and Coauthors, 2015: Evaluation of a probabilistic forecasting methodology for severe convective weather in the 2014 hazardous weather testbed. Wea. Forecasting, $30,1551-1570$.

Karstens, C.D., J. Correia Jr., D.S. LaDue, J. Wolfe, T.C. Meyer, D.R. Harrison, J.L. Cinteneo, K.M. Calhoun, T.M. Smith, A.E. Gerard, and L.P. Rothfusz, 2018: Development of a Human-Machine Mix for Forecasting Severe Convective Events. Published in Weather and Forecasting, 33, 715-737.

Kelly, D. S., and J. E. Ghirardelli, 1998: A general overview of methodology and applications of the Local AWIPS MOS Program (LAMP), a short-range forecast guidance product. Preprints, 16th Conf. on Weather Analysis and Forecasting, Phoenix, AZ, Amer. Meteor. Soc., 437-439. 
Kelsch, M. and L. Wharton, 1996: Comparing PIREPs with NAWAU Turbulence and Icing Forecasts: Issues and Results. Wea. Forecasting, 11, 385-390.

Kessinger, C. , Paul Herzegh, Gary Blackburn , Robert Sharman , Gerry Wiener, Benjamin Hendrickson, Kay Levesque , Jason Craig , Ted Tsui , Jeffrey Hawkins , Richard Bankert, Earle Williams, Michael Donovan, Gary Ellrod, Robert Kistler, and David Fleming, 2006: The FAA AWRP oceanic weather program development team. Preprints, AMS 12th Conf. on Aviation Range and Aerospace. Poster 3.9/P1.19.

Kessinger, C. et al., 2006: The FAA AWRP Oceanic weather program development team. Preprints-CD, 12th Aviation, Range and Aerospace Meteorology Conference, AMS, Atlanta, GA, 30 Jan. - 2 Feb. 2006.

Key, J. R., D. Santek, C. S. Velden, N. Bormann, J.-N. The'paut, L. P. Riishojgaard, Y. Zhu, and W. P. Menzel, 2003: Cloud drift and water vapor winds in the polar regions from MODIS. IEEE Trans. Geosci. Remote Sens., 41, 482-492.

Khairoutdinov, M., and Y. Kogan, 2000: A new cloud physics parameterization in a large-eddy simulation model of marine stratocumulus. Mon. Wea. Rev., 128, 229-243.

Khairoutdinov, M. and D. Randall, 2006: High-Resolution Simulation of Shallow-to-Deep Convection Transition over Land. J. Atmos. Sci., 63, 3421-3436,

Kilpinen, J., 1994: Computer-aided weather forecasting system set to enter operation in Scandinavia. ICAO J., 49 (8), 17-18.

Kim, J.-H., Chun, H.-Y., R. D. Sharman and T. L. Keller, 2011: Evaluations of upper-level turbulence diagnostics performance using the Graphical Turbulence Guidance (GTG) 
system and pilot reports (PIREPs) over East Asia. J. Appl. Meteor. Climatol., 50, 1936-1951; Corrigendum, 50, 2193.

Kim, S.-H., H.-Y. Chun, and P. W. Chan, 2017: Comparison of turbulence indicators obtained from in situ flight data. J. Appl. Meteor. Climatol., 56, 1609-1623. doi: 10.1175/JAMC-D-16-0291.1.

Kim J. H, W. N. Chan, S. Banavar, and R. D. Sharman, 2015: Combined winds and turbulence prediction system for automated air-traffic management applications. J. Appl. Meteor. Climatol., 54, 766-784, doi:10.1175/JAMC-D-14-0216.1.

Kim J.H., W.N. Chan, B. Sridhar, R. D. Sharman, P. D. Williams, and M. Strahan, 2016: Impact of the North Atlantic Oscillation on transatlantic flight routes and clear-air turbulence. J. Appl. Meteor. Climatol., 55, 763-771, doi:10.1175/JAMC-D-15-0261.1.

Knox, J. A., 1997: Possible mechanisms of clear-air turbulence in strongly anticyclonic flow. Mon. Wea. Rev., 125, 1251-1259.

Knox, J.A., D.W. McCann, and P.D. Williams, 2008: Application of the Lighthill-Ford Theory of Spontaneous Imbalance to Clear-Air Turbulence Forecasting. J. Atmos. Sci., 65, 3292-3304, https://doi.org/10.1175/2008JAS2477.1.

Knox, J. A. and Coauthors, 2016: Automated turbulence forecasting strategies. Aviation Turbulence: Processes, Detection, Prediction, R. Sharman and T. Lane, Eds., Springer, 243-260. 
Knüppfer, K., 1997: Automation of aviation forecasts. The projects AUTOTAF and AUTOGAFOR. Preprints, Seventh Conf. on Aviation, Range, and Aerospace Meteorology, Long Beach, CA, Amer. Meteor. Soc., 444-449.

Kober, K., G. C. Craig, C. Keil, and A. Dörnbrack, 2012: Blending a probabilistic nowcasting method with a high-resolution numerical weather prediction ensemble for convective precipitation forecasts, Q. J. R. Meteorol. Soc. 138: 755-768.

Koch, S. E., and F. Caracena, 2002: Predicting clear-air turbulence from diagnosis of unbalanced flow. Preprints, 10th Conf. on Aviation, Range, and Aerospace Meteorology, Portland, OR, Amer. Meteor. Soc., 10.4. Available at http://ams.confex.com/ams/pdfpapers/39012.pdf.

Kopeć, J. M., Kwiatkowski, K., de Haan, S., and Malinowski, S. P., 2016: Retrieving atmospheric turbulence information from regular commercial aircraft using Mode-S and ADS-B, Atmos. Meas. Tech., 9, 2253-2265, doi:10.5194/amt-9-2253-2016.

Kumjian, M. R., 2012: Freezing of raindrops in deep convective updrafts: A microphysical and polarimetric model. J. Atmos. Sci., 69, 3471-3490.

—, 2013a: Principles and applications of dual-polarization weather radar. Part I: Description of the polarimetric radar variables. J. Oper. Meteor., 1, 226-242.

_, 2013b: Principles and applications of dual-polarization weather radar. Part II: Warm- and cold-season applications. J. Oper. Meteor., 1, 243-264. 
Kücken, M., D. Hauffe, and H. Österle, 2012: A High-Resolution Simulation of the Year 2003 for Germany Using the Regional Model COSMO. J. Appl. Meteor. Climatol., 51, 1889-1903,

Lakshmanan, V., and T. Smith, 2009: Data mining storm attributes from spatial grids. J. Atmos. Oceanic Technol., 26, 2353-2365.

Landolt, S., M. Politovich, R. Rasmussen, and A. Gaydos, 2010: A Comparison of an Automated Freezing Drizzle Algorithm to Human Observations. AMS Annual Meeting, Atlanta, Georgia, on 16-21 Jan 2010., 14th Conference on Aviation, Range, and Aerospace Meteorology 4 pp.Langland, R. H., and Coauthors, 1999: The North Pacific Experiment (NORPEX-98): Targeted observations for improved North American weather forecasts. Bull. Amer. Meteor. Soc., 80, 1363-1384.

Langmuir, I., VJ Schaefer, B. Vonnegut, K. Maynard, R. Smith-Johannsen, D. Blanchard, and R.E. Falconer, 1948: Final reports, Project Cirrus, RL140. General Electric Res. Lab. Req 21190 with the Depart. Of the Army Project: 3-99-07-022, 119 pp.

Lawrence, D. A., and B. B. Balsley, 2013: High-resolution atmospheric sensing of multiple atmospheric variables using the DataHawk small airborne measurement system. J. Atmos. Oceanic Technol., 30, 2352-2366. doi: 10.1175/JTECH-D-12-00089.1

Lawson, R. P., Angus, L. J., and Heymsfield, A. J. 1998: Cloud 5 particle measurements in thunderstorm anvils and possible weather threat to aviation, J. Aircraft, 35, 113-121. 
Lee, D. R., R. S. Stull, and W. S. Irvine, 1984: Clear air turbulence forecasting techniques. Air Weather Service Tech. Note AFGWC/TN-79/001 (REV), Air Force Global Weather Central, Offutt AFB, NE, 16 pp.

Leroy, D., E. Fontaine, A. Schwarzenboeck, and J.W. Strapp, 2016: Ice Crystal Sizes in High Ice Water Content Clouds. Part I: On the Computation of Median Mass Diameter from In Situ Measurements. J. Atmos. Oceanic Technol., 33, 2461-2476.

Leroy, D., E. Fontaine, A. Schwarzenboeck, J.W. Strapp, A. Korolev, G. McFarquhar, R. Dupuy, C. Gourbeyre, L. Lilie, A. Protat, J. Delanoe, F. Dezitter, and A. Grandin, 2017: Ice Crystal Sizes in High Ice Water Content Clouds. Part II: Statistics of Mass Diameter Percentiles in Tropical Convection Observed during the HAIC/HIWC Project. J. Atmos. Oceanic Technol., 34, 117-136.

Lewis, W. 1947. A flight investigation of the meteorological conditions conducive to the formation of ice on airplanes. NACA TN 1393.

Lin, C-Y, Z. Zhang, Z. Pu , F. Wang, 2017: Numerical Simulations of an Advection Fog Event over the Shanghai Pudong Airport with the WRF Model. Journal of Meteorological Research, 31, 874-889.

Lin, Y.L., R. D. Farley, and H. D. Orville, 1983: Bulk Parameterization of the Snow Field in a Cloud Model. J. Of Clim.and Appl. Meteor., 22, 1065-1092.

Linden, P. F., and J. E. Simpson (1985): Microbursts: a hazard to aviation. Nature 317 (17), 601-602. 
Liu, Y., Xia, J., Shi, C. X., and Hong, Y., 2009: An improved cloud classification algorithm for China's FY-2C multi-channel images using artificial neural network, Sensor, 9, pp. $5558-5579$.

Liu, YQ, YM Wang, L.LI, S. Han, and D. Infield, 2016: NWP wind correction methods and its impact on CFD based wind power forecasting. Journal of Renewable and Sustainable Energy 8, 033302 (20168, 033302 (2016); https://doi.org/10.1063/1.4950972Luce, H., T. Nakamura, M.K. Yamamoto, M. Yamamoto, and S. Fukao, 2010: MU Radar and Lidar Observations of Clear-Air Turbulence underneath Cirrus. Mon. Wea. Rev., 138, $438-452$.

Löffler-Mang, M., M. Kunz, and W. Schmid, 1999: On the Performance of a Low-Cost K-Band Doppler Radar for Quantitative Rain Measurements. J. Atmos. Oceanic Technol., 16, 379-387.Ludlam, F.H., 1956: Fall-streak holes, Weather, 11, 89-90.

Lynn, K. J., 1997: International survey of TAF automation systems. Forecasting systems 9, Met Office Internal Rep., 20 pp.

Mancuso, R. L., and R. M. Endlich, 1966: Clear air turbulence frequency as a function of wind shear and deformation. Mon.Wea. Rev., 94, 581-585.

Mandel, E., 1975: An Early Look at the Development of an Unmanned Automated Surface Aviation Weather Observation System. Bull. Amer. Meteor. Soc., 56, 979-982.

Markowicz, K.M. and M.L. Witek, 2011: Simulations of Contrail Optical Properties and Radiative Forcing for Various Crystal Shapes. J. Appl. Meteor. Climatol., 50, 17401755. 
Marroquin, A., 1998: An advanced algorithm to diagnose atmospheric turbulence using numerical model output. Preprints, 16th Conf. on Weather Analysis and Forecasting, Phoenix, AZ,Amer. Meteor. Soc., 79-81.

Mason, J. G., Strapp, J. W., and Chow, P. 2006: The ice particle threat to engines in flight, in: 44th AIAA Aerospace Sciences Meeting, Reno, Nevada, abstract number AIAA 2006206, 9-12 January.

Matrosov, S.Y., 2005: Attenuation-Based Estimates of Rainfall Rates Aloft with Vertically Pointing $\mathrm{K}_{\mathrm{a}}$-Band Radars. J. Atmos. Oceanic Technol., 22, 43-54,

Matthes, S., U. Schumann, V. Grewe, C. Frömming, K. Dahlmann, A. Koch, and H. Mannstein, 2012: Climate optimized air transport. In Atmospheric Physics - Background, Methods, Trends, Prediction, U. Schumann, Ed., Springer, 727-746.

McCann, D. W., 2001: Gravity waves, unbalanced flow, and clear air turbulence. Natl. Wea. Dig., 25, 3-14.

McCann, D. W., J. A. Know, and P. D. Williams, 2012: An improvement in clear-air turbulence forecasting based on spontaneous imbalance theory: the ULTURB algorithm. Meteorol. Appl. 19: 71-78.

McCarthy, J., and Serafin, R. J., 1984: The microburst hazard to aircraft. Weatherwise, 37, 120127.

McCarthy, J., J. W. Wilson, and T. T. Fujita, 1982: The Joint Airport Weather Studies (JAWS) Project. Bull. Amer. Meteor. Soc., 63, 15-22. 
McCarty, J., R.M. Banta, J.B. Olson, J.R. Carley, M.C. Marquis, W.A. Brewer, J.M. Wilczak, I.V. Djalalova, L. Bianco, E.P. James, S.G. Benjamin, and J. Cline, 2017: Assessment of NWP forecast models in simulating offshore winds through the lower boundary layer by measurements from a ship-based scanning Doppler lidar. Mon Wea. Rev., Doi:10.1175/MWR-D-16-0442.1.

McGovern, A., K.L. Elmore, D.J. Gagne, S.E. Haupt, C.D. Karstens, R. Lagerquist, T. Smith, and J.K. Williams, 2017: Using Artificial Intelligence to Improve Real-Time DecisionMaking for High-Impact Weather. Bull. Amer. Meteor. Soc., 98, 2073-2090.

Mead, J.B., R.E. Mcintosh, D. Vandemark, and C.T. Swift, 1989: Remote Sensing of Clouds and Fog with a 1.4-mm Radar. J. Atmos. Oceanic Technol., 6, 1090-1097.

Meckalski, J.R., W.F. Feltz, J.J. Murray, D.B. Johnson, K.M. Bedka, S.T. Bedka, A.J. Wimmers, M. Pavolonis, T.A. Berendes, J. Haggerty, P. Minnis, B. Bernstein, and E. Williams, 2007: Aviation Applications for Satellite-Based Observations of Cloud Properties, Convection Initiation, In-Flight Icing, Turbulence, and Volcanic Ash. Bull. Amer. Meteor. Soc., 88, 1589-1607.

Meckalski, J.R., and Coauthors, 2002: NASA Advanced Satellite Aviation-weather Products (ASAP) Study Report. NASA Tech. Rep., 65 pp.

Meischner, P., R. Baumann, H. Höller, and T. Jank, 2001: Eddy Dissipation Rates in Thunderstorms Estimated by Doppler Radar in Relation to Aircraft In Situ Measurements. J. Atmos. Oceanic Technol., 18, 1609-1627. 
Menzel, W.P., T.J. Schmit, P. Zhang, and J. Li, 2018: Satellite-Based Atmospheric Infrared Sounder Development and Applications. Bull. Amer. Meteor. Soc., 99, 583-603, https://doi.org/10.1175/BAMS-D-16-0293.1

Merritt, L.P., 1969: Comparison of Airborne and Ground Based Weather Radars. J. Appl. Meteor., 8, 963-974.

Michelson, M., W. W. Shrader, and J. G. Wieler, 1990: Terminal Doppler Weather Radar. Microwave J., 33, 139-148.

Miller, T. P., and T. J. Casadevall, 1999: Volcanic ash hazards to aviation. Encyclopedia of Volcanoes, H. Sigurdsson et al., Eds., Academic Press, 925-930.

Miller, Steven D., and Coauthors, 2014: Estimating Three-Dimensional Cloud Structure via Statistically Blended Satellite Observations. J. Appl. Meteor. Climatol., 53, 437-455.

Minnis, P., K. Bedka, Q. Trepte, C. R. Yost, S. T. Bedka, B. Scarino, K. Khlopenkov, and M. M. Khaiyer, 2016: A consistent long-term cloud and clear-sky radiation property dataset from the Advanced Very High Resolution Radiometer (AVHRR). Climate Algorithm Theoretical Basis Document (C-ATBD), CDRP-ATBD-0826 Rev 1 AVHRR Cloud Properties - NASA, NOAA CDR Program, 19 September, 159 pp., DOI:10.789/V5HT2M8T.

Minnis, P., S. T. Bedka, D. P. Duda, K. M. Bedka, T. L. Chee, J. K. Ayers, R. Palikonda, D. A. Spangenberg, K. V. Khlopenkov, and R. Boeke, 2013: Linear contrails and contrail cirrus properties determined from satellite data. Geophys. Res. Lett., 40, 3220-3226, doi:10.1002/grl.50569. 
Minnis, P., L. Nguyen, R. Palikonda, P. W. Heck, D. A. Spangenberg, D. R. Doelling, J. K. Ayers, W. L. Smith, Jr., M. M. Khaiyer, Q. Z. Trepte, L. A. Avey, F.-L. Chang, C. R. Yost, T. L. Chee, and S. Sun-Mack, 2008: Near-real time cloud retrievals from operational and research meteorological satellites. Proc. SPIE 7108, Remote Sens. Clouds Atmos. XIII, Cardiff, Wales, UK, 15-18 September, 8 pp., doi: $10.1117 / 12.800344$

Minnis, P., U. Schumann, D. R. Doelling, K. M. Gierens, and D. W. Fahey, 1999: Global distribution of contrail radiative forcing. Geophys. Res. Lett., 26, 1853-1856.

Minnis, P., S. Sun-Mack, D. F. Young, P. W. Heck, D. P. Garber, Y. Chen, D. A. Spangenberg, R. F. Arduini, Q. Z. Trepte, W. L. Smith, Jr., J. K. Ayers, S. C. Gibson, W. F. Miller, V. Chakrapani, Y. Takano, K.-N. Liou, Y. Xie, and P. Yang, 2011: CERES Edition-2 cloud property retrievals using TRMM VIRS and Terra and Aqua MODIS data, Part I: Algorithms. IEEE Trans. Geosci. Remote Sens., 49, 11, 4374-4400, doi:10.1109/TGRS.2011.2144601.

Minnis, P., D. F. Young, L. Nguyen, D. P. Garber, W. L. Smith, Jr., and R. Palikonda, 1998: Transformation of contrails into cirrus during SUCCESS. Geophys. Res. Lett., 25, 1157-1160.

Minnis, P., U. Schumann, D. R. Doelling, K. M. Gierens, and D. W. Fahey, 1999: Global distribution of contrail radiative forcing. Geophys. Res. Lett., 26, 1853-1856.

Mittaz, J. and A. Harris, 2011: A Physical Method for the Calibration of the AVHRR/3 Thermal IR Channels. Part II: An In-Orbit Comparison of the AVHRR Longwave Thermal IR 
Channels on board MetOp-A with IASI. J. Atmos. Oceanic Technol., 28, 1072-1087, https://doi.org/10.1175/2011JTECHA1517.1

Moninger, W.R., R.D. Mamrosh, and P.M. Pauley, 2003: Automated Meteorological Reports from Commercial Aircraft. Bull. Amer. Meteor. Soc., 84, 203-216.

Moninger, W.R., S.G. Benjamin, B.D. Jamison, T.W. Schlatter, T.L. Smith, and E.J. Szoke, 2010: Evaluation of Regional Aircraft Observations Using TAMDAR. Wea. Forecasting, 25, 627-645.

Moosakhanian, A., S. Schmidt, E. R. Dash, T.vS. Daniels, and P. Stough, 2006: FAA-NASA collaboration on automated aircraft weather observations - culminating in TAMDAR. 12th Conference on Aviation Range and Aerospace Meteorology, Atlanta, GA, Amer. Meteor. Soc. Annual Meeting. Available at https://ams.confex.com/ams/pdfpapers/104168.pdf

Morrison, H. and J. Milbrandt, 2015: Parameterization of cloud microphysics based on the prediction of bulk ice particle properties. Part I: Scheme description and idealized tests. J. Atmos. Sci., 72, 287-311.

Motta, M., R. J. Barthelmie, and P. Vølund. 2005. “The Influence of Non-Logarithmic Wind Speed Profiles on Potential Power Output at Danish Offshore Sites." Wind Energy 8: 219-236. doi:10.1002/(ISSN)1099-1824.

Mueller, C., T. Saxen, R. Roberts, J. Wilson, T. Betancourt, S. Dettling, N. Oien, and J. Yee, 2003: NCAR Auto-Nowcast System. Wea. Forecasting, 18, 545-561. 
Mueller, C. K., J. W. Wilson, and N. A. Crook, 1993: The utility of sounding and mesonet data to nowcast thunderstorm initiation. Wea. Forecasting, 8, 132-146.

Myhre, G., and F. Stordal, 2001: Global sensitivity experiments of the radiative forcing due to mineral aerosols. J. Geophys. Res., 106, 18 193-18 204.

Nair, U. S., R. C. Weger, K. S. Kuo, and R. M. Welch,1998: Clustering, randomness, and regularity in-cloud fields. The nature of regular cumulus cloud fields. J. Geophys. Res., 103, $11363-11380$.

Nance, L. B., and D. R. Durran, 1997: A modeling study of nonstationary trapped mountain lee waves. Part I: Mean-flow variability. J. Atmos. Sci., 54, 2275-2291.

Neely, R.R. and J.P. Thayer, 2011: Raman Lidar Profiling of Tropospheric Water Vapor over Kangerlussuaq, Greenland. J. Atmos. Oceanic Technol., 28, 1141-1148,

Newton, D. W. (1978). An integrated approach to the problem of aircraft icing. Journal of Aircraft, 15, 374-381.

Nicholls, M., R. Pielke, and R. Meroney (1993), Large eddy simulation of microburst winds flowing around a building, J. Wind Eng. Ind. Aerodyn., 46-47, 229-237.

NOAA NWS, 2016: Terminal aerodrome forecasts. Instruction 10-813. (http://www.nws.noaa.gov/directives/) 
Noh, Y., C.J. Seaman, T.H. Vonder Haar, and G. Liu, 2013: In Situ Aircraft Measurements of the Vertical Distribution of Liquid and Ice Water Content in Midlatitude Mixed-Phase Clouds. J. Appl. Meteor. Climatol., 52, 269-279.

NTSB, 1996: Aircraft accident report. Vol. 1. National Transportation Safety Board NTSB/AAR-96/01-PB96-910401, 322 pp. [Available from NTSB, 490 L’Enfant Plaza, S.W., Washington, DC 20594.].

NTSB, 2010: NASDAC Review of National Transportation Safety Board (NTSB) weatherrelated accidents (2003-2007). Available at http://www.asias.faagov/.

NWPSD, 2004: Operations and Services, Aviation Weather Services, NWSPD, 10-8, 2004, NWS Instruction 10-813,Terminal Aerodrome Forecasts, Feb. 1, 2004. 51 pp.

Ødegaard, V., 1997: Ice Phase Parameterization in a Numerical Weather Prediction Model. Wea. Forecasting, 12, 127-139

Orf, L. G., and J. R. Anderson 1999): A numerical study of traveling microbursts, Mon. Weather Rev., 127, 1244-1257.

Orf, L. G., J. R. Anderson, and J. M. Straka, 1996: A three-dimensional numerical analysis of colliding microburst outflow dynamics, J. Atmos. Sci., 53, 2490-2511.

Orville, R. E., 2008: Development of the National Lightning Detection Network. Bull. Amer. Meteor. Soc., 89, 180-190.

Oude Nijhuis, A., L. Thobois, F. Barbaresco, S. De Haan, A. Dolfi-Bouteyre, D. Kovalev, O. Krasnov, D. Vanhoenacker-Janvier, R. Wilson, and A. Yarovoy, 0: Wind hazard and 
turbulence monitoring at airports with lidar, radar and Mode-S downlinks: The UFO Project. Bull. Amer. Meteor. Soc., 0, https://doi.org/10.1175/BAMS-D-15-00295.1.

Pasini, A., and C. Marzban, Eds., 2008: Artificial Intelligence Methods in the Environmental Sciences. Springer, 424 pp.

Pavolonis, M. J., 2010a: Advances in extracting cloud composition information from space borne infrared radiances: A robust alternative to brightness temperatures. Part I: Theory. J. Appl. Meteor. Climatol., 49, 1992-2012.

Pavolonis, M. J, 2010b: ABI cloud type/phase algorithm theoretical basis document. NOAA/NESDIS/Center for Satellite Applications and Research (STAR), 60 pp.

Pavolonis, M. J., W. F. Feltz, A. K. Heidinger, and G. M. Gallina, 2006: A daytime complement to the reverse absorption technique for improved automated detection of volcanic ash. Atmos. Oceanic Technol., 23, 1422-1444.

Pavolonis, M. J, and A. K. Heidinger and T. Uttal, 2005: Daytime global cloud typing from AVHRR and VIIRS: Algorithm description, validation, and comparisons. J. Atmos. Oceanic Technol., 44, 804-826.

Pavolonis, M. J, and A. K. Heidinger, 2004: Daytime cloud overlap detection from AVHRR and VIIRS. J. Appl. Meteor., 43, 762-778.

Pearson, J.M. and R.D. Sharman, 2017: Prediction of Energy Dissipation Rates for Aviation Turbulence. Part II: Nowcasting Convective and Nonconvective Turbulence. J. Appl. Meteor. Climatol., 56, 339-351, https://doi.org/10.1175/JAMC-D-16-0312.1 
Peters, G., D. Hasselmann, and S. Pang, 1988: Radio acoustic sounding using an FM CW radar. Radio Sci., 23, 640-646.

Peters, G., 1990: Temperature and wind profiles from radar wind profilers equipped with acoustic sources. Meteor. Rundsch., 42,152-154.

Pinto, J.O., J.A. Grim, and M. Steiner, 2015: Assessment of the High-Resolution Rapid Refresh Model's Ability to Predict Mesoscale Convective Systems Using Object-Based Evaluation. Wea. Forecasting, 30, 892-913

Pleim, J. E., and A. Xiu, 1995: Development and testing of a surface flux and planetary boundary layer model for application in mesoscale models. J. Appl. Meteor., 34, 16-31.

Politovich, M.K., 1989: Aircraft Icing Caused by Large Supercooled Droplets. J. Appl. Meteor., 28, 856-868.

Politovich, M.K., 1996. Response of a research aircraft to icing and evaluation of severity indices. J. Aircr. 33, 291-297.

Prata, A. J., 1989: Observations of volcanic ash clouds in the 10-12 micrometer window using AVHRR/2 data. Int. J. Remote Sens., 10, 751-761.

Proctor, F. H. (1988), Numerical simulations of an isolated microburst. Part I: Dynamics and structure, J. Atmos. Sci., 45, 3137-3160.

Proctor, F. H. (1989), Numerical simulations of an isolated microburst. Part II: Sensitivity experiments, J. Atmos. Sci., 46, 2143-2165. 
Protat, A., S. Rauniyar, V.V. Kumar, and J.W. Strapp, 2014: Optimizing the Probability of Flying in High Ice Water Content Conditions in the Tropics Using a Regional-Scale Climatology of Convective Cell Properties. J. Appl. Meteor. Clim., 53, 2438-2456.Pu, Z., C. Lin, X. Dong, S. Krueger, 2018: Sensitivity of numerical simulations of a mesoscale convective system to ice hydrometeors in bulk microphysical parameterization. Pure and Applied Geophysics, DOI: 10.1007/s00024-018-1787-z

$\mathrm{Pu}, \mathrm{Z} ., 2017$ : Surface data assimilation and near-surface weather prediction over complex terrain. Book Chapter, "Data Assimilation for Atmospheric, Oceanic and Hydrologic Applications (Vol. III)", Ed. By S.K. Park and L. Xu, Springer. pp.219-240. DOI 10.1007/978-3-319-43415-5_10.

Pu, Z. , C. Chachere*, S. Hoch, E. Pardyjak, I. Gultepe, 2016: Numerical Prediction of Cold Season Fog Events Over Complex Terrain: The Performance of the WRF Model During MATERHORN-Fog and Early Evaluation, Pure and Applied Geophysics, doi:10.1007/s00024-016-1375-z.

Puempel, H. and P. D. Williams, 2016: The impacts of climate change on aviation: Scientific challenges and adaptation pathways. ICAO Environmental Report, pp 205-207. https://www.icao.int/environmental-protection/Pages/env2016.aspx

Ralph, F.M., J. Intrieri, D. Andra, R. Atlas, S. Boukabara, D. Bright, P. Davidson, B. Entwistle, J. Gaynor, S. Goodman, J. Jiing, A. Harless, J. Huang, G. Jedlovec, J. Kain, S. Koch, B. Kuo, J. Levit, S. Murillo, L.P. Riishojgaard, T. Schneider, R. Schneider, T. Smith, 
and S. Weiss, 2013: The Emergence of Weather-Related Test Beds Linking Research and Forecasting Operations. Bull. Amer. Meteor. Soc., 94, 1187-1211.

Ramsay, A. C., 1999: A multi-sensor freezing drizzle algorithm for the automated surface observing system. Preprints, 15th Int. Conf. on Interactive Information and Processing Systems for Meteorology, Oceanography, and Hydrology, Dallas, TX, Amer. Meteor. Soc., 193-196.

Rasmussen, R. M., J. Vivekanandan, J. Cole, B. Myers, and C. Masters, 1999: The estimation of snowfall rate using visibility. J. Appl. Meteor., 38, 1542-1563, doi:10.1175/15200450(1999)038<1542:TEOSRU>2.0.CO;2.

Rasmussen, R., M. Dixon, S. Vasiloff, F. Hage, S. Knight, J. Vivekanandan, and M. Xu, 2003: Snow nowcasting using a real-time correlation of radar reflectivity with snow gauge accumulation. J. Appl. Meteor., 42, 20-36, doi: 10.1175/15200450(2003)042<0020:SNUART>2.0.CO;2

Rasmussen, R., M. Dixon, F. Hage, J. Cole, C. Wade, J. Tuttle, S. McGettigan, T. Carty, L. Stevenson, W. Fellner, S. Knight, E. Karplus, and N. Rehak, 2001: Weather Support to Deicing Decision Making (WSDDM): A Winter Weather Nowcasting System. Bull. Amer. Meteor. Soc., 82, 579-596,

Rasmussen, R., B. Baker, J. Kochendorfer, T. Meyers, S. Landolt, A.P. Fischer, J. Black, J.M. Thériault, P. Kucera, D. Gochis, C. Smith, R. Nitu, M. Hall, K. Ikeda, and E. Gutmann, 
2012: How Well Are We Measuring Snow: The NOAA/FAA/NCAR Winter

Precipitation Test Bed. Bull. Amer. Meteor. Soc., 93, 811-829.

Rasmussen, R., M. Politovich, J. Marwitz, W. Sand, J. McGinley, J. Smart, R. Pielke, S. Rutledge, D. Wesley, G. Stossmeister, B. Bernstein, K. Elmore, N. Powell, E. Westwater, B.B. Stankov, and D. Burrows, 1992: Winter Icing and Storms Project (WISP). Bull. Amer. Meteor. Soc., 73, 951-974.

Raytheon, 2016: AWIPS CAVE-D2D user's manual: AWIPS II operational build 13.4.1. Raytheon Doc. AWP.MAN.UM.A2-OB13.4.1, 609 pp. [Available online at www.unidata.ucar.edu/software/awips2 /doc/CAVE_D2D_Manual.pdf.].

Reehorst, A.L., D. J. Brinker, and T.P. Ratvasky, C.C. Ryerson and G. G. Koenig, 2005: The NASA Icing Remote Sensing System. NASA/TM—2005-213591. Paper \# 80776. 11 pp.

Reineman, B.D., L. Lenain, and W.K. Melville, 2016: The Use of Ship-Launched Fixed-Wing UAVs for Measuring the Marine Atmospheric Boundary Layer and Ocean Surface Processes. J. Atmos. Oceanic Technol., 33, 2029-2052.

Reineman, B.D., L. Lenain, N.M. Statom, and W.K. Melville, 2013: Development and Testing of Instrumentation for UAV-Based Flux Measurements within Terrestrial and Marine Atmospheric Boundary Layers. J. Atmos. Oceanic Technol., 30, 1295-1319.

Reitebuch, O., 2012: Wind lidar for atmospheric research. Atmospheric Physics - Background, Methods, Trends, Prediction, U. Schumann, Ed., Springer, 487-507. 
Roberts, R. D., and S. Rutledge, 2003: Nowcasting storm initiation and growth using GOES-8 and WSR-88D data. Wea. Forecasting, 18, 562-584.

Roberts, R.D., T. Saxen, C. Mueller, J. Wilson, A. Crook, J. Sun, and S. Henry, 1999: Operational application and use of NCAR's thunderstorm nowcasting system. Preprints, Int. Conf. on Interactive Information and Processing Systems, Dallas, TX, Amer. Meteor. Soc., 158-161.

Roquelaure, S. and T. Bergot, 2008: A Local Ensemble Prediction System for Fog and Low Clouds: Construction, Bayesian Model Averaging Calibration, and Validation. J. Appl. Meteor. Climatol., 47, 3072-3088.

Roquelaure, S. and T. Bergot, 2009: Contributions from a Local Ensemble Prediction System (LEPS) for Improving Fog and Low Cloud Forecasts at Airports. Wea. Forecasting, 24, 39-52,

Roquelaure, S., and T. Bergot, 2007: Seasonal sensitivity on COBEL-ISBA local forecast system for fog and low clouds. Pure Appl. Geophys., 164, 1283-1301.

Rose, S.F., P.V. Hobbs, J.D. Locatelli, and M.T. Stoelinga, 2004: A 10-Yr Climatology Relating the Locations of Reported Tornadoes to the Quadrants of Upper-Level Jet Streaks. Wea. Forecasting, 19, 301-309.

Rudack, D.E. and J.E. Ghirardelli, 2010: A Comparative Verification of Localized Aviation Model Output Statistics Program (LAMP) and Numerical Weather Prediction (NWP) Model Forecasts of Ceiling Height and Visibility. Wea. Forecasting, 25, 1161-1178. 
Rudra, R., Dickinson, W.T., Ahmed, S. I., Patel, P., Zhou, J., \& Gharabaghi, B., 2015: Changes in Rainfall Extremes in Ontario. International Journal of Environmental Research, 9 (4), 1117-1372.

Ryerson, W.R. and J.P. Hacker, 2014: The Potential for Mesoscale Visibility Predictions with a Multimodel Ensemble. Wea. Forecasting, 29, 543-562.

Ryzhkov, A.V., D.S. Zrnic, J.C. Hubbert, V.N. Bringi, J. Vivekanandan, and E.A. Brandes, 2002: Polarimetric Radar Observations and Interpretation of Co-CrossPolarCorrelation Coefficients. J. Atmos. Oceanic Technol., 19, 340-354.

Ryzhkov, A.V., M.R. Kumjian, S.M. Ganson, and P. Zhang, 2013: Polarimetric Radar Characteristics of Melting Hail. Part II: Practical Implications. J. Appl. Meteor. Climatol., 52, 2871-2886.

Santel, D., 2010: The impact of satellite-derived polar winds on lower-latitude forecasts. Mon. Wea. Rev., 123-139.

Sathe, A., J. Mann, J. Gottschall, and M.S. Courtney, 2011: Can Wind Lidars Measure Turbulence?. J. Atmos. Oceanic Technol., 28, 853-868.

Sattar, A. M., Elhakeem, M., Gerges, B. N., Gharabaghi, B., \& Gultepe, I. 2018: Wind-Induced Air-Flow Patterns in an Urban Setting: Observations and Numerical Modeling. Pure and Applied Geophysics, DOI: 10.1007/s00024-018-1846-5.

Schmit, T.J., P. Griffith, M.M. Gunshor, J.M. Daniels, S.J. Goodman, and W.J. Lebair, 2017: A Closer Look at the ABI on the GOES-R Series. Bull. Amer. Meteor. Soc., 98, 681698. 
Schmit, T.J., M. M. Gunshor, W. P. Menzel, J. Li, S. Bachmeier, and J. J. Gurka, 2005:

Introducing the next-generation Advanced Baseline Imager on GOES-R. Bull. Amer. Meteor. Soc., 86, 1079-1096.

Schreiner, A. J., D. A. Unger, W. P. Menzel, G. P. Ellrod, K. I. Strabala, and J. L. Pellett, 1993: A comparison of ground and satellite observations of cloud cover. Bull. Amer. Meteor. Soc., 74, 1851-1861.

Schultz, P., and M. K. Politovich, 1992: Toward the improvement of aircraft-icing forecasts for the continental United States. Wea. Forecasting, 7, 491-500.

Schultz, P., and M. K. Politovich, 1992: Toward the improvement of aircraft-icing forecasts for the continental United States. Wea.Forecasting, 7, 491-500.

Schuur, T.J., H. Park, A.V. Ryzhkov, and H.D. Reeves, 2012: Classification of Precipitation Types during Transitional Winter Weather Using the RUC Model and Polarimetric Radar Retrievals. J. Appl. Meteor. Climatol., 51, 763-779.

Schumann, U., K. Graf, H. Mannstein, and B. Mayer, 2012: Contrails: Visible aviation induced climate impact. Atmospheric Physics - Background, Methods, Trends, Prediction, U. Schumann, Ed., Springer, 239-257.

Schumann, U., B. Mayer, K. Graf, and H. Mannstein, 2012: A Parametric Radiative Forcing Model for Contrail Cirrus. J. Appl. Meteor. Climatol., 51, 1391-1406.

Schumann, U. and A.J. Heymsfield, 2017: On the Life Cycle of Individual Contrails and Contrail Cirrus. Meteorological Monographs, 58, 3.1-3.24. 
Schumann, U., and B. Mayer, 2017: Sensitivity of surface temperature to radiative forcing by contrail cirrus in a radiative-mixing model. Atm. Chem. Phys., 17, 13833-13848.

Schwartz, B., 1996: The quantitative use of PIREPs in developing aviation weather guidance products. Wea. Forecasting, 11, 372-384, doi:10.1175/1520434(1996)011,0372:TQUOPI.2.0.CO;2.

Schwartz, B. E., and S. G. Benjamin, 1995: A comparison of temperature and wind measurements from ACARS equipped aircraft and rawinsondes. Wea. Forecasting, 10, $528-544$.

Seity Y, Brousseau P, S. Malardel, G. Hello, P. Benard, F. Bouttier, V. Lac C,Masson, 2011. The AROME-France convective-scale operational model. Mon. Weather Rev. 139: 976-991.

Selz, T. and G.C. Craig, 2015: Upscale Error Growth in a High-Resolution Simulation of a Summertime Weather Event over Europe. Mon. Wea. Rev., 143, 813-827.

Serke, D., Politovich, M., Reehorst, A., and Gaydos, A., 2008: “The Use of X-band Radar to Support theDetection of In-Flight Icing Hazards by the NASA Icing Remote Sensing System During AIRS-II,’Proc. SPIE 7088, \#18, 2008.

Serke, D., E. Hall, J. Bogna, A.Jordan, S. Abdo, K. Baker, T.Seitel, M. Nelson, R. Ware, F. McDonough, M. Politovich 2014: Supercooled liquid water content profiling case studies with a new vibrating wire sonde compared to a ground-based microwave radiometer. Atmospheric Research 149 (2014) 77-87. 
Sharman, R.D. \& Trier, S.B. 2018: Influences of Gravity Waves on Convectively Induced Turbulence (CIT): A Review. Pure and Appl. Geophys. https://doi.org/10.1007/s00024-018-1849-2 .

Sharman, R., 2016: Nature of aviation turbulence. Aviation Turbulence: Processes, Detection, Prediction, R. Sharman and T. Lane, Eds., Springer, 3-30.

Sharman, R., and T. Lane, 2016: Aviation Turbulence: Processes, Detection, Prediction. Springer, 523 pp.

Sharman, R., and J. M. Pearson, 2017: Prediction of energy dissipation rates for aviation turbulence. Part I: Forecasting non-convective turbulence. J. Appl. Meteor. Climatol., $56,317-337$.

Sharman, R., S. B. Trier, T. P. Lane, and J. D. Doyle, 2012: Sources and dynamics of turbulence in the upper troposphere and lower stratosphere: A review. Geophys. Res. Lett., 39, L12803, doi:10.1029/2012GL051996.

Sharman, R., L. B. Cornman, G. Meymaris, J. Pearson, and T. Farrar, 2014: Description and derived climatologies of automated in situ eddy dissipation rate reports of atmospheric turbulence. J. Appl. Meteor. Climatol., 53, 1416-1432, doi:10.1175/JAMC-D-130329.1.

Sharman, R., C. Tebaldi, G. Wiener, and J. Wolff, 2006: An integrated approach to mid- and upper-level turbulence forecasting. Wea. Forecasting, 21, 268-287. 
Sieglaff, J.M., L.M. Cronce, W.F. Feltz, K.M. Bedka, M.J. Pavolonis, and A.K. Heidinger, 2011: Nowcasting Convective Storm Initiation Using Satellite-Based Box-Averaged CloudTop Cooling and Cloud-Type Trends. J. Appl. Meteor. Climatol., 50, 110-126.

Sillmann, J., V.V. Kharin, X. Zhang, F.V. Zwiers, and D. Bronaugh 2013a: Climate extremes indices in the CMIP5 multimodel ensemble: Part 1: Model evaluation in the present climate. J. Geophy. Res.-Atmosphere, V 118, 1716-1733.

Sillmann, J., V. V. Kharin, F. W. Zwiers, X. Zhang, and D. Bronaugh, 2013b: Climate extreme indices in the CMIP5 multi-model ensemble. Part 2: Future projections, J. Geophys. Res., accepted doi:10.1002/jgrd.50188.

Silva, W. L., F. A. Albuquerque Neto, G. B. França, and M. Matschinske. 2016. “Conceptual Model for Runway Change Procedure in Guarulhos International Airport Based on SODAR Data.” The Aeronautical Journal 120 (1227): 725-734. doi:10.1017/aer.2016.33.

Simpson, J. J., G. L. Hufford , R. Servranckx, J. Berg, and D. Pieri, 2003: Airborne Asian dust: Case study of long-range transport and implications for the detection of volcanic ash. Wea. Forecasting, 18, 121-141.

Simpson, J. J., G. L. Hufford, D. C. Pieri, and J. Berg, 2000: Failures in detecting volcanic ash from satellite-based technique. Remote Sens. Environ., 72, 191-217.

Sims, D. L., C. B. Fidalgo and T. C. Carty, 2000: Integrated Icing Diagnostic Algorithm assessment at regional airlines. 9th Conference on Aviation, Range, and Aerospace Meteorology. AMS 2000 Annual Meeting. Preprints, \#4.16. 
Skofronick-Jackson, G., W.A. Petersen, W. Berg, C. Kidd, E.F. Stocker, D.B. Kirschbaum, R. Kakar, S.A. Braun, G.J. Huffman, T. Iguchi, P.E. Kirstetter, C. Kummerow, R. Meneghini, R. Oki, W.S. Olson, Y.N. Takayabu, K. Furukawa, and T. Wilheit, 2017: The Global Precipitation Measurement (GPM) Mission for Science and Society. Bull. Amer. Meteor. Soc., 98, 1679-1695.

Smith, W. L., 2014: 4-D cloud properties from passive satellite data and applications to resolve the flight icing threat to aircraft. PhD Dissertation, University of Wisconsin-Madison, July 22, 15 pp.

Smith, W.L., P. Minnis, C. Fleeger, D. Spangenberg, R. Palikonda, and L. Nguyen, 2012: Determining the Flight Icing Threat to Aircraft with Single-Layer Cloud Parameters Derived from Operational Satellite Data. J. Appl. Meteor. Climatol., 51, 1794-1810.

Smith, T.M., V. Lakshmanan, G.J. Stumpf, K.L. Ortega, K. Hondl, K. Cooper, K.M. Calhoun, D.M. Kingfield, K.L. Manross, R. Toomey, and J. Brogden, 2016: Multi-Radar MultiSensor (MRMS) Severe Weather and Aviation Products: Initial Operating Capabilities. Bull. Amer. Meteor. Soc., 97, 1617-1630.

Soden, B.J., S.A. Ackerman, DOC Starr, and S.H. Melfi, and R.A. Ferrare, 1994: Comparison of upper tropospheric water vapor from GOES, Raman lidar, and cross-chain loran atmospheric sounding system measurements. J. Geoph. Res., 99, D10, 21005-21016.

Sokol, Z., and P. Zacharov, 2012: Nowcasting of precipitation by an NWP model using assimilation of extrapolated radar reflectivity. Quart. J. Roy. Meteor. Soc., 138, 10721082. 
Solheim, F., J. Godwin and R. Ware, 1998: Passive ground-based remote sensing of atmospheric temperature, water vapor, and cloud liquid water profiles by a frequency synthesized microwave radiometer, Met. Zeit., 7, 370-376.

Song, J.-I., S. S. Yum, K.-H. Chang, B.-G. Kim and B.-J. Kim, 2018: Development of a new visibility parameterization based on long term in-situ measurement of fog (cloud) microphysics at a mountainous site in Korea, J. of Pure and Applied Geophysics, In press..

Sorenson, J. E., 1964: Synoptic patterns for clear air turbulence. UAL Meteorology Circular 56, 64 pp. [Available from Dept. of Atmospheric Science, Colorado State University, Fort Collins, CO 80523.]

Spangenberg, D. A., P. Minnis, S. T. Bedka, R. Palikonda, D. P. Duda, and F. G. Rose, 2013: Contrail radiative forcing over the Northern Hemisphere from 2006 Aqua MODIS data. Geophys. Res. Lett., 40, doi:10.1002/grl.50168, 595-600.

Stano, G. T., K. K. Fuell, and G. J. Jedlovec, 2010: NASA SPoRT GOES-R Proving Ground activities. Preprints, Sixth Annual Symp. on Future National Operational Environmental Satellite Systems: NPOESS and GOES-R, Atlanta, GA, Amer. Meteor. Soc., 8.2. Available att https://ams.confex.com/ams/90annual/techprogram/.

Steiner, M., W. Deierling, K. Ikeda, M. Robinson, A. Klein, J. Bewley and R. Bass, 2016: Air traffic impacts caused by lightning safety procedures, AIAA 2016-4213. AIAA Aviation 2016 conference. Washington DC. 13-17 June 2016. Doi: 10.2514/6.20164213. 
Stickland, J. J., 1998: An assessment of two algorithms for automatic measurement and reporting of turbulence from commercial public transport aircraft. Rep. to the ICAO METLINK Study Group, Bureau of Meteorology, Melbourne, Australia, 42 pp.

Stoelinga, M.T., and T.T. Warner, 1999: Nonhydrostatic, meso-beta scale model simulations of cloud ceiling and visibility for an east coast winter precipitation event. J. Appl. Meteor., 38, 385-404.

Storer, L. N., Williams, P. D., \& Joshi, M. M., 2017: Global response of clear-air turbulence to climate change. Geophysical Research Letters, 44, 9976-9984. https://doi.org/10.1002/2017GL074618.

Strapp, J.W., A. Korolev, T. Ratvasky, R. Potts, A. Protat, P. May, A. Ackerman, A. Fridlind, P. Minnis, J. Haggerty, J. T. Riley, L. E. Lilie, and G. A. Isaac, 2016: The high ice water content study of deep convective clouds: Report on science and technical plan. Final Report. DOT/FAA/TC-14/31, 92 pp. Available at http://www.tc.faa.gov/its/worldpac/techrpt/tc14-31.pdf.

Sumner, J., and C. Mason, 2006: A Turbulence-Based Model for Resolving Velocity and Temperature Profiles in the Atmospheric Surface Layer, Wind Energy, 30, 317-340. https://doi.org/10.1260/030952406779295462.

Sun, J., M. Xue, J.W. Wilson, I. Zawadzki, S.P. Ballard, J. Onvlee-Hooimeyer, P. Joe, D.M. Barker, P. Li, B. Golding, M. Xu, and J. Pinto, 2014: Use of NWP for Nowcasting Convective Precipitation: Recent Progress and Challenges. Bull. Amer. Meteor. Soc., $95,409-426$. 
Sun-Mack, S., Minnis, P., Smith, W. L., Hong, G., Chen, Y.: Detection of single and multilayer clouds in an artificial neural network approach, Proc. SPIE 10424, Remote Sensing of Clouds and the Atmosphere XXII, 1042408 (13 October 2017); doi:

10.1117/12.2277397; https://doi.org/10.1117/12.2277397.

Tafferner, A., T. Hauf, C. Leifeld, T. Hafner, H. Leykauf, and U. Voigt, 2003: ADWICE: Advanced Diagnosis and Warning System for Aircraft Icing Environments. Wea. Forecasting, 18, 184-203

Tag, P. M., R. L. Bankert, and L. R. Brody, 2000: An AVHRR multiple cloud-type classification package. Appl. Meteor., 39, 125-134.

Tan, I. and T. Storelvmo, 2016: Sensitivity Study on the Influence of Cloud Microphysical Parameters on Mixed-Phase Cloud Thermodynamic Phase Partitioning in CAM5. J. Atmos. Sci., 73, 709-728.

Tardif, R. and R.M. Rasmussen, 2007: Event-Based Climatology and Typology of Fog in the New York City Region. J. Appl. Meteor. Climatol., 46, 1141-1168,

Teixeira, J., and Coauthors, 2008: Parameterization of the atmospheric boundary layer: A view from just above the inversion. Bull. Amer. Meteor. Soc., 89, 453-458.

Thompson, G., R.T. Bruintjes, B.G. Brown, and F. Hage, 1997: Intercomparison of In-Flight Icing Algorithms. Part I: WISP94 Real-Time Icing Prediction and Evaluation Program. Wea. Forecasting, 12, 878-889. 
Thompson, G., M.K. Politovich, and R.M. Rasmussen, 2017: A Numerical Weather Model's Ability to Predict Characteristics of Aircraft Icing Environments. Wea. Forecasting, $32,207-221$.

Thobois, L, Cariou, J. P., \& Gultepe, I. 2018. Review of lidar based applications for aviation weather. Pure and Applied Geophysics. (submitted).

Tomita, H., 2008: New Microphysical Schemes with Five and Six Categories by Diagnostic Generation of Cloud Ice. Journal of the Meteorological Society of Japan. Ser. II, Special Issue: The International Workshop on High-Resolution and Cloud Modeling, 2006, 86A, 121-142.

TC, 2004: Small and large aircraft; Aircraft critical surface contamination training for aircrew and ground crew. TP 10643E, 12/2004. Ottawa, Ont., Canada. 138 pp.

Trier, S. B., R. D. Sharman, and T. P. Lane, 2012: Influences of moist convection on a coldseason outbreak of clear-air turbulence (CAT). Mon. Wea. Rev., 140, 2477-2496.

Tucker, S.C., C.J. Senff, A.M. Weickmann, W.A. Brewer, R.M. Banta, S.P. Sandberg, D.C. Law, and R.M. Hardesty, 2009: Doppler Lidar Estimation of Mixing Height Using Turbulence, Shear, and Aerosol Profiles. J. Atmos. Oceanic Technol., 26, 673-688.

Turcotte, M.-F., and R. Verret, 1999: In-flight icing and turbulence forecasts for aviation. Proc. Sixth Workshop on Operational Meteorology, Halifax, NS, Canada, Canadian Meteorological and Oceanographic Society, 53-56.

Turner, J., and D. E. Warren, 1989: Cloud track winds in the polar regions from sequences of AVHRR images. Int. J. Remote Sens., 10, 695-703. 
Turner, D., Clough, S., Liljegren, J., Clothiaux, E., Cady-Pereira, K., \& Gaustad, K. (2007). Retrieving Liquid Water Path and Precipitable Water Vapor from the Atmospheric Radiation Measurement (ARM) Microwave Radiometers, TGRS.

Turp, D., and P. Gill, 2008: Developments in numerical clear air turbulence forecasting at the U.K. Met Office. Preprints, 13thConf. on Aviation, Range and Aerospace Meteorology, New Orleans, LA, Amer. Meteor. Soc., P3.10A. [Available online at http://ams.confex.com/ams/pdfpapers/131782.pdf.]

Uccellini, L.W. and D.R. Johnson, 1979: The Coupling of Upper and Lower Tropospheric Jet Streaks and Implications for the Development of Severe Convective Storms. Mon. Wea. Rev., 107, 682-703.

Uccellini, L.W., 1980: On the Role of Upper Tropospheric Jet Streaks and Leeside Cyclogenesis in the Development of Low-Level Jets in the Great Plains. Mon. Wea. Rev., 108, $1689-1696$.

Van den Berg, G. P. 2008. "Wind Turbine Power and Sound in Relation to Atmospheric Stability." Wind Energy 11.2 (2008): 151-169. doi:10.1002/we.240.

Van den Berg, G. P. 2008. "Wind Turbine Power and Sound in Relation to Atmospheric Stability." Wind Energy 11.2 (2008): 151-169. doi:10.1002/we.240

Van Den Broeke, M.S., D.M. Tobin, and M.R. Kumjian, 2016: Polarimetric Radar Observations of Precipitation Type and Rate from the 2-3 March 2014 Winter Storm in Oklahoma and Arkansas. Wea. \& Forecasting, 31, 1179-1196. 
Van Den Broeke, M.S., 2016: Polarimetric Variability of Classic Supercell Storms as a Function of Environment. J. Appl. Meteor. Climatol., 55, 1907-1925.

Velden, C., J. Daniels, D. Stettner, D. Santek, J. Key, J. Dunion, K. Holmlund, G. Dengel, W. Bresky, and P. Menzel, 2005: Recent Innovations in Deriving Tropospheric Winds from Meteorological Satellites. Bull. Amer. Meteor. Soc., 86, 205-224.

Velden, C. S., C. M. Hayden, S. Nieman, W. P. Menzel, S. Wanzong, and J. Goerss, 1997: Upper-tropospheric winds derived from geostationary satellite water vapor observations. Bull. Amer. Meteor. Soc., 78, 173-195.

Velden, C.S., T. L. Olander, and S. Wanzong, 1998: The impact of multispectral GOES-8 wind information on Atlantic tropical cyclone track forecasts in 1995. Part I: Dataset methodology, description, and case analysis. Mon. Wea. Rev., 126, 1202-1218.

Verlinden, K.L. and D.R. Bright, 2017: Using the Second-Generation GEFS Reforecasts to Predict Ceiling, Visibility, and Aviation Flight Category. Wea. Forecasting, 32, 17651780.

Westwater, E. (1978). The accuracy of water vapor and cloud liquiddeter minations by dualfrequency ground-based microwave radiometry. Radio Sci. 13, 677-685.

Vislocky, R.L. and J.M. Fritsch, 1995: Generalized Additive Models versus Linear Regression in Generating Probabilistic MOS Forecasts of Aviation Weather Parameters. Wea. Forecasting, 10, 669-680.

Vislocky, R.L. and J.M. Fritsch, 1997: An Automated, Observations-Based System for ShortTerm Prediction of Ceiling and Visibility. Wea. Forecasting, 12, 31-43. 
.Vivekanandan, J., G. Zhang, and M.K. Politovich, 2001: An Assessment of Droplet Size and Liquid Water Content Derived from Dual-Wavelength Radar Measurements to the Application of Aircraft Icing Detection. J. Atmos. Oceanic Technol., 18, 1787-1798.

Vrancken, P. S., 2016: Airborne remote detection of turbulence with forward-pointing LIDAR. In: Aviation Turbulence: Processes, Detection, and Prediction. R. D. Sharman and T. P. Lane, Eds., Chapter 22, 443-464. Springer.

Walker, John R; MacKenzie, Wayne M, JR; Mecikalski, John R; Jewett, Christopher P., 2012: An Enhanced Geostationary Satellite-Based Convective Initiation Algorithm for 0-2h Nowcasting with Object Tracking. Journal of Applied Meteorology and Climatology. 1931-1949.

Wang, L., and C. Cao, 2008: On-orbit calibration assessment of AVHRR longwave channels on MetOp-A using IASI. IEEE Trans. Geosci. Remote Sens., 46, 4005-4013.

Wang, L., Y. Han,D. Tremblay, F.Weng, andM.Goldberg, 2012: Intercomparison of NPP/CrIS radiances with VIIRS, AIRS, and IASI: A post-launch calibration assessment. Earth Observing Missions and Sensors: Development, Implementation, and Characterization II, H. Shimoda et al.,Eds., International Society for Optical Engineering (SPIE Proceedings, Vol. 8528), 85280J, doi:10.1117/12.978769.

Warner, T. T., 2011: Numerical Weather and Climate Prediction. Cambridge, 526 pp.

Ware, R., Cimini, D., Campos, E., Giuliani, G., Albers, S., Nelson, M., Koch, S.E., Joe, P., \& Cober, S. (2013). Thermodynamic and liquid profiling during the 2010 Winter Olympics. Atmos. Research. 132-133, 278-290. 
Weber, M. E., and M. L. Stone, 1995: Low altitude wind shear detection using airport surveillance radars. IEEE Aerosp. Electron. Syst. Mag., 10, 3-9, doi:10.1109/62.387970.

Weisman, M. L., C. Davis, W. Wang, K. W. Manning, and J. B. Klemp, 2008: Experiences with 0-36-h explicit convective forecasts with the WRF-ARW model. Wea. Forecasting, $23,407-437$

Wen, Y., P. Kirstetter, J.J. Gourley, Y. Hong, A. Behrangi, and Z. Flamig, 2017: Evaluation of MRMS Snowfall Products over the Western United States. J. Hydrometeor., 18, 17071713.

Weygandt, S., T. Smirnova, S. Benjamin, K. Brundage, S. Sahm, C. Alexander, and B. Schwartz, 2009: The High Resolution Rapid Refresh (HRRR): An hourly updated convection resolving model utilizing radar reflectivity assimilation from the RUC/RR. 23rd Conf. on Weather Analysis and Forecasting/19th Conf. on Numerical Weather Prediction, Omaha, NE, Amer. Meteor. Soc., 15A.6.

Whiteman, D.N., S. H. Melfi, and R. A. Ferrare, 1992: Raman lidar system for the measuremen of water vapor and aerosols in the earth's atmosphere. Appl. Opt. 31, 3068-3082.

Wick, G., T. Hock, P. Neiman, H. VÖmel, M. Black, and J. Spackman, 2018: The NCAR/NOAA Global Hawk Dropsonde System. J. Atmos. Oceanic Technol. doi:10.1175/JTECH-D-17-0225.1, in press. 
Williams, J. K., and G. Meymaris, 2016: Remote turbulence detection using ground-based Doppler radar, 2016: Aviation turbulence forecast verification. Aviation Turbulence: Processes, Detection, Prediction, R. Sharman and T. Lane, Eds., Springer, 149-177.

Williams, J. K., 2014: Using random forests to diagnose aviation turbulence. Mach. Learn., 95, 51-70, doi:10.1007/s10994-013-5346-7.

Williams, P.D., 2017: Increased light, moderate, and severe clear-air turbulence in response to climate change. Adv. Atmos. Sci., 34, 576-586. . https://doi.org/10.1007/s00376-0176268-2.

Williams, P. D., and M. M. Joshi 2013: Intensification of winter transatlantic aviation turbulence in response to climate change. Nature Climate Change. Published online: 8 April 2013. DOI: 10.1038/NCLIMATE1866. 644-647.

Williams, P.D., 2016: Transatlantic flight times and climate change. Environmental Research Letters. 11 (2016) doi:10.1088/1748-9326/11/2/024008.

Wilson, J. W., 1966: Movement and predictability of radar echoes. National Severe Storms Laboratory Tech. Memo. ERTM-NSSL-28, 30 pp.

Wilson, J. W., N. A. Crook, C. K. Mueller, J. Sun, and M. Dixon, 1998: Nowcasting thunderstorms: A status report. Bull. Amer. Meteor. Soc., 79, 2079-2099.

Wilson, F. W., and R. H. Gramzow, 1991: The redesigned Low Level Wind Shear Alert System. Preprints, 4th Int. Conf. on Aviation Weather Systems, Paris, France, 370-375 
Wilson, J. W., Roberts, R. D., Kessinger, C, and McCarthy, J. (1984): Microburst structure and evaluation of Doppler radar for airport wind shear detection. J. Climate and Appl. Meteorol., 23, 898-915.

Wilson, J. W., and Wakimoto, R. M. (1982). The discovery of the downburst: T. T. Fijita's contribution. Bull. Amer. Meteorol. Soc., 82(1), 49-62.

Wilson, J. W., E. Ebert, T. Saxen, R. Roberts, C. Mueller, M. Sleigh, C. Pierce, and A. Seed, 2004: Sydney 2000 Forecast Demonstration Project: Convective storm nowcasting. Wea. Forecasting, 19, 131-150.

Wilson, J. W., and R. D. Roberts, 2006: Summary of convective storm initiation and evolution during IHOP: Observational and modeling perspective. Mon. Wea. Rev., 134, 2347.Wirth, M., 2012: Measuring water vapor with Differential Absorption Lidar. In Atmospheric Physics - Background, Methods, Trends, Prediction, U. Schumann, Ed., Springer, 465-476.

Wolfson, M. M., Delanoy, R. L., Forman, B. E., Hallowell, R. G., Pawlak, M. L., and Smith, P. D. (1944). Automated microburst wind-shear prediction. The Lincoln Laboratory Journal, 7(2), 399-426

Wong, M., W.C. Skamarock, P.H. Lauritzen, and R.B. Stull, 2013: A Cell-Integrated SemiLagrangian Semi-Implicit Shallow-Water Model (CSLAM-SW) with Conservative and Consistent Transport. Mon. Wea. Rev., 141, 2545-2560. 
Woodley, W.L., T.J. Henderson, B. Vonnegut, G. Gordon, R. Breidenthal, and S.M. Holle, 1991: Aircraft-produced ice particles (APIPs) in supercooled clouds and the probable mechanism for their production. J. Appl. Meteor., 30, 1469-1489

Wulfmeyer, V., 1999: Investigation of Turbulent Processes in the Lower Troposphere with Water Vapor DIAL and Radar-RASS. J. Atmos. Sci., 56, 1055-1076.

Wulfmeyer, V., 1998: Ground-based differential absorption lidar for water-vapor and temperature profiling: Development and specifications of a high-performance laser transmitter. Appl. Opt., 37, 3804-3824.

Wulfmeyer, V., 1999: Investigation of Turbulent Processes in the Lower Troposphere with Water Vapor DIAL and Radar-RASS. J. Atmos. Sci., 56, 1055-1076,

Wulfmeyer, V., and J. Bosenberg, 1996: Single-mode operation of an injection seeded alexandrite ring laser for application in water-vapor and temperature differential absorption lidar. Opt. Lett., 21, 1150- 1152.

Wulfmeyer, V., and J. Bosenberg, 1998: Ground-based differential absorption lidar for watervapor profiling: Assessment of accuracy, resolution, and meteorological applications. Appl. Opt., 37, 3825-3844.

Wulfmeyer, V., S. Lehmann, C. Senff, and S. Schmitz, 1995: Injection seeded alexandrite ring laser: Performance and application in a water-vapor differential absorption lidar. Opt. Lett., 20, 638-640. 
Wurman, J., D. Dowell, Y. Richardson, P. Markowski, E. Rasmussen, D. Burgess, L. Wicker, and H.B. Bluestein, 2012: The Second Verification of the Origins of Rotation in Tornadoes Experiment: VORTEX2. Bull. Amer. Meteor. Soc., 93, 1147-1170.

Yang, J., Z. Zhang, C. Wei, F. Lu, and Q. Guo, 2017: Introducing the New Generation of Chinese Geostationary Weather Satellites, Fengyun-4. Bull. Amer. Meteor. Soc., 98, 1637-1658. https://doi.org/10.1175/BAMS-D-16-0065.1

Yano, J., M.Z. Ziemiański, M. Cullen, P. Termonia, J. Onvlee, L. Bengtsson, A. Carrassi, R. Davy, A. Deluca, S.L. Gray, V. Homar, M. Köhler, S. Krichak, S. Michaelides, V.T. Phillips, P.M. Soares, and A.A. Wyszogrodzki, 2018: Scientific Challenges of Convective-Scale Numerical Weather Prediction. Bull. Amer. Meteor. Soc., 99, 699710, https://doi.org/10.1175/BAMS-D-17-0125.1

Yost, C.R., K. M. Bedka, P. Minnis, L. Nguyen, J. W. Strapp, R. Palikonda, K. Khlopenkov, D. Spangenberg, William L. Smith, A. Protat, and J. Delanoe, 2017: A Prototype Method for Diagnosing High Ice Water Content Probability Using Satellite Imager Data. https://doi.org/10.5194/amt-2017-367. J. of Atmos. Meas. Tech. In Press.

Zhang, J., and Coauthors, 2011: National Mosaic and Multi-Sensor QPE (NMQ) system: Description, results, and future plans. Bull. Amer. Meteor. Soc.,92, 1321-1338, doi:10.1175/2011BAMS-D-11-00047.1.

Zang, J., and Coauthors, 2016: Multi-Radar Multi-Sensor (MRMS) quantitative precipitation estimation: Initial operating capabilities. Bull. Amer. Meteor. Soc., 97, 621-637, doi:10.1175/BAMS-D-14-00174.1. 
Zhou, B. et al. 2004, An Introduction to NCEP SREF Aviation Project, 11th Conference on Aviation Range and Aerospace, Oct 4-8, Hyannis, MA, Amer. Meteor. Soc.

Zhou, B. and J. Du, 2010: Fog Prediction from a Multimodel Mesoscale Ensemble Prediction System. Wea. Forecasting, 25, 303-322.

Zhou, B., J. Du, J. McQueen, and G. Dimego, 2009: Ensemble forecast of ceiling, visibility, and fog with NCEP Short-Range Ensemble Forecast system (SREF). Preprints. Aviation, Range, and Aerospace Meteorology Special Symp. on Weather-Air Traffic Management Integration, Phoenix, AZ, Amer. Meteor.Soc., 4.5. [Available online at http://www.emc.ncep.noaa.gov/.mmb/SREF/AMS_2009CV_fog.pdf.] 